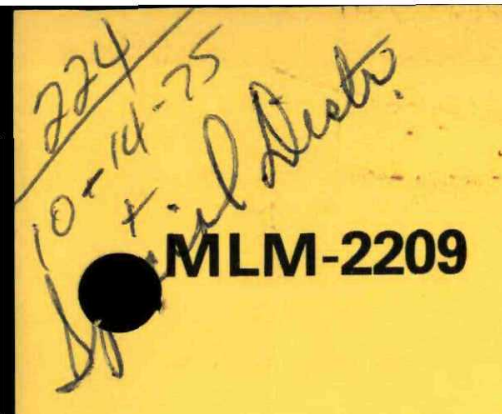

Or-1681

\title{
MLM-2209
}

\section{Plutonium-238 Dioxide/T-111 \\ Compatibility Studies}

\author{
G. J. Jones, J. E. Selle and P. E. Teaney
}

September 19, 1975

Research and Development Report

\section{MOUND LABORATORY}

Miamisburg, Ohio

operated by

MONSANTO RESEARCH CORPORATION a subsidiary of Monsanto Company for the

UNITED STATES ENERGY RESEARCH AND DEVELOPMENT ADMINISTRATION

U. S. Government Contract No. E-33-1-GEN-53 


\section{DISCLAIMER}

This report was prepared as an account of work sponsored by an agency of the United States Government. Neither the United States Government nor any agency Thereof, nor any of their employees, makes any warranty, express or implied, or assumes any legal liability or responsibility for the accuracy, completeness, or usefulness of any information, apparatus, product, or process disclosed, or represents that its use would not infringe privately owned rights. Reference herein to any specific commercial product, process, or service by trade name, trademark, manufacturer, or otherwise does not necessarily constitute or imply its endorsement, recommendation, or favoring by the United States Government or any agency thereof. The views and opinions of authors expressed herein do not necessarily state or reflect those of the United States Government or any agency thereof. 


\section{DISCLAIMER}

Portions of this document may be illegible in electronic image products. Images are produced from the best available original document. 


\title{
Plutonium-238 Dioxide/T-111 Compatibility Studies
}

\author{
G. J. Jones, * J. E. Sellet and P. E. Teaney
}

Issued: September 19, 1975

*Sandia Laboratories, Albuquerque, N. M.

tPresent Address: Holifield National Laboratory, Oak Ridge, Tenn.

\section{NOTICE}

This report was prepared as an account of work sponsored by the United States Government. Neither the United States nor the United States Energy Research and Development Administration, nor any of their employees, nor any of their contractors, subcontractors, or their employees, makes any warranty, express or implied, or assumes any legal liability or responsibility for the accuracy, com-

pleteness or usefulness of any information, apparatus, product or process disclosed or represents that its use would not infringe privately owned rights.

PRINTED IN THE UNITED STATES OF AMERICA

Available from

National Technical information Service

U. S. Department of Commerce

5285 Port Royal Road

Springfield, Virginia 22161

Price: Printed Copy $\$ 5.45$; Microfiche $\$ 2.25$

\section{MONSANTO RESEARCH CORPORATION}

A Subsidiary of Monsanto Company

\section{MOUND IABORATORY}

Miamisburg, Ohio $\quad 45342$

operated for

\section{UNITED STATES ENERGY RESEARCH AND DEVELOPMENT ADMINISTRATION}

U.S. Government Contract No. E-33-1-GEN-53 
DISTRIBUTION

\section{EXTERNAL}

TID-4500, UC-25

T. C. Jones, ERDA/AIO

E. A. Walker, ERDA/DAO

A. J. Kuntz, GEND/Pinellas

INL

J. H. DeVan

R. Donnelly

II. Inouye

C. T. Liu

A. C. Schaffhauser

J. E. Selle

\section{I,ASL}

S. Bronisz

I. K. Keenan

R. N. R. Mulford

F. W. Schonfeld

SLA

I. M. Berry

C. C. Burks

J. A. Cooper

n. J. Davis

J. A. Hood

I. E. Ives

R. T. Jankowski

G. J. Jones $(20)$

O. E. Jones

J. L. Ledman

V. J. Magrani

D. M. Mattox

J. F. Ney

P. D. O'Brien

D. M. Olsen

M. K. Parsons

E. N. Reece

W. R. Reynolds
R. W. Rohde

R. I. Schwoebel

J. P. Shoup

L. D. Smith

A. W. Snyder

W. I. Stevens

P. Syroid

Technical Iibrary

SLL

J. F. Barham

R. C. Wayne

SRL

R. A. Grega

R. T. Huntoon

R. D. Sisson

P. K. Smith

\section{Consultants}

C. F. Curtiss University of Wisconsin

M. L. Curtis Centerville, ohio

H. W. Mattson Monsanto Company

D. F. Griffing Miami university

R. E. Miers Et. Wayne, Indiana

G. W. Powe 11 Ohio State university

A. Shapiro University of Cincinnati

H. F. Swift University of Dayton Research Institute

D. White

University of Pennsylvania

\section{IJTERNAI}

W. R. Amos

C. G. Anderson

C. O. Brewer

W. T. Cave

D. L. Coffey

D. E. Friedline

R. K. Flitcraft

K. V. Gilbert

R. R. Jaeger

E. W. Johnson

I. V. Jones

D. P. Kelly

B. R. Kokenge

D. F. Luthy
D. L. Prosser

D. R. Rogers

B. D. Scearce

D. R. Schaeffer

E. Stacy

P. E. Teaney (2)

R. E. Vallee

J. G. Villars

R. I. Wise

W. C. Wyder

R. E. Zielinski

Publications

Library (20) 


\section{TABLE OF CONTENTS}

Page

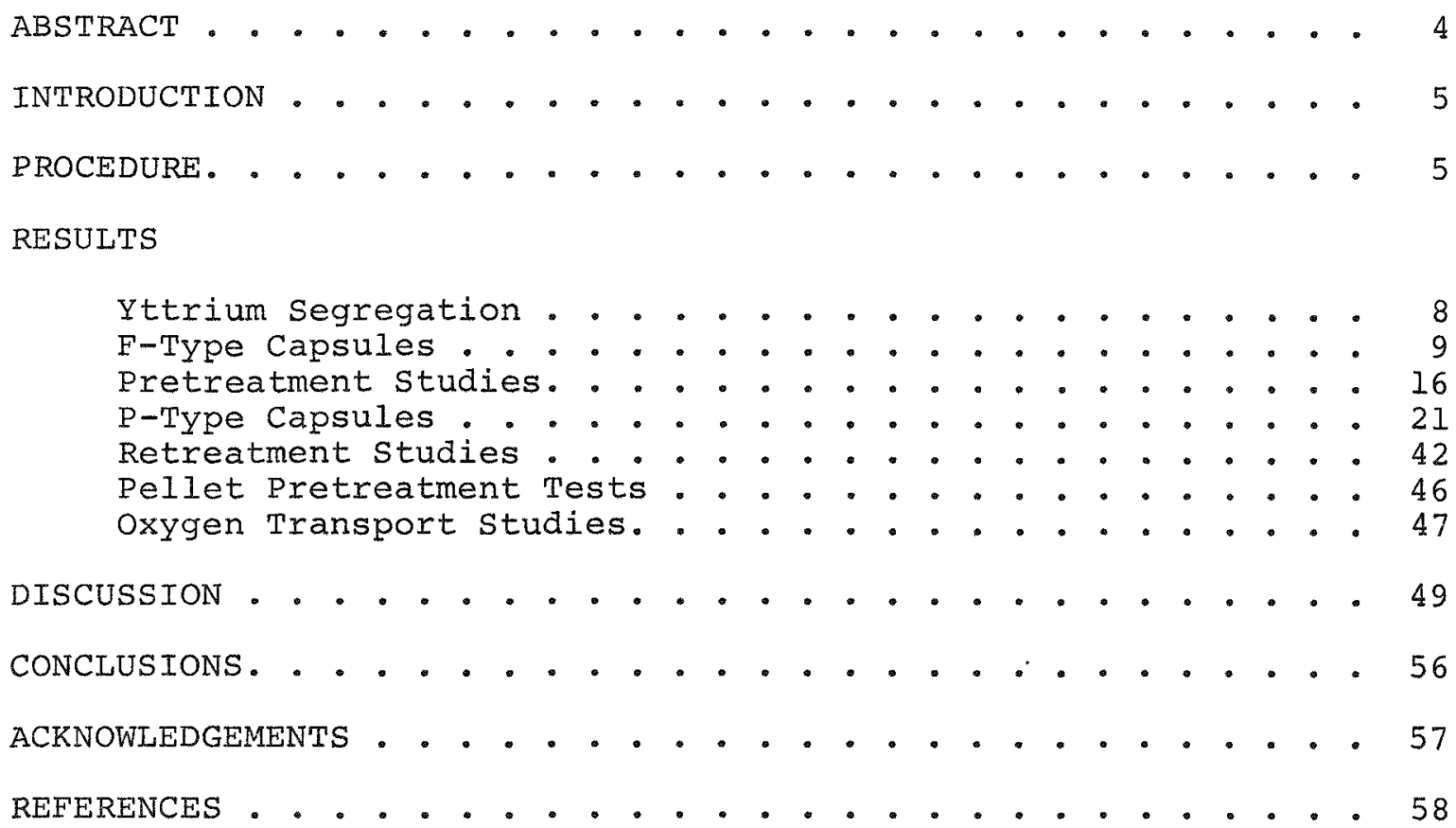




\section{ABSTRACT}

The tantalum-base alloy, T-11l, is an ideal radioisotope encapsulant from the aspect of mechanical properties, but unfortunately undergoes severe oxygen embrittlement during long-term, high-temperature exposure to $\mathrm{PuO}_{2}$. The present study was undertaken in an effort to improve T-111/ $\mathrm{PuO}_{2}$ compatibility by testing the hypothesis that reduction of fuel stoichiometry to the range $\mathrm{PuO}_{1.75}$ to $\mathrm{PuO}_{1.8}$ would suspend the embrittlement process by producing a state of thermodynamic equilibrium within the capsule. Reduction was to be accomplished in situ using yttrium metal. Test temperatures ranged from $773 \mathrm{~K}$ to $1373 \mathrm{~K}$, with aging times of 60 days, 240 days, and 2 yr.

Initial results indicated the desired reaction did not proceed rapidy enough at the aging temperatures to stop T-lll embrittlement. However, efforts to force the reduction prior to aging by heating specimens to above $1573 \mathrm{~K}$ for $1 \mathrm{hr}$ were successful. Such pretreated capsules showed no signs of embrittlement during aging, even after 2 yr at temperatures as high as $1173 \mathrm{~K}$.

Test specimens employing pelletized fuel indicated the solid-state diffusion of oxygen from the fuel to the T-11l was the dominating transport process, although some vapor-phase transport was observed. The latter can only be attributed to volatile oxide impurities in the fuel.

Analysis of the oxygen absorption rates for nonpretreated capsules showed that oxygen diffusion in T-lil was the rate-controlling process. This result, coupled with known values for oxygen mobility in substoichiometric plutonia, indicates that "pretreatment" does result in the desired thermodynamic equilibrium at temperatures up to at least $1173 \mathrm{~K}$. 


\section{INTRODUCTION}

Radioisotopic thermoelectric generators (RTG's) are finding increasing use in applications where reliable, long-term, low-wattage power is required and access is difficult. In these devices, the heat generated by decay of a radioisotope is directly converted to electrical energy by means of thermoelectric materials.

Safety considerations necessitate complete containment of the radioactive fuel in these units in any credible accident environment. This requires encapsulation materials which have sufficient high-temperature toughness to survive such situations as fire or high-velocity impact and which are not degraded by prolonged exposure to the generator environment.

One of the most widely used radioisotopic fuels in such units is plutonium-238 dioxide. Since this isotope is an alpha-emitter, extensive radiological shielding is unnecessary, while its 87.4 -yr half-life makes it ideal for long-term, higher-power sources. The dioxide form of this material has good thermal stability and high specific power.

As for encapsulation, tantalum-base materials possess the necessary toughness, as well as being formable and weldable. Unfortunately, these alloys become embrittled by prolonged high-temperature exposure to $\mathrm{PuO}_{2}$ due to oxidation by the fuel. 1,2 The present program was designed primarily to study this interaction in the $773-1373 \mathrm{~K}$ region with one such alloy, T-111, a solid-solution consisting of $90 \mathrm{wt} \div \mathrm{Ta}, 8 \mathrm{wt} \div \mathrm{W}$, and 2 wt $\frac{\mathrm{Hf}}{\circ}$, originally developed for use in space power systems. It was also desired to evaluate a technique proposed to suppress the oxygen transport process in an attempt to reduce the embrittlement.

It has been suggested ${ }^{3}$ that, if the stoichiometry of the fuel can be reduced, a point will be reached where the oxygen partial pressure of the fuel is equal to, or less than, that of oxygen in tantalum. This would effectively stop the net transfer of oxygen to such encapsulating materials. (The effect of the presence of hafnium in T-11l on the desired equilibrium was not known.) In this work, the reduction technique chosen was to mix the plutonia with a reducing agent such as yttrium or hafnium in the heat source. If the oxygen "getter" was effective, the stoichiometry of the plutonia could be reduced before the encapsulants absorbed appreciable oxygen. The reducing agent used in these tests was'yttrium, chosen mostly because of its ease of handling at room temperature, although its ability to entrap a wide number of volatile impurities was also a consideration. 4,5

\section{PROCEDURE}

The test specimens consisted of two T-111 layers with deep-drawn bodies and flat caps GTA (gas-tungsten arc) welded at one end. The liner cap and body were both $0.51 \mathrm{~mm}$ thick with approximately $2.7 \mathrm{~cm}^{3}$ * occupied by

FThis corresponds to approximately $6 \mathrm{~W}$ (thermal) or $15 \mathrm{~g}$ of $\mathrm{PuO}_{2} / \mathrm{Y}$ mixture. 
the fuel/yttrium mixture. The strength member, or second layer, employed a 1.02-mm-thick cup and a 1.53-mm-thick cap. A thin T-111 shim covered the fuel during closure to protect the weld from contamination. The actual configuration is shown in Figure 1. Typical T-111 analysis data are listed in Table 1 , while the maximum allowable and average impurity levels for the inert gas atmosphere in the welding glovebox are listed in Table 2.

The fuel used was hydroxide-precipitated $\mathrm{PuO}_{2}$ shards, from 53 to $500 \mu \mathrm{m}$ in diameter; they received their final sintering at $1873 \mathrm{~K}$ for 2 to $4 \mathrm{hr}$ (depending on the quantities present), during which time they also underwent oxygen-16 exchange. Table 3 lists the maximum and average impurity levels seen in the several fuel batches used. The yttrium was added to these specimens in the form of small machine turnings on the same size scale as the fuel. The analytical results for the yttrium are listed in Table 4. A single yttrium level was used, corresponding to reduction of plutonia to $\mathrm{PuO}_{1.75}$

Test temperatures varied from $773 \mathrm{~K}$ to $1373 \mathrm{~K}$ with times of 60 days to 2 yr; however, no single capsule type saw all test conditions. Because of the rather extreme temperatures, those capsules being heated to over $1173 \mathrm{~K}$ were secondarily encapsulated in 3.7-mm-thick Hastelloy-x, while those held at $1173 \mathrm{~K}$ or below used only a $0.51-\mathrm{mm}$ Hastelloy-C clad. All heating was done in continuously monitored high-temperature ovens.

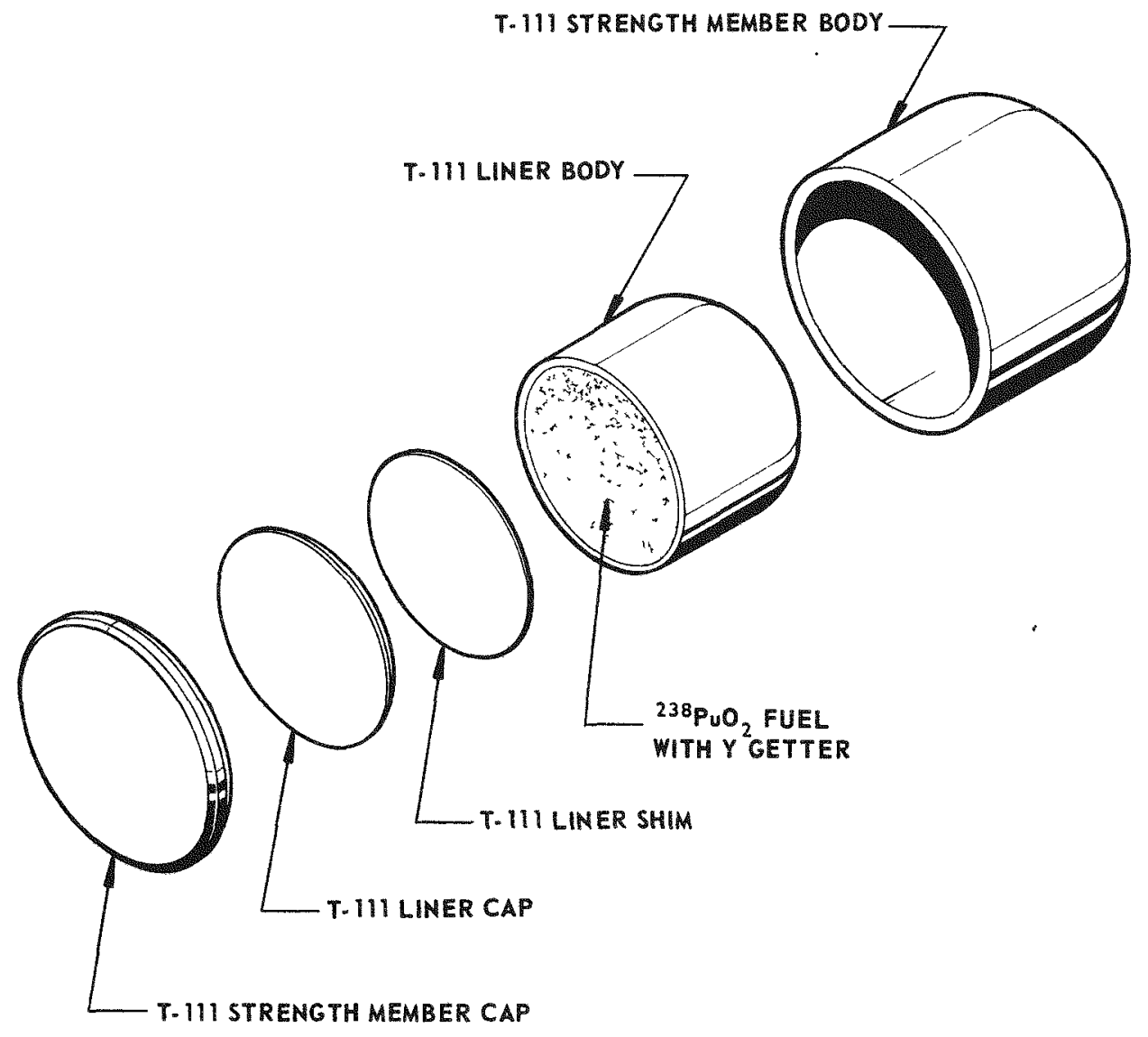

FIGURE I - Basic test capsule configuration. 
Table 1

T-111 PURITY SPECIFICATION

Element Minimum Maximum

$\begin{array}{lrr}\text { W } & 7.0 & 8.5 \mathrm{wt} \% \\ \mathrm{Hf} & 1.7 & 2.3 \mathrm{wt} \% \\ \mathrm{Nb} & & 1000 \mathrm{ppm} \\ \mathrm{MO} & & 200 \mathrm{ppm} \\ \mathrm{Ni} & & 50 \mathrm{ppm} \\ \mathrm{Fe} & & 50 \mathrm{ppm} \\ \mathrm{Zr} & & 1000 \mathrm{ppm} \\ \mathrm{H} & & 10 \mathrm{ppm} \\ \mathrm{O} & & 100 \mathrm{ppm} \\ \mathrm{N} & & 50 \mathrm{ppm} \\ \mathrm{C} & & 50 \mathrm{ppm}\end{array}$

Total of All Other $300 \mathrm{ppm}$

Impurities

Any Other Single

Impurity

$50 \mathrm{ppm}$
Table 2

WELDING ATMOSPHERE SPECIFICATION

Component Concentration

He

$75 \%$

Ar

$25 \%$

0

$<25$ ppm

$\mathrm{N}$

$<160$ ppm

$\mathrm{H}_{2} \mathrm{O}$

$<60 \mathrm{ppm}$
Table 3

PLUTONIA PURITY SPECIFICATION ${ }^{\circ}$

\begin{tabular}{|c|c|c|}
\hline Element & Average & Maximum \\
\hline $\begin{array}{l}\mathrm{A} I \\
\mathrm{~B}\end{array}$ & $\begin{array}{r}50 \\
<10\end{array}$ & $\begin{array}{l}50 \\
-\end{array}$ \\
\hline $\mathrm{Ba}$ & $<25$ & - \\
\hline $\mathrm{Ca}$ & $<250$ & - \\
\hline $\mathrm{Cd}$ & $N D^{0}$ & - \\
\hline $\mathrm{Cr}$ & 75 & 120 \\
\hline $\mathrm{Cu}$ & $<50$ & - \\
\hline $\mathrm{Fe}$ & 250 & 380 \\
\hline $\mathrm{Mg}$ & $<20$ & - \\
\hline $\mathrm{Mn}$ & $<20$ & - \\
\hline $\mathrm{Na}$ & ND & - \\
\hline $\mathrm{Ni}$ & $<50$ & 80 \\
\hline $\mathrm{Pb}$ & ND & - \\
\hline Si & $<50$ & 50 \\
\hline$S n$ & ND & - \\
\hline $\mathrm{Ta}$ & ND & - \\
\hline & & - \\
\hline
\end{tabular}

aalues in parts per million.

${ }^{b}$ ND - Not detected.
Table 4

YTTRIUM ANALYSIS RESULTS ${ }^{a}$

\begin{tabular}{|c|c|c|}
\hline Element & Powder & $\begin{array}{l}\text { Foil } \\
\text { and } \\
\text { Chips }\end{array}$ \\
\hline AI & 20 & 12 \\
\hline $\mathrm{Ca}$ & $\mathrm{ND}^{\mathrm{b}}$ & 55 \\
\hline $\mathrm{Cr}$ & $--^{c}$ & 1 \\
\hline $\mathrm{Cu}$ & 20 & $-\infty c$ \\
\hline $\mathrm{Fe}$ & 100 & 90 \\
\hline $\mathrm{Mn}$ & 5 & $<1$ \\
\hline $\mathrm{Ni}$ & 50 & 38 \\
\hline $\mathrm{Si}$ & 50 & 80 \\
\hline $\mathrm{Ta}$ & $\begin{array}{l}>0.3 \% \\
<1.0 \%\end{array}$ & $>0.3 \%$ \\
\hline C & $0.41 \%$ & $0.11 \%$ \\
\hline $\mathrm{F}$ & $\ldots c$ & 840 \\
\hline $\mathrm{H}$ & 330 & 190 \\
\hline 0 & $1.41 \%$ & $2.16 \%$ \\
\hline$N$ & & \\
\hline
\end{tabular}

Parts per million except where noted.

${ }^{\mathrm{b}} \mathrm{ND}$ - Not detected.

c Not reported. 
The majority of the specimens were bare capsules and these are designated by the $F^{\prime} \mathrm{S}$ in Table 5. In addition, several $F$-type units were encased in Min-K TE 1400 thermal insulation in a partial mockup of an actual generator and are designated by the $\mathrm{M}^{\prime} \mathrm{s}$. In order to obtain information on oxygen transport mechanisms, two special test capsules designated I-type were fabricated. These units employed fuel in the form of a vacuum hotpressed, monolithic pellet, at approximately $85 \%$ of theoretical density. In one of these specimens the fuel pellet was held in contact with one segment of the capsule wall, while in the second the pellet was completeIy supported by iridium wire standoffs. A schematic representation of the configurations is shown in Figure 2. After 60 days at $1173 \mathrm{~K}$ these units were metallographically examined to obtain estimates of the relative importance of the two principal transport mechanisms: vapor-phase and solidstate surface.

Table 5

$\mathrm{PuO}_{2} / \mathrm{T}-111$ COMPATIBILITY TEST MATRIX

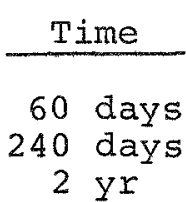

\begin{tabular}{|c|c|c|c|c|}
\hline \multicolumn{5}{|c|}{ Temperature $\left({ }^{\circ} \mathrm{K}\right)$} \\
\hline 773 & 873 & 1073 & 1173 & 1373 \\
\hline M & MP & $\mathrm{F}$ & FPL & $P$ \\
\hline M & MP & $\mathrm{F}$ & FP & $\mathrm{P}$ \\
\hline M & MP & $\mathrm{F}$ & $\mathrm{FP}$ & \\
\hline
\end{tabular}

Key: $F=$ Capsule with enough $Y$ to produce $\mathrm{PuO}_{1.75}$.

$M=F$ capsule encased in thermal insulation (generator mock-up).

$\mathrm{P}=\mathrm{F}$ capsule pretreated for $1 \mathrm{hr}$ at $1623 \mathrm{~K}$.

$I=$ Oxygen transport study capsules.

Once specimens were removed from test they were sectioned and the fuel was set aside for later study. The capsule segments were mounted and metallographically examined. Microhardness traverses were obtained using a Leitz Miniload to make indentations at constant intervals* and a Leitz Classimet for evaluation. ${ }^{6}$ If a reaction product was noted, it was further examined by means of an electron microprobe. oxygen and nitrogen determinations were also routinely made on each specimen. Finally, fuel stoichiometry determinations were attempted by x-ray diffraction, TGA weight gain, and neutron count calculations. The last, based on increased neutron emission from atmospheric-reoxidized, oxygen-exchanged fuel, proved the most satisfactory if the original neutron count values were available.

RESULTS

\section{Yttrium Segregation}

Initial metallographic work on the "M" and "F" type capsules indicated that there was no hardening of the strength members, but that irregular hardening of the liners occurred (hardness numbers for as-formed T-Ill average about 250 VHN; readings above 300 VHN are usually indicative of

*The instrument calibration for the microhardness indenter was in mils, where $I \mathrm{mil}=25.4 \mathrm{\mu m}$. For this reason all traverse distances will be denoted in mils. 

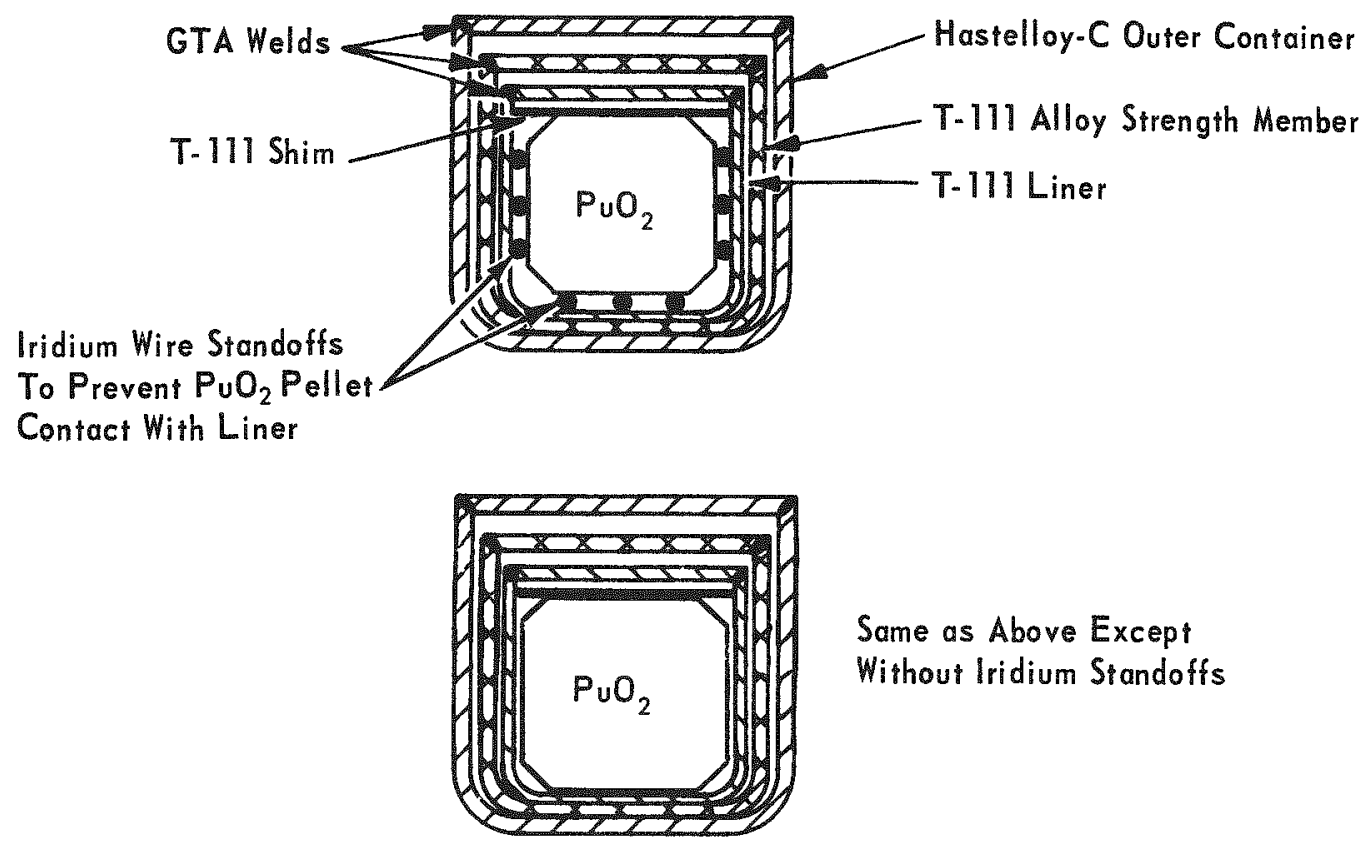

Same as Above Except

Without Iridium Standoffs

FIGURE 2 - L-type capsule design (for oxygen transport mechanism studies).

embrittled material). Parallel microhardness traverses across the sidewall of the liners gave values that varied by as much as several hundred Vickers hardness numbers. The reason for this became evident when a microhardness traverse was made down the sidewall of the specimen tested at $1173 \mathrm{~K}$. The indentations were made at $0.127-\mathrm{mm}$ intervals, $0.025 \mathrm{~mm}$ from the inside edge, beginning near the top and continuing to the bottom of the specimen. These data are shown in Figure 3. Note that the microhardness values are higher near the top and bottom and lower near the middle, indicating less oxygen entered the container wall in the latter area. This could occur if, due to fuel loading techniques, there were a higher concentration of yttrium in the middle of the capsule than at the top and the bottom. Examination of radiographs (Figure 4) of these capsules did show definite segregation of the yttrium, with the highest concentration approximately midway between the top and bottom of each specimen. The yttrium is indicated by the light bands in the figure. Following these observations the tests were repeated and care was taken to ensure a homogeneous distribution of yttrium in the capsules.

\section{F-Type Capsules}

Samples were run for 60 days, 240 days, and 2 yr at the various temperatures. The oxygen and nitrogen values are listed in Table 6 along with Vickers hardness numbers (VHN) for various capsules. Photomicrographs of the liners and microhardness traverses across the liners and strength members of the domes and sidewalls of the $2-y \mathrm{r} 873 \mathrm{~K}, 1073 \mathrm{~K}$ and $1173 \mathrm{~K}$ specimens are given in Figures 5 through 7 . (Note that $773 \mathrm{~K}$ data have not been included since they are essentially identical with $873 \mathrm{~K}$ data.) There was no indication of embrittlement or reactions in the specimen tested for $2 \mathrm{yr}$ at $873 \mathrm{~K}$ or below. Embrittlement of the liners of the specimens tested at $1073 \mathrm{~K}$ and $1173 \mathrm{~K}$ is indicated by the microhardness 
traverses in Figures 6 and 7. Microhardness gradients ranging from 240 VHN at the inside edge to approximately 275 VHN at the outside edge are indicated for the strength member dome and sidewall of the specimen tested at $1073 \mathrm{~K}$. Electron microprobe analysis revealed no explanation for the gradients. However, they most probably are due to nitrogen diffusion through the Hastelloy-C clad. This probably also accounts for the high values obtained along the outside edge of the strength member dome of the specimen tested at $1173 \mathrm{~K}$, shown in Figure 7 .

It is evident from these results that the yttrium was not effective in reducing the plutonia at these temperatures. This may be due either to the failure of the yttrium protective oxide to completely disappear or

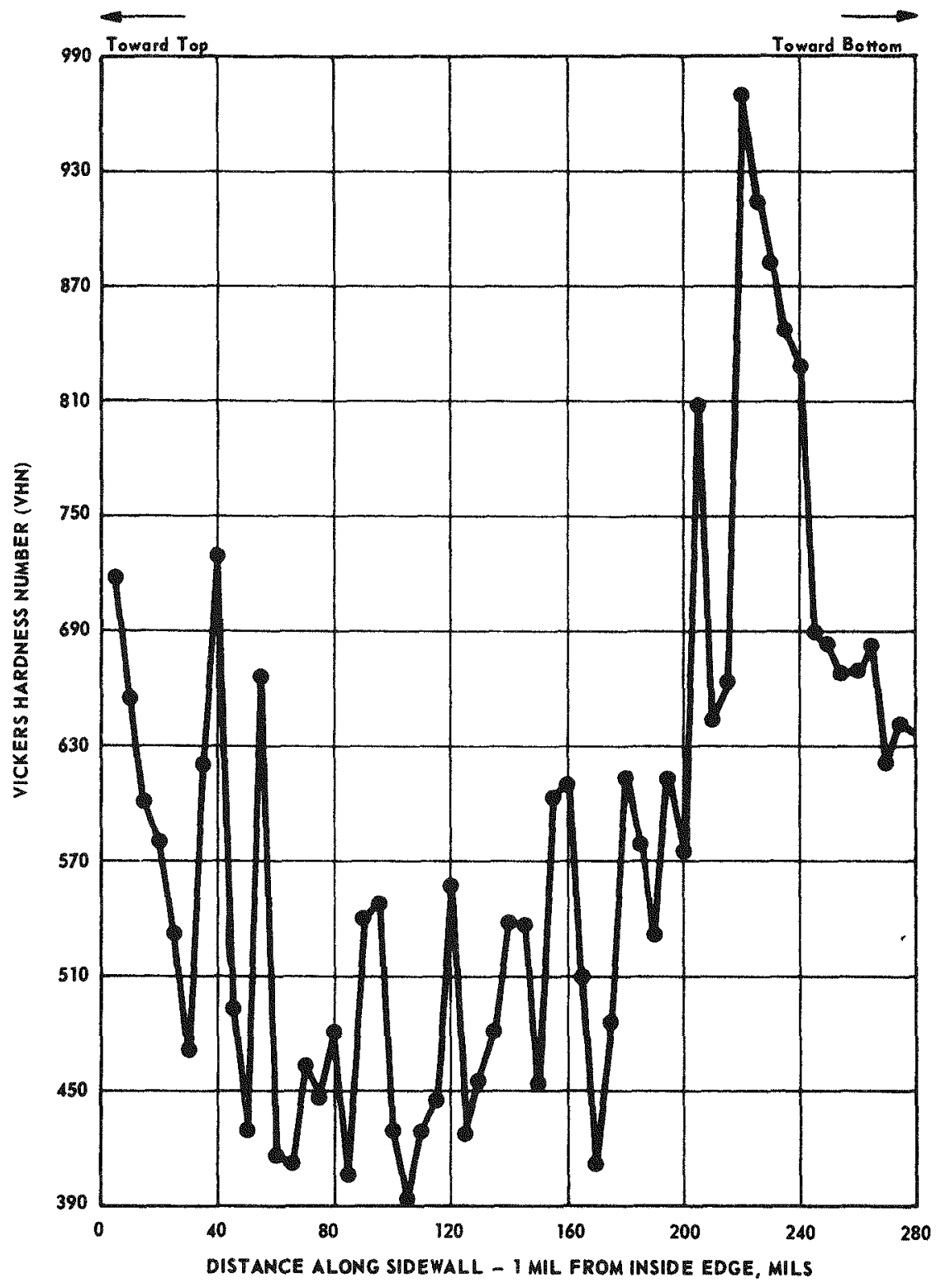

FIGURE 3 - Microhardness traverse of original Il73 K, 60-day F-type capsule. 


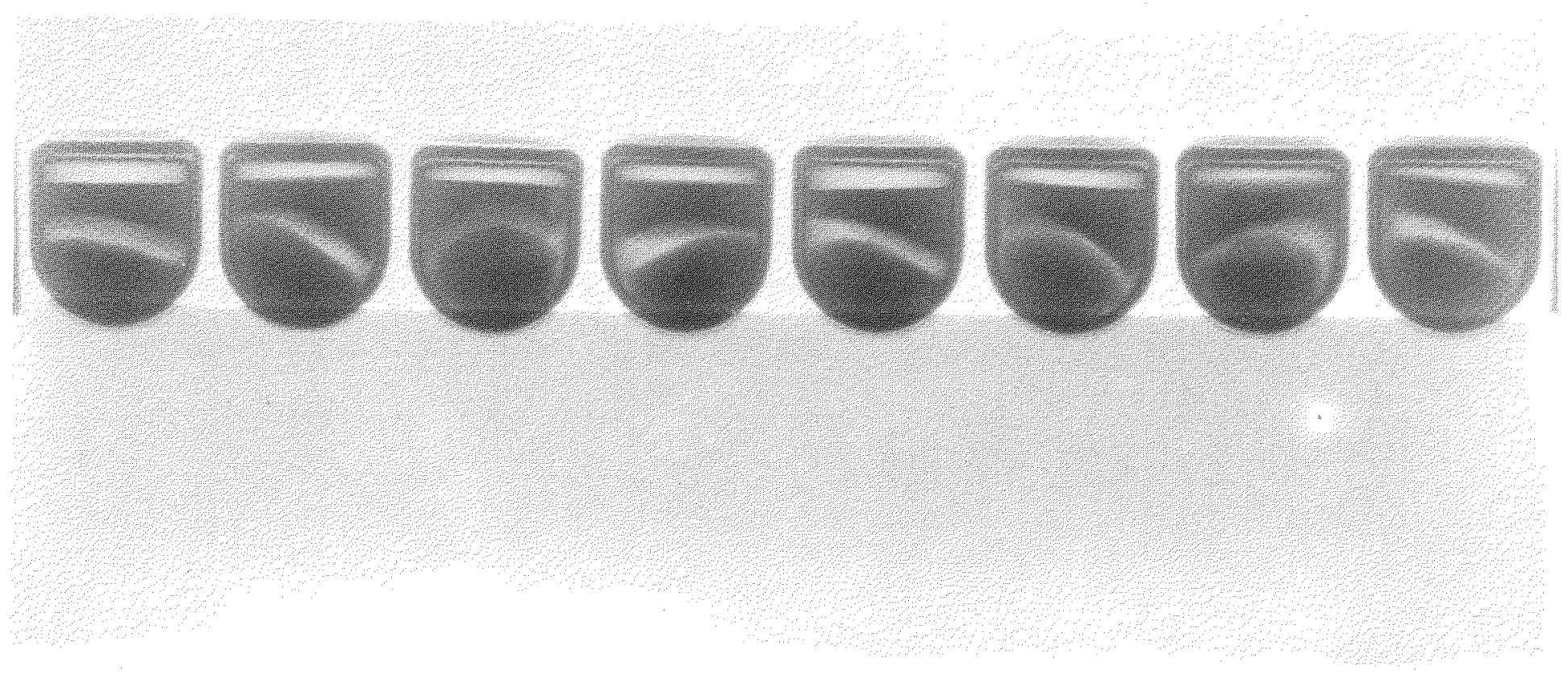

FIGURE 4 - Radiograph showing yttrium segregation as light band in fuel. 
Table 6

"F" TYPE SPECIMEN DATA

\begin{tabular}{|c|c|c|c|c|}
\hline Specimen & Sample Origin & $\begin{array}{l}\mathrm{O}_{2} \\
(\mathrm{ppm}) \\
\end{array}$ & $\begin{array}{l}\mathrm{N}_{2} \\
(\mathrm{ppm}) \\
\end{array}$ & $\begin{array}{l}\text { Average } \\
\text { Hardness } \\
\text { (VHN) }\end{array}$ \\
\hline $\begin{array}{l}\text { Fueled Control } \\
\text { (No Heat Treatment) }\end{array}$ & $\left\{\begin{array}{l}\text { Liner Side } \\
\text { Liner Dome } \\
\text { Strength Member Side } \\
\text { Strength Member Dome }\end{array}\right.$ & $\begin{array}{l}107 \\
151 \\
143 \\
147\end{array}$ & $\begin{array}{r}7 \\
7 \\
2 \\
53\end{array}$ & $\begin{array}{l}235 \\
254 \\
238 \\
248\end{array}$ \\
\hline 60 days a $1073 \mathrm{~K}$ & $\left\{\begin{array}{l}\text { Liner Dome } \\
\text { Liner Side } \\
\text { Strength Member Dome } \\
\text { Strength Member Side }\end{array}\right.$ & $\begin{array}{r}37 \\
321 \\
74 \\
10\end{array}$ & $\begin{array}{l}49 \\
80 \\
31 \\
50\end{array}$ & $\begin{array}{l}250 \\
260 \\
255 \\
251\end{array}$ \\
\hline 60 days a $1173 \mathrm{~K}$ & $\left\{\begin{array}{l}\text { Liner Dome } \\
\text { Iiner Side } \\
\text { Strength Member Dome } \\
\text { Strength Member Side }\end{array}\right.$ & $\begin{array}{r}1070 \\
1883 \\
29 \\
23\end{array}$ & $\begin{array}{r}100 \\
110 \\
72 \\
45\end{array}$ & $\begin{array}{l}252 \\
328 \\
263 \\
255\end{array}$ \\
\hline 240 days d $873 \mathrm{~K}$ & $\left\{\begin{array}{l}\text { Liner Side } \\
\text { Liner Bottom } \\
\text { Strength Member Side } \\
\text { Strength Member Bottom }\end{array}\right.$ & $\begin{array}{r}72 \\
220 \\
52 \\
56\end{array}$ & $\begin{array}{r}2 \\
11 \\
20 \\
11\end{array}$ & $\begin{array}{l}291 \\
262 \\
253 \\
238\end{array}$ \\
\hline 240 days a $1073 \mathrm{~K}$ & $\begin{array}{l}\text { Liner Side } \\
\text { Liner Bottom } \\
\text { Strength Member Side } \\
\text { Strength Member Bottom }\end{array}$ & $\begin{array}{r}1184 \\
452 \\
91 \\
53\end{array}$ & $\begin{array}{r}3 \\
1 \\
20 \\
20\end{array}$ & $\begin{array}{l}541 \\
581 \\
247 \\
229\end{array}$ \\
\hline 240 days @ $1173 \mathrm{~K}$ & $\left\{\begin{array}{l}\text { Liner Side } \\
\text { Liner Bottom } \\
\text { Strength Member Side } \\
\text { Strength Member Bottom }\end{array}\right.$ & $\begin{array}{r}1330 \\
>2000 \\
69 \\
79\end{array}$ & $\begin{array}{r}6 \\
11 \\
49 \\
59\end{array}$ & $\begin{array}{l}816 \\
728 \\
243 \\
240\end{array}$ \\
\hline $2 \mathrm{yr}$ @ $873 \mathrm{~K}$ & $\left\{\begin{array}{l}\text { Liner Sidewall } \\
\text { Liner Dome } \\
\text { Strength Member Sidewall } \\
\text { Strength Member Dome }\end{array}\right.$ & $\begin{array}{r}156 \\
158 \\
48 \\
45\end{array}$ & $\begin{array}{l}18 \\
16 \\
<5 \\
6\end{array}$ & $\begin{array}{l}249 \\
260 \\
252 \\
260\end{array}$ \\
\hline 2 yr a $1073 \mathrm{k}$ & $\left\{\begin{array}{l}\text { Liner Sidewall } \\
\text { Liner Dome } \\
\text { Strength Member Sidewall } \\
\text { Strength Member Dome }\end{array}\right.$ & $\begin{array}{r}1630 \\
2010 \\
60 \\
284\end{array}$ & $\begin{array}{l}42 \\
10 \\
30 \\
36\end{array}$ & $\begin{array}{l}634 \\
621 \\
256 \\
260\end{array}$ \\
\hline 2 yr $\mathrm{g} 1173 \mathrm{~K}$ & $\left\{\begin{array}{l}\text { Liner Sidewall } \\
\text { Liner Dome } \\
\text { Strength Member Sidewall } \\
\text { Strength Member Dome }\end{array}\right.$ & $\begin{array}{r}2543 \\
3667 \\
61 \\
106\end{array}$ & $\begin{array}{r}96 \\
40 \\
44 \\
102\end{array}$ & $\begin{array}{l}717 \\
834 \\
265 \\
296\end{array}$ \\
\hline
\end{tabular}




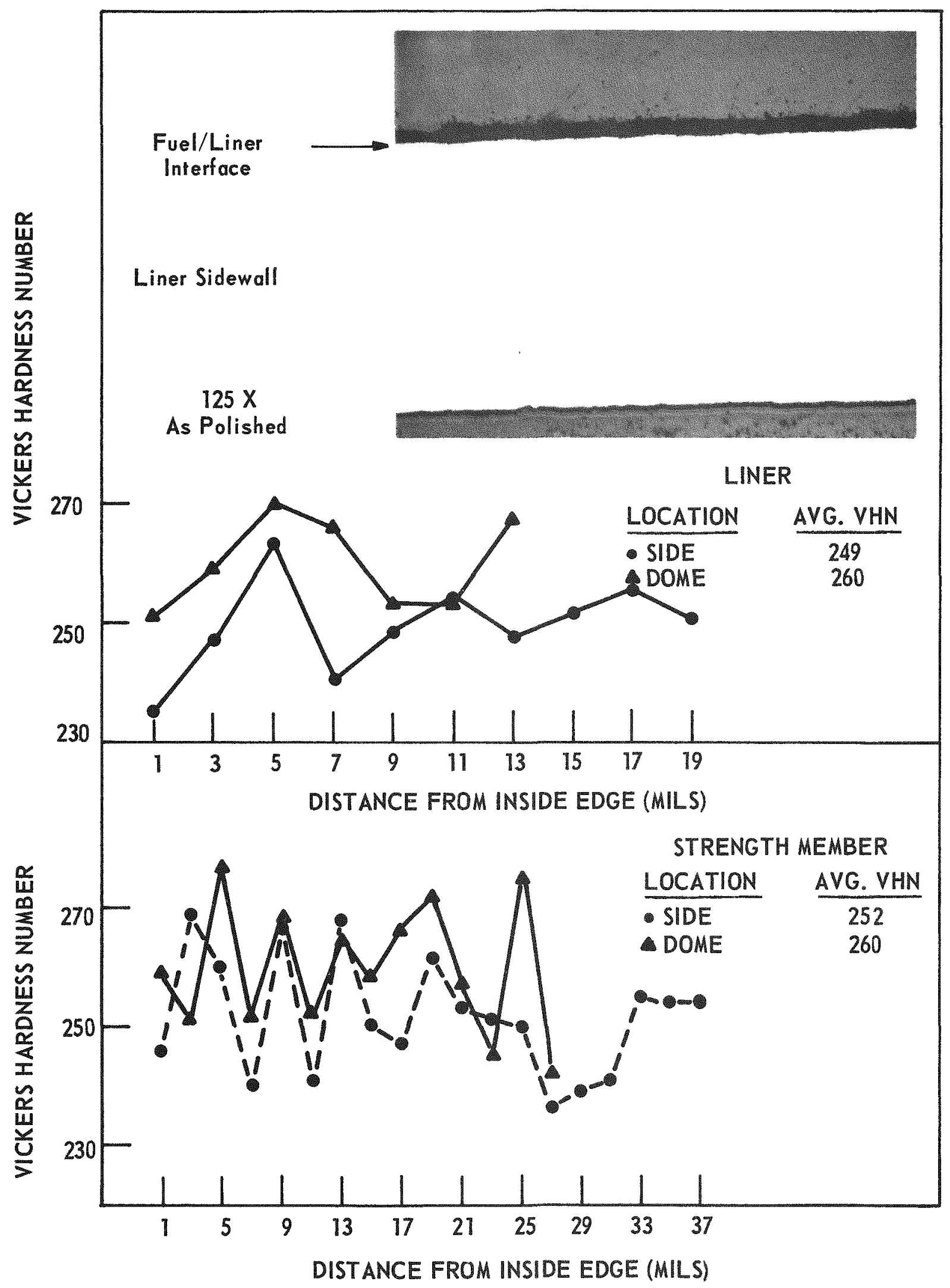

FIGURE 5 - Photomicrograph and microhardness traverses for $873 \mathrm{~K}, 2-y \mathrm{r}-$ type capsule. 


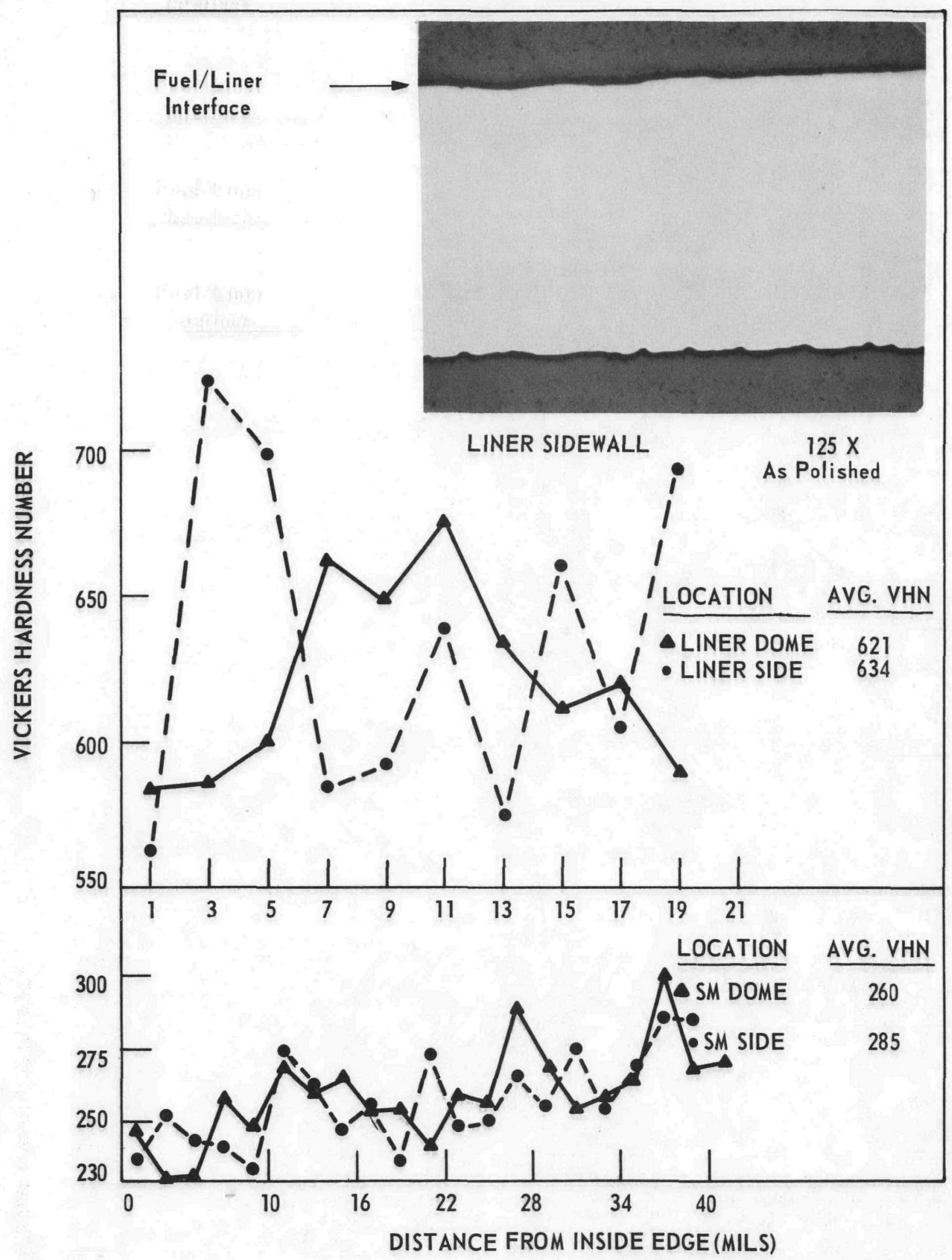

FIGURE 6 - Photomicrograph and microhardness traverses for $1073 \mathrm{~K}, 2-y \mathrm{r}$ F-type capsule. 


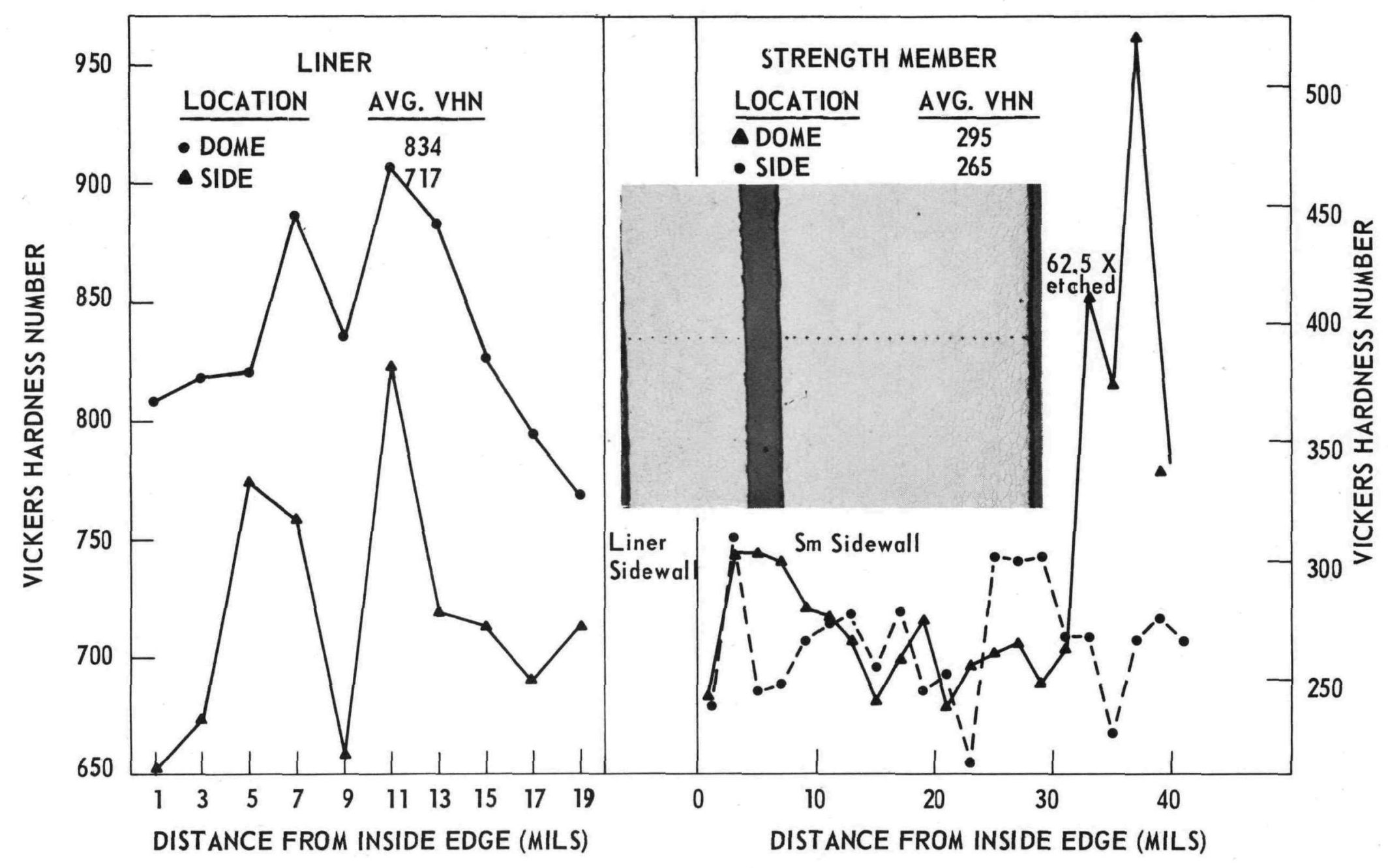


to the predominance of solid-state oxygen transport under these conditions. The results of the inhomogeneous capsules tend to support the latter hypothesis, although there is also independent evidence of the former.

Further insight was gained when the original $1073 \mathrm{~K}, 60$-day capsule was examined. Apparently the fuel/yttrium mixture was close to the weld during closure, since some of this material was found melted near the weld. Although this capsule had to be replaced, the data obtained were significant because the T-lll in the vicinity of the melted material was significantly more ductile than anywhere else on the liner. This effect was attributed to the reduction of the fuel when the $\mathrm{PuO}_{2} / \mathrm{Y}$ material was heated to an elevated temperature; therefore it was decided to try to use this technique to force the reduction process.

\section{pretreatment studies}

Three F-type capsules were heated to temperatures of $1573 \mathrm{~K}, 1673 \mathrm{~K}$, and $1723 \mathrm{~K}$, respectively, for $\mathrm{I} \mathrm{hr}$, then placed on test at $1173 \mathrm{~K}$ for 60 days. A fourth specimen was "pretreated" at $1673 \mathrm{k}$ for $\mathrm{l} \mathrm{hr}$ and then examined without any aging.

Microhardness traverses were made across the liner and strength nember of each specimen. Plots of the values obtained from each specimen are given in Figures 8 through 11. Also, the average hardness values for the domes and sides of the liners are listed in Table 7 along with oxygen and nitrogen analysis results.

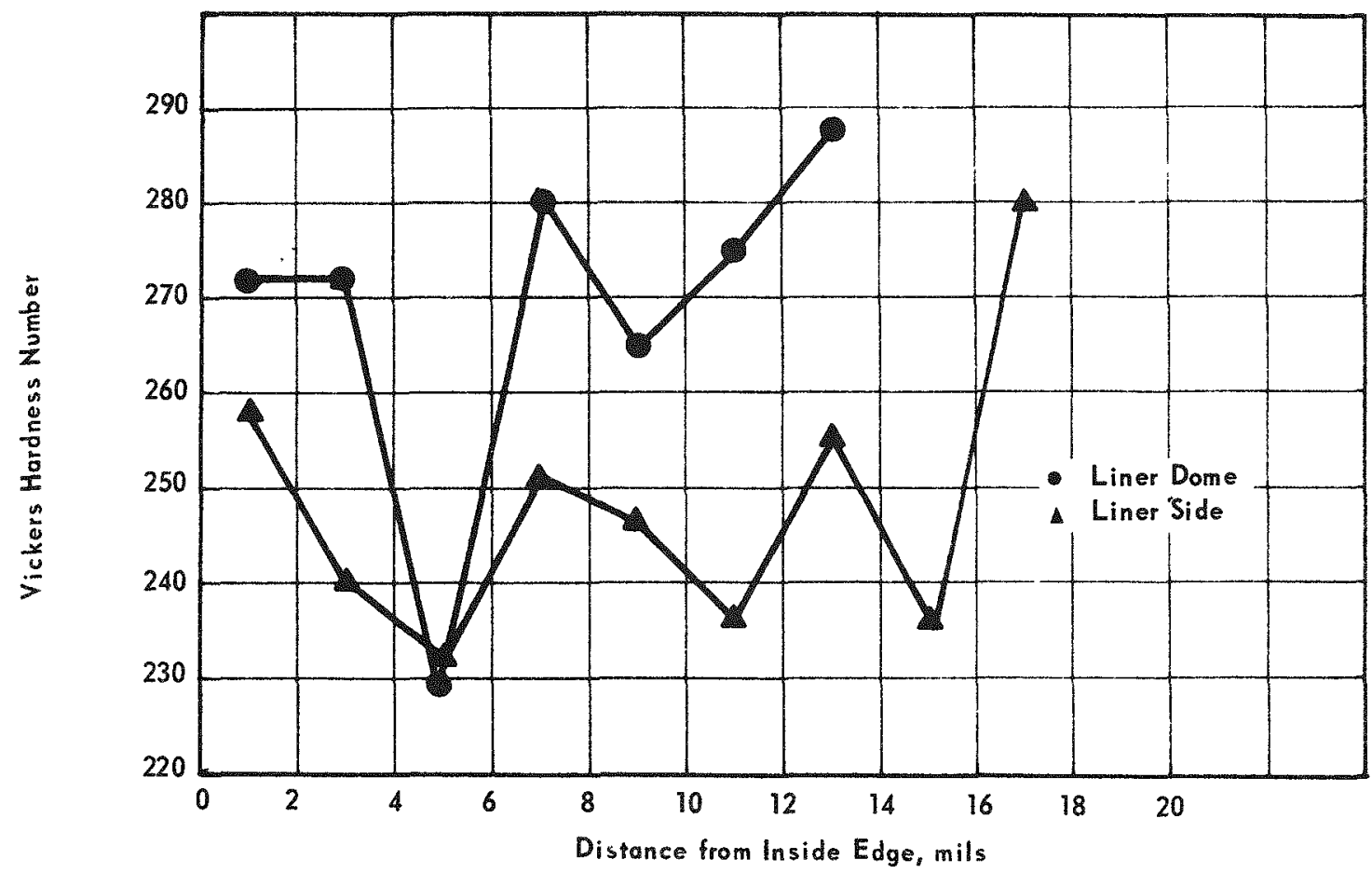

FIGURE 8 - Microhardness traverses for pretreated capsule ( $I$ h @ $1573 K$ ) aged at $1173 \mathrm{~K}$ for 60 days. 


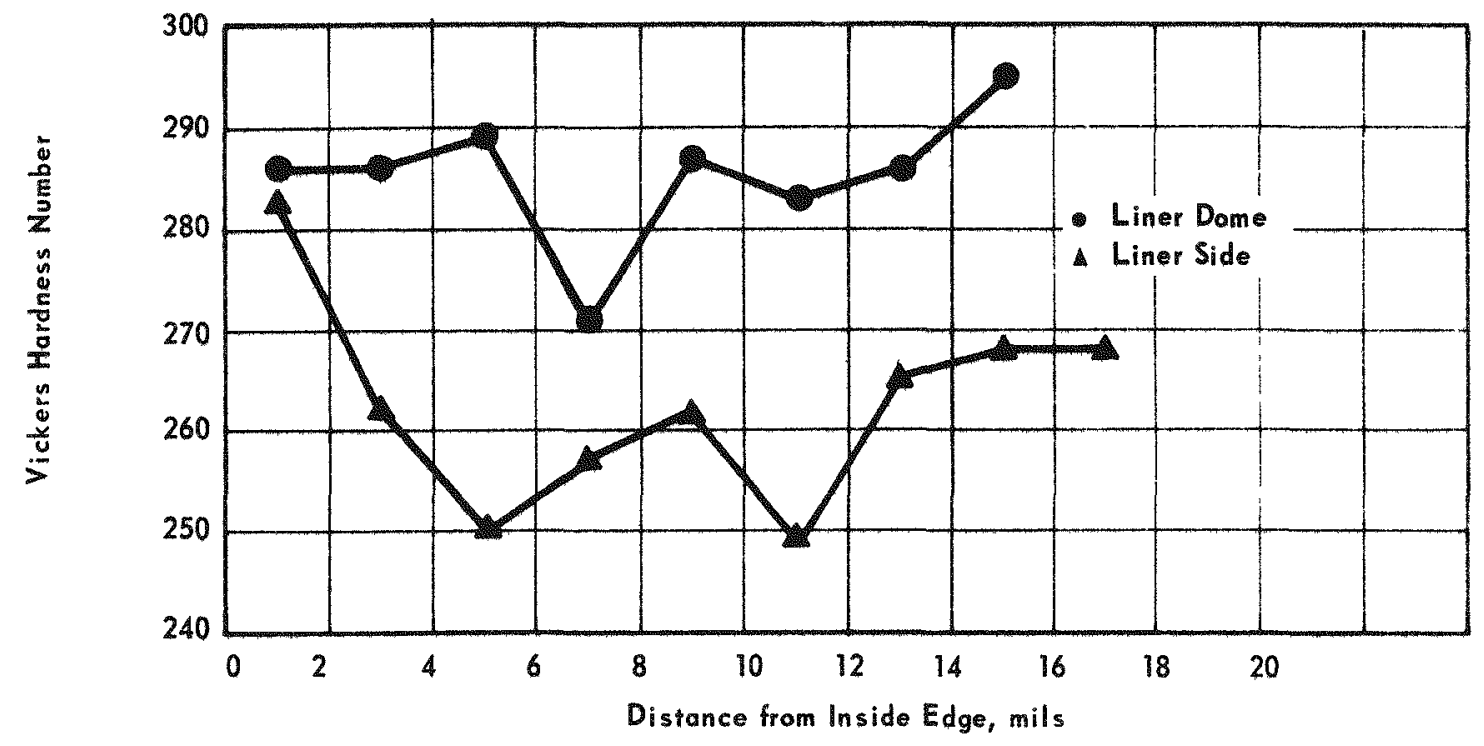

FIGURE 9 - Microhardness traverses for pretreated capsule ( $1 \mathrm{hr}$ (g $1673 \mathrm{~K}$ ) aged at $1173 \mathrm{~K}$ for 60 days.

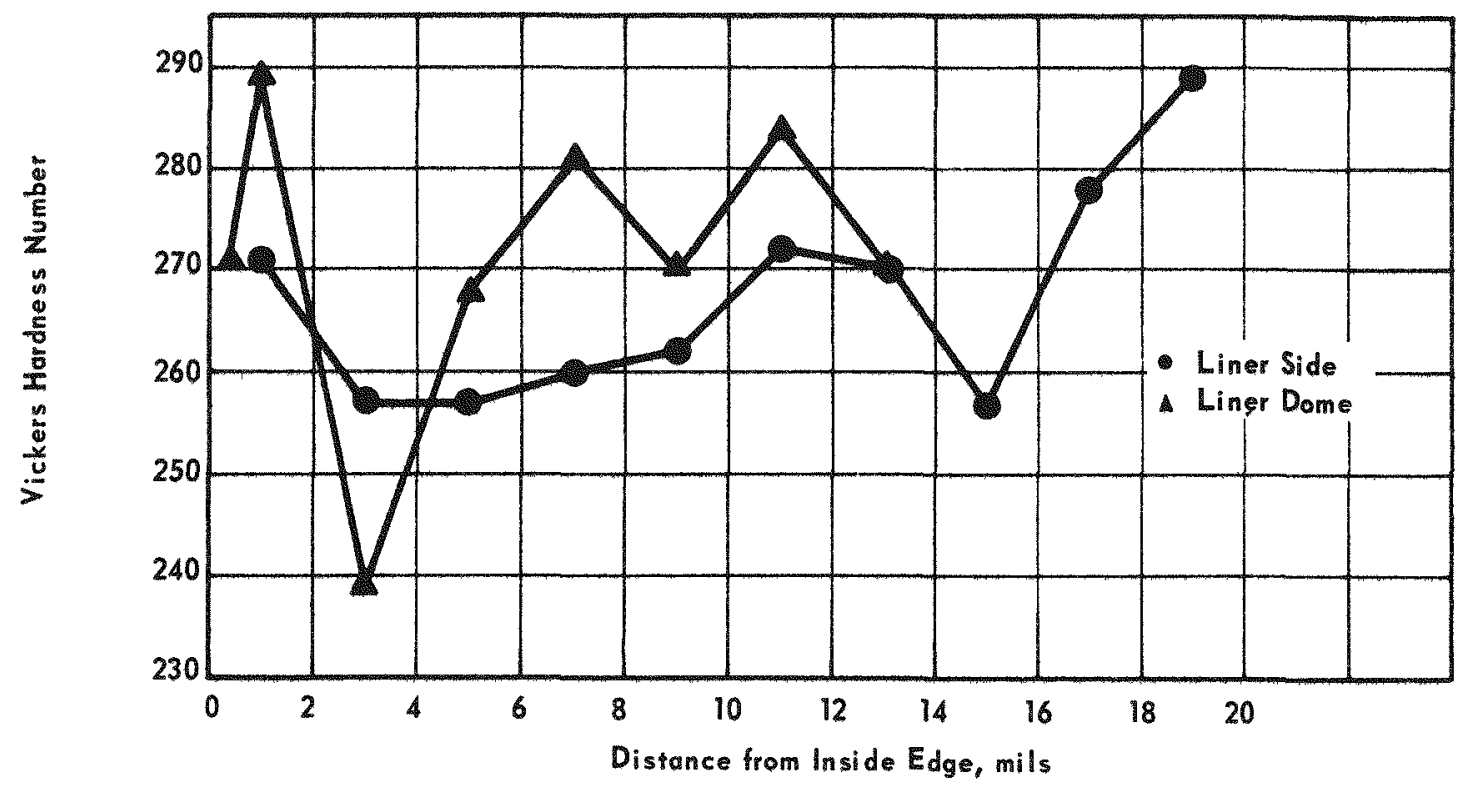

FIGURE 10 - Microhardness traverses for pretreated capsule ( $1 \mathrm{hr}$ a $1673 \mathrm{~K}$ ) - no aging. 


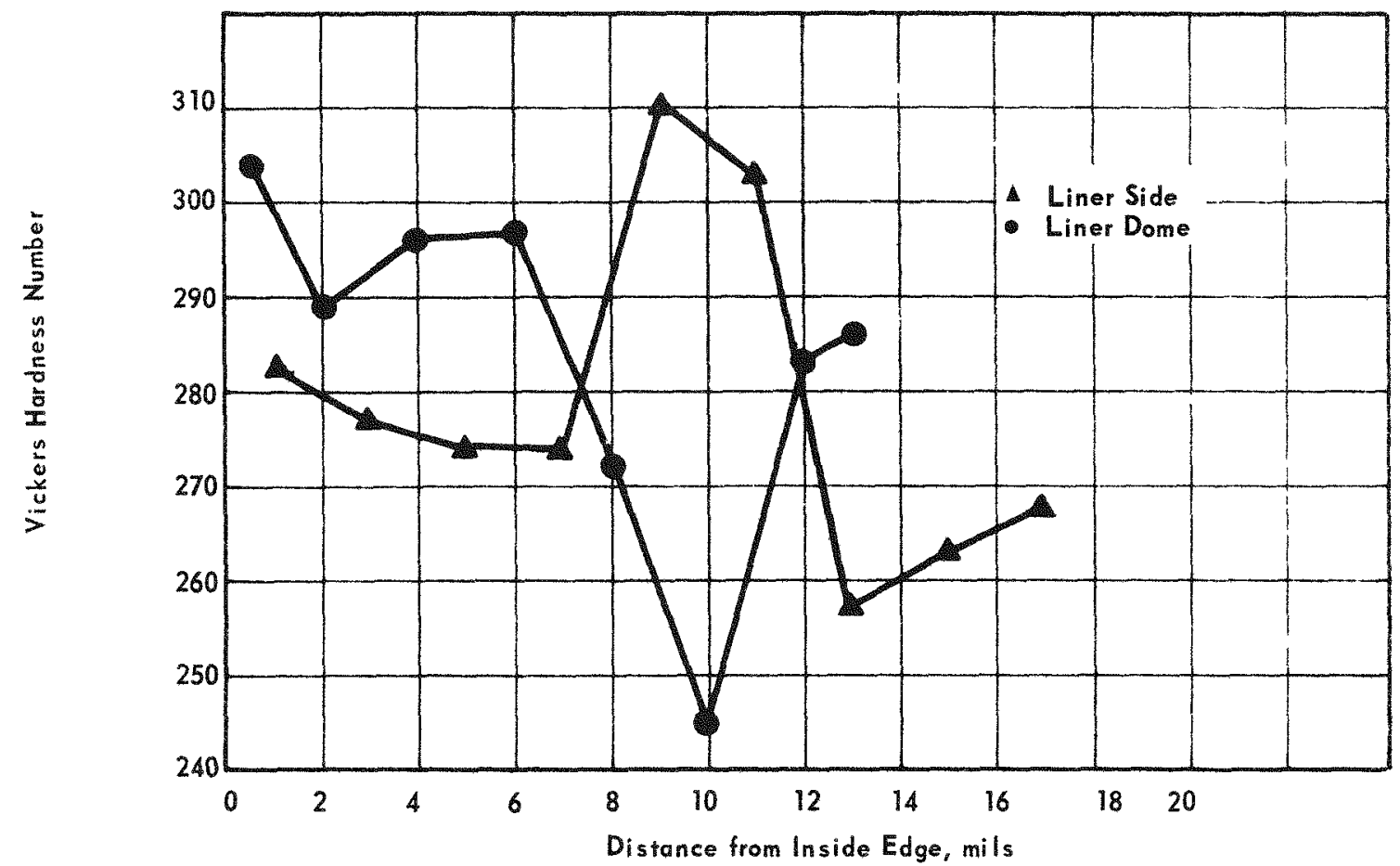

FIGURE 11 - Microhardness traverses for pretreated capsule (l hr e 1723 K) aged at $1173 \mathrm{~K}$ for 60 days.

Table 7

INITIAL PRETREATMENT STUDY RESULTS

\begin{tabular}{|c|c|c|c|c|}
\hline Conditions & Sample origin & $\begin{array}{r}\mathrm{O}_{2} \\
\text { (ppm) } \\
\end{array}$ & $\begin{array}{r}\mathrm{N}_{2} \\
\text { (ppm) }\end{array}$ & $\begin{array}{l}\text { Average } \\
\text { Hardness } \\
\text { (VHN) }\end{array}$ \\
\hline $\begin{array}{l}\text { Pretreated at } 1573 \mathrm{~K} \\
\text { followed by } 60 \text { days } \\
\text { at } 1173 \mathrm{~K}\end{array}$ & $\left\{\begin{array}{l}\text { Liner Side } \\
\text { Liner Bottom } \\
\text { Strength Member Side } \\
\text { Strength Member Dome }\end{array}\right.$ & $\begin{array}{l}187 \\
134 \\
101 \\
155\end{array}$ & $\begin{array}{r}14 \\
14 \\
20 \\
332\end{array}$ & $\begin{array}{l}248 \\
269\end{array}$ \\
\hline $\begin{array}{l}\text { Pretreated at } 1673 \mathrm{~K} \\
\text { followed by } 60 \text { days } \\
\text { at } 1173 \mathrm{~K}\end{array}$ & $\left\{\begin{array}{l}\text { Liner Side } \\
\text { Liner Bottom } \\
\text { Strength Member Side } \\
\text { Strength Member Bottom }\end{array}\right.$ & $\begin{array}{l}286 \\
151 \\
131 \\
203\end{array}$ & $\begin{array}{l}21 \\
12 \\
64 \\
29\end{array}$ & $\begin{array}{l}263 \\
285\end{array}$ \\
\hline $\begin{array}{l}\text { Pretreated at } 1723 \mathrm{~K} \\
\text { followed by } 60 \text { days } \\
\text { at } 1173 \mathrm{~K}\end{array}$ & $\left\{\begin{array}{l}\text { Liner Side } \\
\text { Liner Bottom } \\
\text { Strength Member Side } \\
\text { Strength Member Bottom }\end{array}\right.$ & $\begin{array}{l}547 \\
429 \\
145 \\
157\end{array}$ & $\begin{array}{l}35 \\
45 \\
11 \\
12\end{array}$ & $\begin{array}{l}279 \\
284\end{array}$ \\
\hline $\begin{array}{l}\text { Pretreated at } 1673 \mathrm{~K} \text {; } \\
\text { no follow-up heat } \\
\text { treatment }\end{array}$ & $\left\{\begin{array}{l}\text { Liner Side } \\
\text { Iiner Bottom } \\
\text { Strength Member Side } \\
\text { Strength Member Bottom }\end{array}\right.$ & $\begin{array}{l}327 \\
220 \\
133 \\
123\end{array}$ & $\begin{array}{l}24 \\
14 \\
14 \\
13\end{array}$ & $\begin{array}{l}267 \\
272\end{array}$ \\
\hline
\end{tabular}


In general, the hardness of T-111 liners increases with increasing pretreatment temperature; however, the values are low, indicating that the liners are ductile and contain an insignificant level of effective interstitial contamination. The oxygen can be considered to be associated with the overaged hafnia precipitates and, therefore, has essentially no effect on mechanical properties. 8,9 Most important, however, the data indicate that, after pretreatment, no additional oxygen was introduced into the liner during the 60 days at $1173 \mathrm{k}$. This cannot be said of the equivalent F-type capsule (Figure 3 ).

Based on these results, a compromise temperature of $1623 \mathrm{~K}$ was chosen for further study. Before aging studies were begun, however, it was decided to run a series of tests to investigate the effect of the form of the yttrium, the mechanical integrity of pretreated plutonia, and the effect of pretreatment of a capsule without yttrium. The specific tests are listed in Table 8. Data for the specimen that contained $\mathrm{PuO}_{2}$ and no getter (specimen E) are shown in Figure 12. Without yttrium, embrittlement of the capsule occurred between 6 and $8 \mathrm{mils}$ ( 152 to $203 \mu \mathrm{m}$ ) into the specimen from the fuel/metal interface. No reaction products were observed in the specimen; however, the inside edge of the specimen was much smoother and more even than the outside edge, indicating a slight general reaction at the inside surface.

Table 8

SPECIAL COMPATIBILITY SPECIMENS

Sample Identification

A

A

$\frac{\text { Description }^{2}}{\text { PuO }_{1.75} \begin{array}{c}\left(2.56 \mathrm{~g} \mathrm{PuO}_{2}+0.140 \mathrm{~g}\right. \\ \mathrm{Y} \text { chips })\end{array}}$
Y chips)

\begin{tabular}{|c|c|}
\hline $\begin{array}{l}B \\
C \\
D\end{array}$ & $\left.\begin{array}{l}2.8 \mathrm{~g} \mathrm{PuO}_{2}+0.295 \mathrm{~g} \mathrm{Y} \text { foil liner } \\
\mathrm{Y} \text { foil liner only }(0.290 \mathrm{~g}) \\
2.89 \mathrm{~g} \mathrm{PuO}_{2}+0.300 \mathrm{~g} \mathrm{Y} \text { foil liner }\end{array}\right\}$ \\
\hline$E$ & $2.8 \mathrm{~g} \mathrm{PuO} 2$ \\
\hline & $\left.\mathrm{PuO}_{1.75} \begin{array}{l}\left(2.8 \mathrm{~g} \mathrm{PuO}_{2}+0.153 \mathrm{~g} \mathrm{Y}\right. \\
\text { powder }\end{array}\right\}$ \\
\hline & $\left.\mathrm{PuO}_{1.75} \begin{array}{l}(2.8 \mathrm{~g} \\
\text { powder })\end{array} \mathrm{PuO}_{2}+0.153 \mathrm{~g} \mathrm{Y}\right)$ \\
\hline
\end{tabular}

Purpose of Test

Determine if yttrium homogeneity is critical for pretreatment.

Evaluate effectiveness and condition of yttrium foil liner.

Pretreatment reference capsule.

Fines analysis of fuel before and after pretreatment.

${ }^{a}$ All encapsulated in T-11I and pretreated for $I$ hr at $1623 \mathrm{~K}$. 


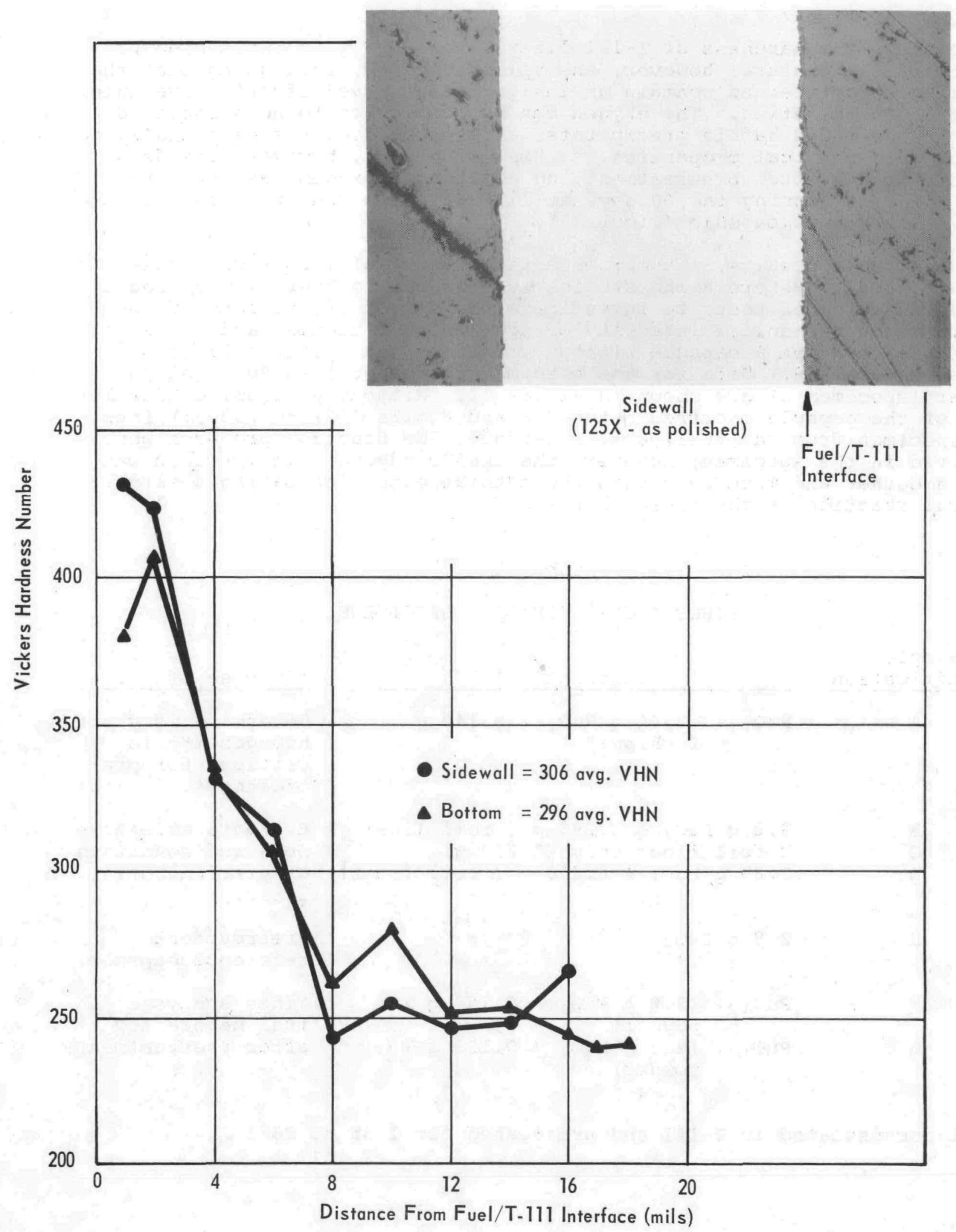

FIGURE 12 - MiCrograph and microhardness traverses for Specimen E (reference capsule - $\mathrm{PuO}_{2}$, no $Y$ - pretreated I hr at $1623 \mathrm{~K}$ ). 
Data for the duplicate fines generation specimens $F$ and $G$, which were loaded with $\mathrm{PuO}_{2}$ and yttrium powder, are shown in Figures 13 and 14 , respectively. When a comparison is made to the data for the specimen loaded with $\mathrm{PuO}_{2}$ only, the effectiveness of the yttrium powder is evident. Uptake of oxygen by the T-lil liner is nearly eliminated. Metallographic examination of the liners of the specimens revealed no evidence of reaction except for the presence of a thin $(<5-\mu m)$ white phase at spots along the fuel/metal interface of one specimen, as shown in Figure 15. This has recently been related to hafnium depletion of the T-111 at the interface and has no detrimental effect on the liner. Fines analyses of these specimens indicated no measurable increase in particles smaller than $5 \mu \mathrm{m}$ as a result of pretreatment.

Metallographic and microhardness data for specimen $A$, loaded with yttrium foil chips $(0.254 \mathrm{~mm}$ thick $\times 3 \mathrm{~mm}$ square), appear to indicate that the chips are just as effective as the powder for gettering the oxygen from the $\mathrm{PuO}_{2}$ during pretreatment. The data are shown in Figure 15. Microhardness values were very similar to those obtained for the specimens that contained yttrium powder. The results of this test also imply that yttrium powder homogeneity would not be as critical in specimens if they were pretreated after fabrication.

Data obtained from the specimens that were lined with yttrium foil were not as favorable as for the specimens loaded with yttrium powder or chips. The exact reason for this is not known at this time, but appears to be related to the passivity of the large sheet surface as compared with the turnings or high-curvature corners of the chips. Data for the specimen that contained yttrium foil only (specimen C) are shown in Figure 16. As expected, the microhardness values are low. However, metallographic examination of the specimen revealed reaction zones between the yttrium foil and the $T-111$ liner in various areas of the specimen. The reaction products can be seen in the high-magnification photomicrograph in Figure 16. Metallographic examination of subsequent specimens revealed more of this eutectic reaction at the $T-111 / y t t r i u m ~ i n t e r f a c e s$ and the interfaces between the yttrium chips. Electron microprobe analysis showed the eutectic to be composed of high-silicon-bearing dendrites in a matrix high in yttrium. The silicon-yttrium phase diagram shows a eutectic at $1533 \mathrm{~K}$ with 13 at. $\frac{\circ}{8}$ silicon. The yttrium foil in this specimen was very friable after the test. As such, particles of yttrium fell out during polishing, which gouged and scratched the polished surface of the T-IIl liner, resulting in a ratherpoor-quality micrograph.

Data for duplicate specimens $B$ and $D$, which were lined with yttrium foil and contained $\mathrm{PuO}_{2}$, are shown in Figures 17 and 18 , respectively. Microhardness values across the sidewalls of the specimens indicate no oxygen contamination of the T-111. However, microhardness values across the domes of the specimens indicated embrittlement of the liner at the inside edge of the T-11l. This is most probably related to the presence of the $\mathrm{PuO}_{2}$, since it was not observed in specimen C. It was subsequently found in other pretreated specimens, especially those using chips, but was much more prominent and serious in those using foil as a getter.

\section{P-Type Capsules}

As shown in Table 5, capsules pretreated for $1 \mathrm{hr}$ at $1623 \mathrm{~K}$ were placed on test at $873 \mathrm{~K}, 1173 \mathrm{~K}$, and $1373 \mathrm{~K}$ for times of 60 days, 240 days, and 2 yr. In the case of the 60-day specimen, microhardness traverses were conducted across the cap, sidewall, and dome of the liners and strength members of 


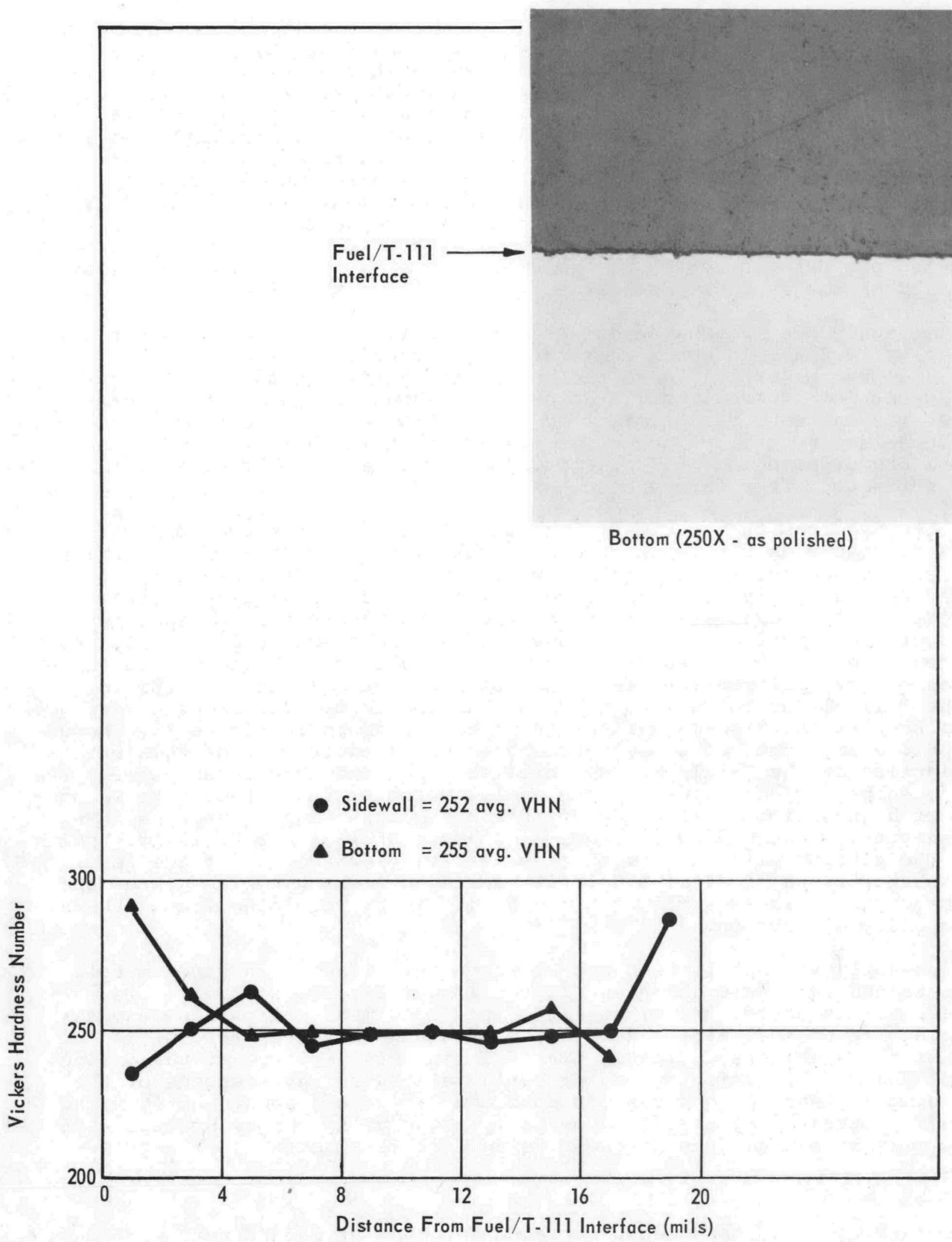

FIGURE 13 - Micrograph and microhardness traverses for specimen $\mathrm{F}\left(\mathrm{PuO}_{2}+\right.$ $y$ powder - for fines analysis - pretreated I hr at $1623 \mathrm{~K}$ ). 
Fuel/T-111

Interface

Bottom (250X - as polished)

- Sidewall $=258$ arg. VHN

Bottom $=252$ avg. VHN

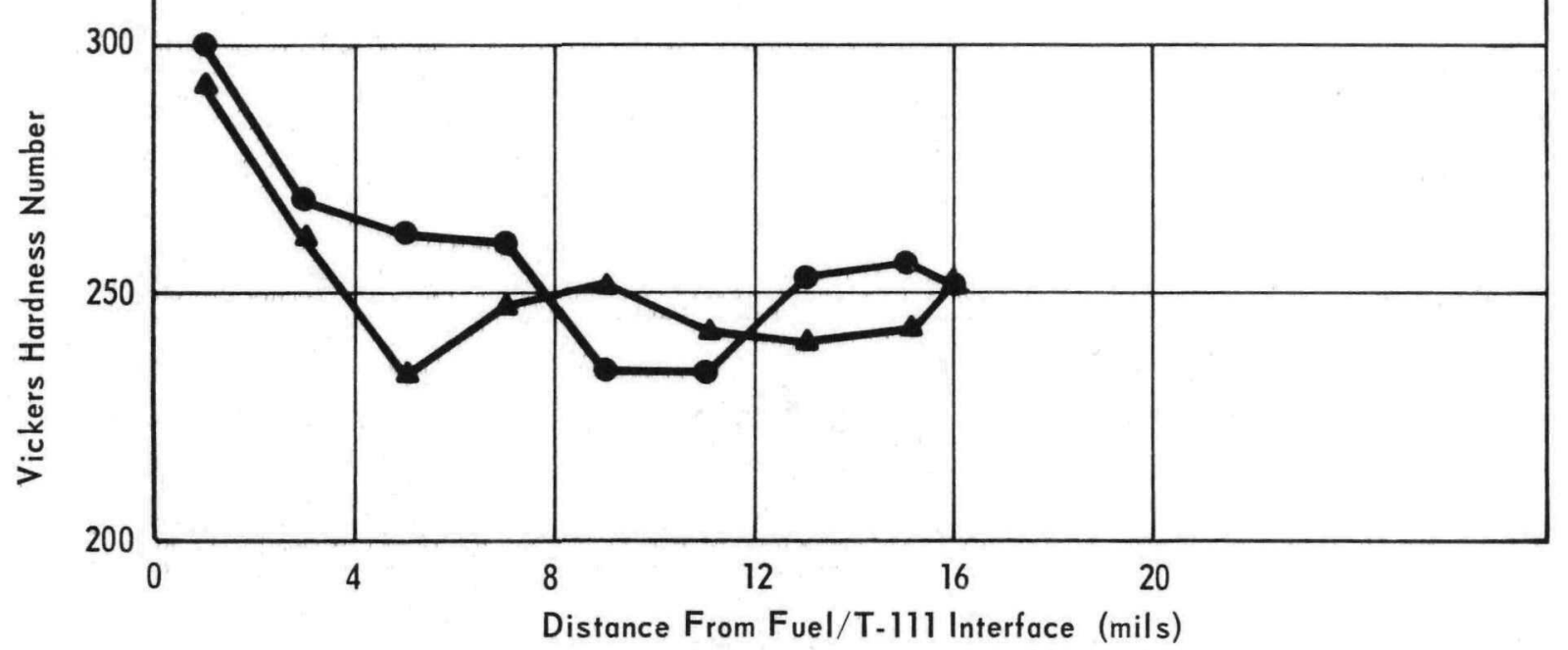

FIGURE 14 - Micrograph and microhardness traverses for specimen $G\left(\mathrm{PuO}_{2}+\right.$ $y$ powder - duplicate fines analysis capsule - pretreated $\mathrm{I} \mathrm{hr}$ at $1623 \mathrm{~K}$ ). 


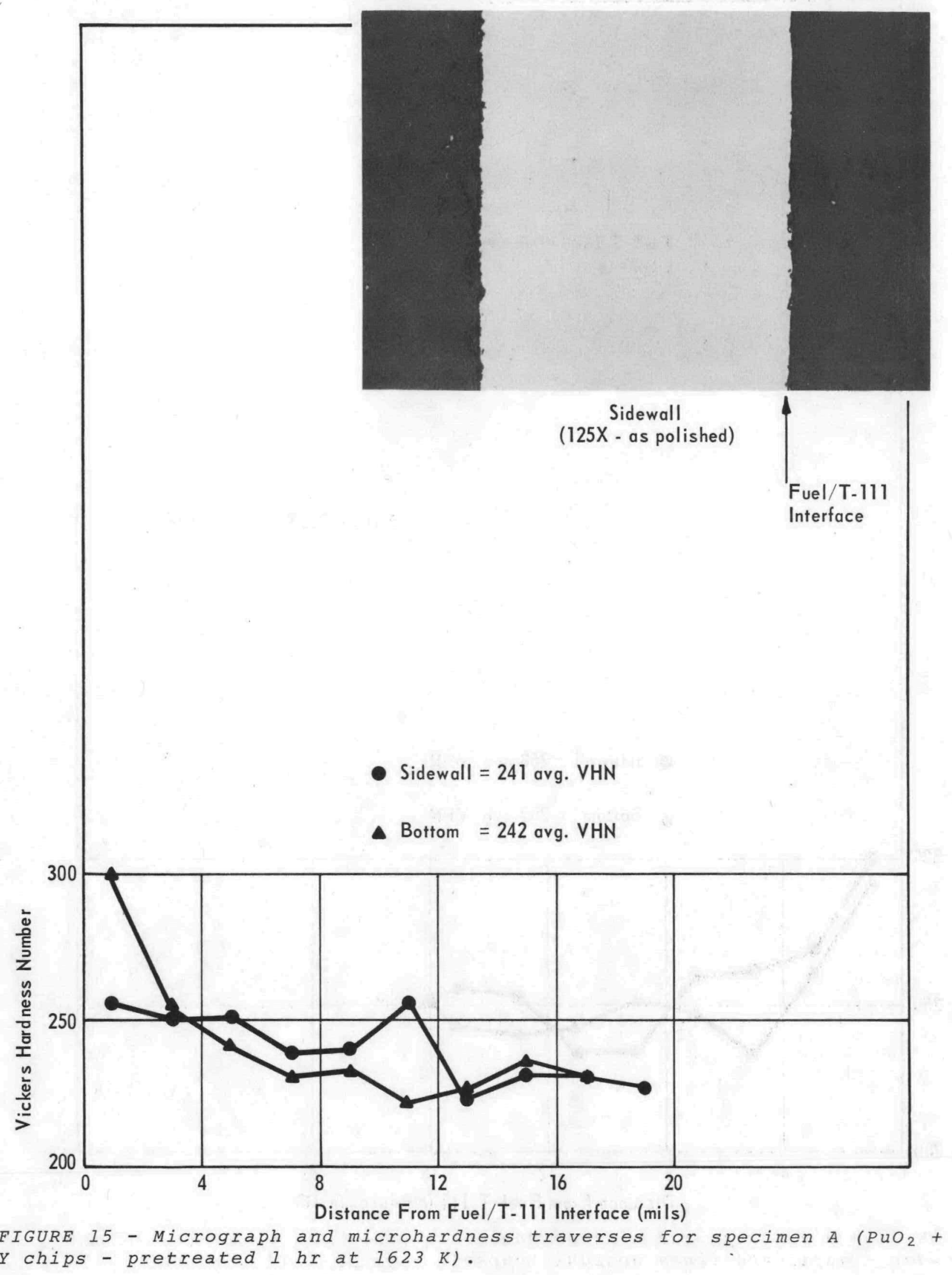




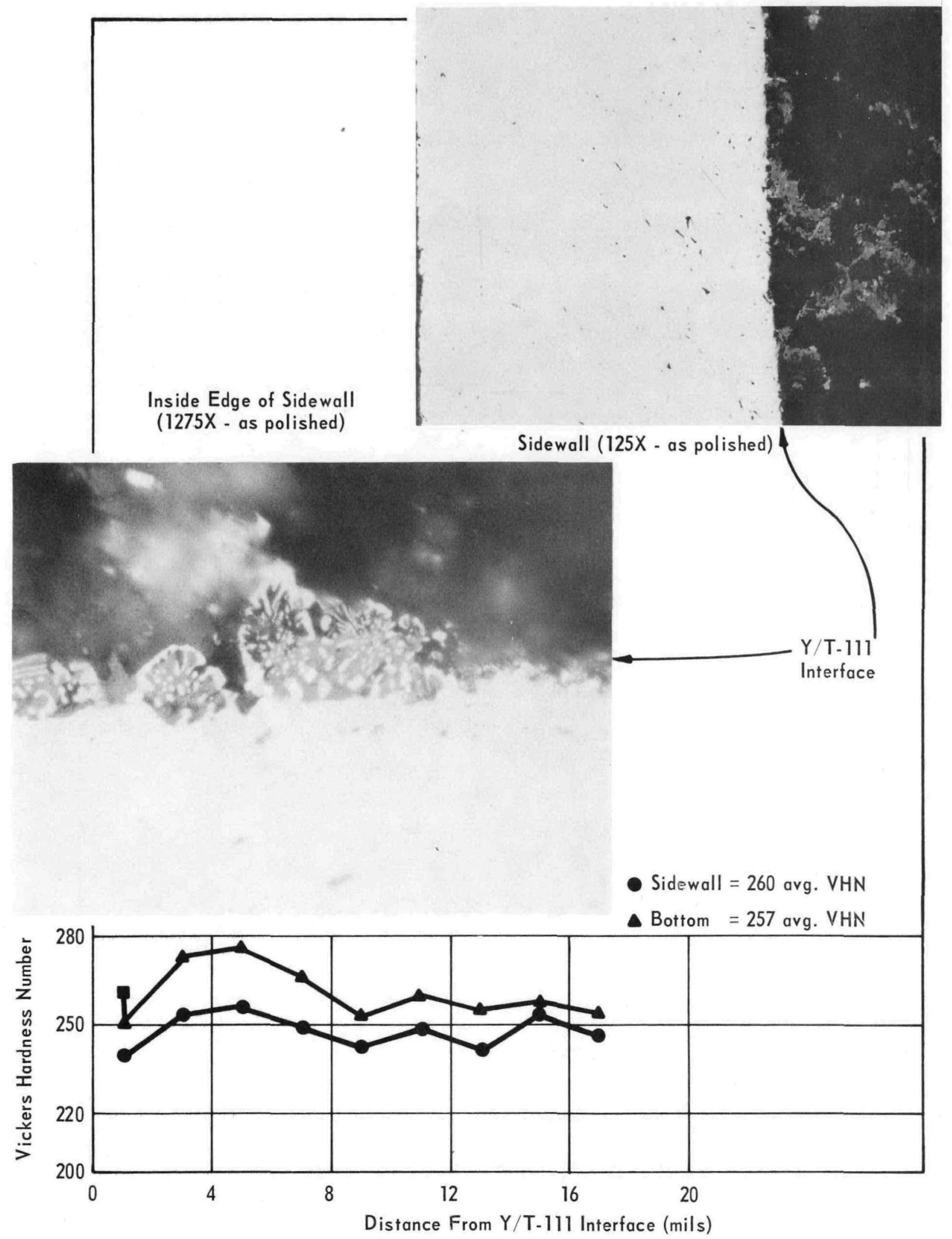

FIGURE 16 - Micrographs showing reaction zone and microhardness traverses for specimen C ( $Y$ foil liner only - pretreated l hr at $1623 \mathrm{~K}$ ). 


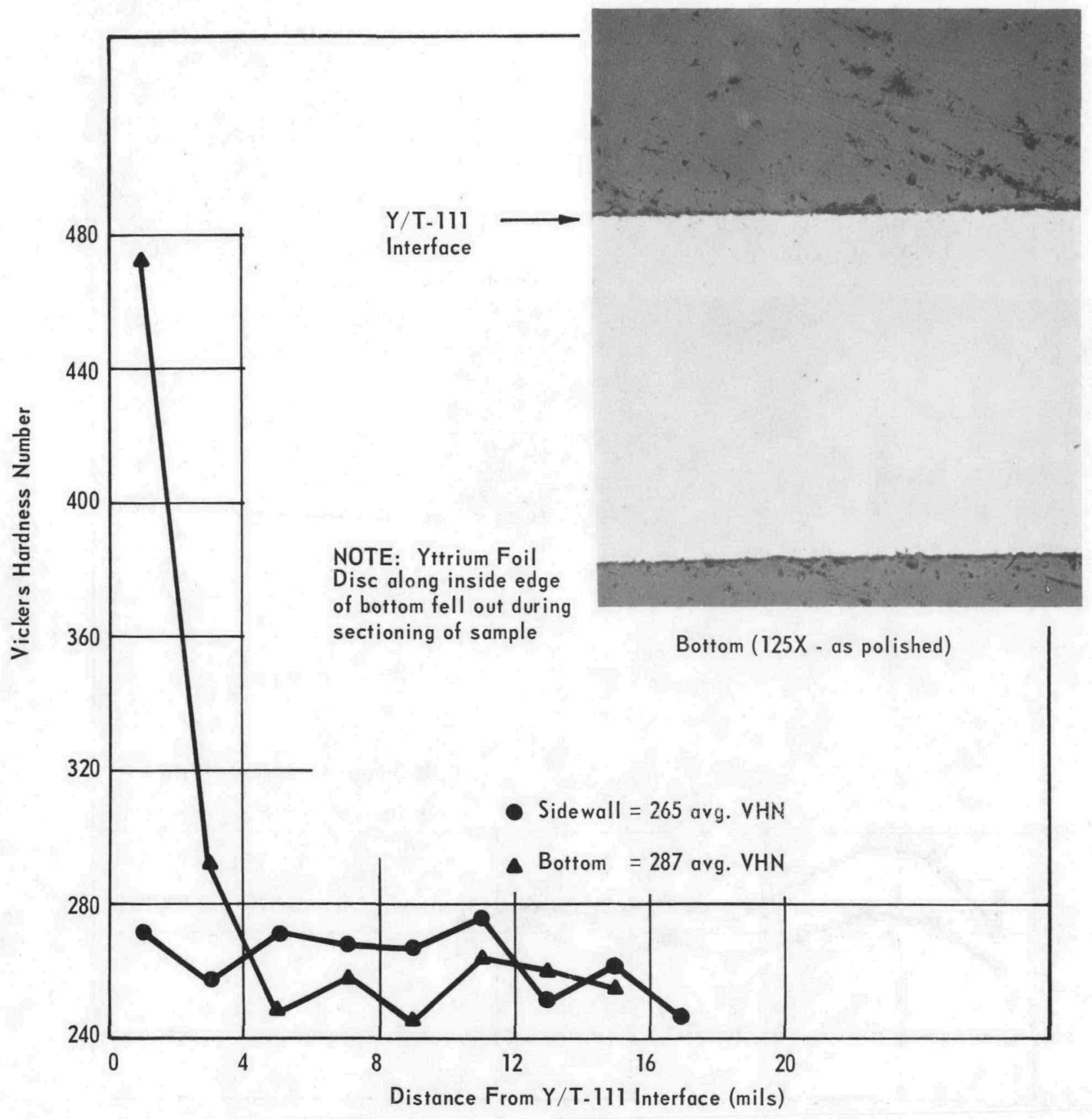

FIGURE 17 - Micrograph and microhardness traverses for specimen $\mathrm{B}_{(\mathrm{PuO}}+$ $y$ foil liner - pretreated $1 \mathrm{hr}$ at $1623 \mathrm{~K}$ ). 


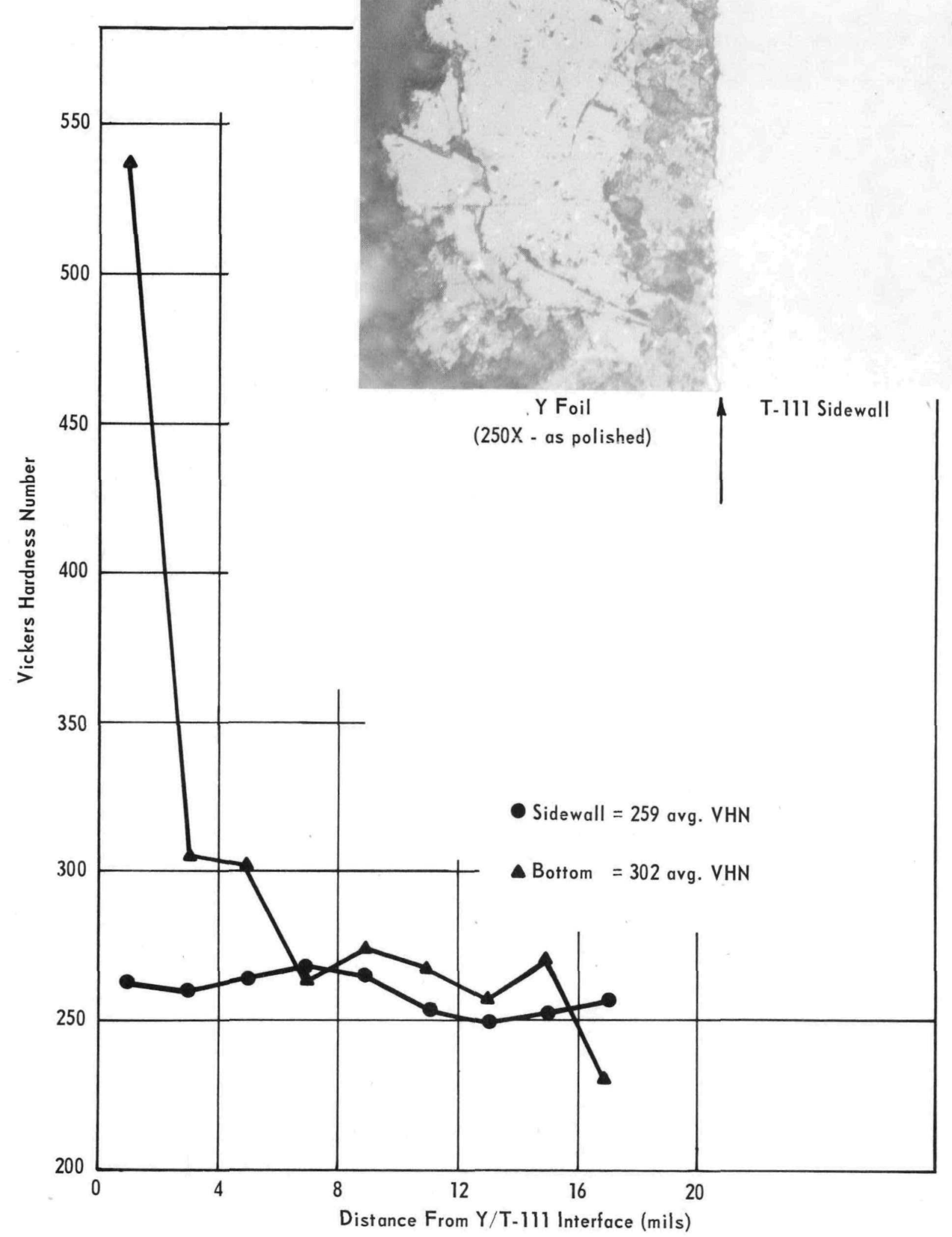

FIGURE 18 - Micrograph showing reaction zone and microhardness traverses for specimen $\mathrm{D}\left(\mathrm{PuO}_{2}+\mathrm{Y}\right.$ foil liner - pretreated $\mathrm{l} \mathrm{hr}$ at $\left.1623 \mathrm{~K}\right)$. 
the specimens. The results for the specimens tested at $873 \mathrm{~K}$ and $1173 \mathrm{~K}$ are shown in Figures 19 and 20. There were no indications of embrittlement of the liners and strength members of either capsule. A very slight microhardness gradient is indicated on the outside edge of the strength member of the specimen tested at $1173 \mathrm{~K}$ (Figure 20), suggesting the possibility of either diffusion of components from the Hastelloy-C
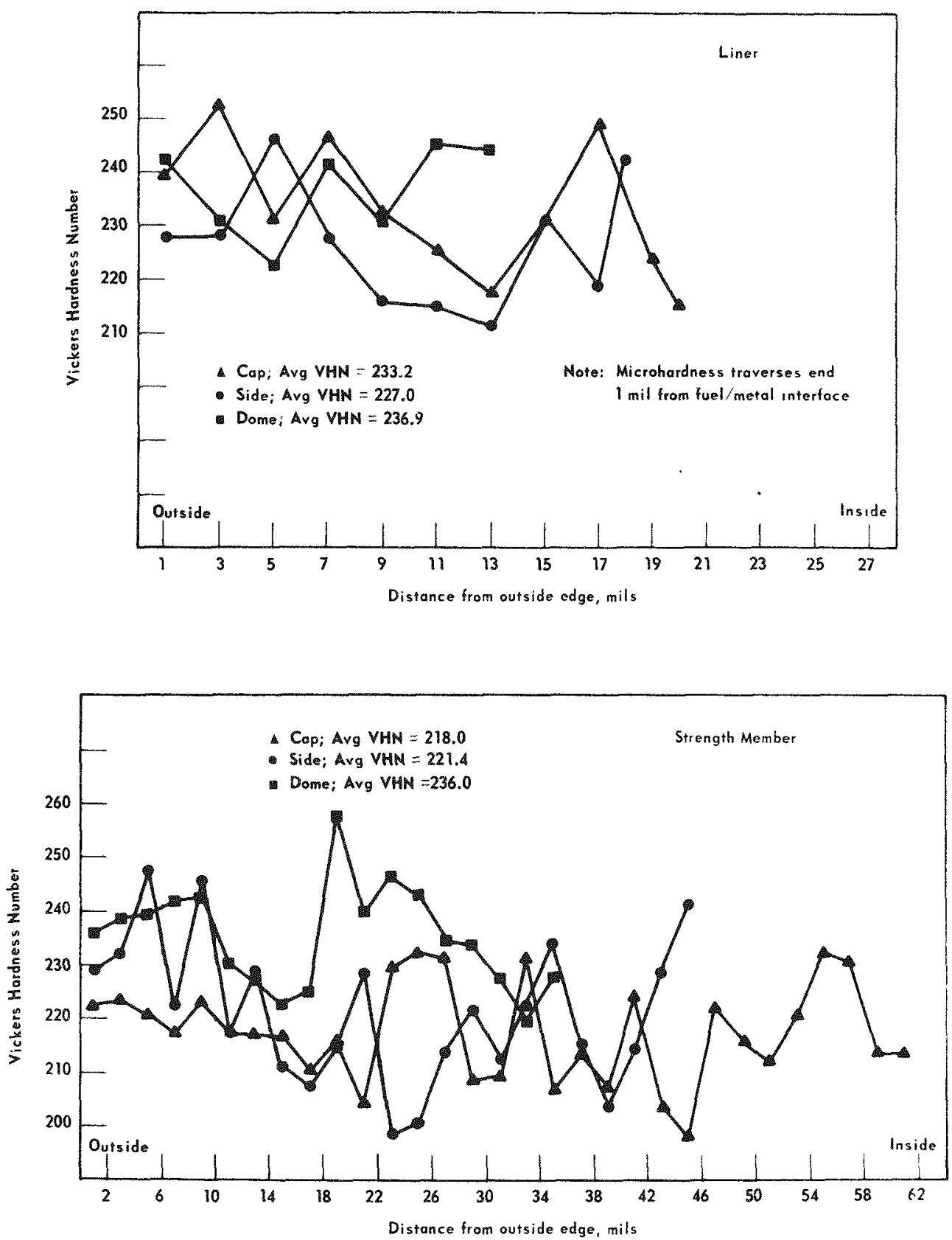

FIGURE 19 - Microharaness traverses for $873 \mathrm{~K}, 60-d a y$ p-type capsule. 

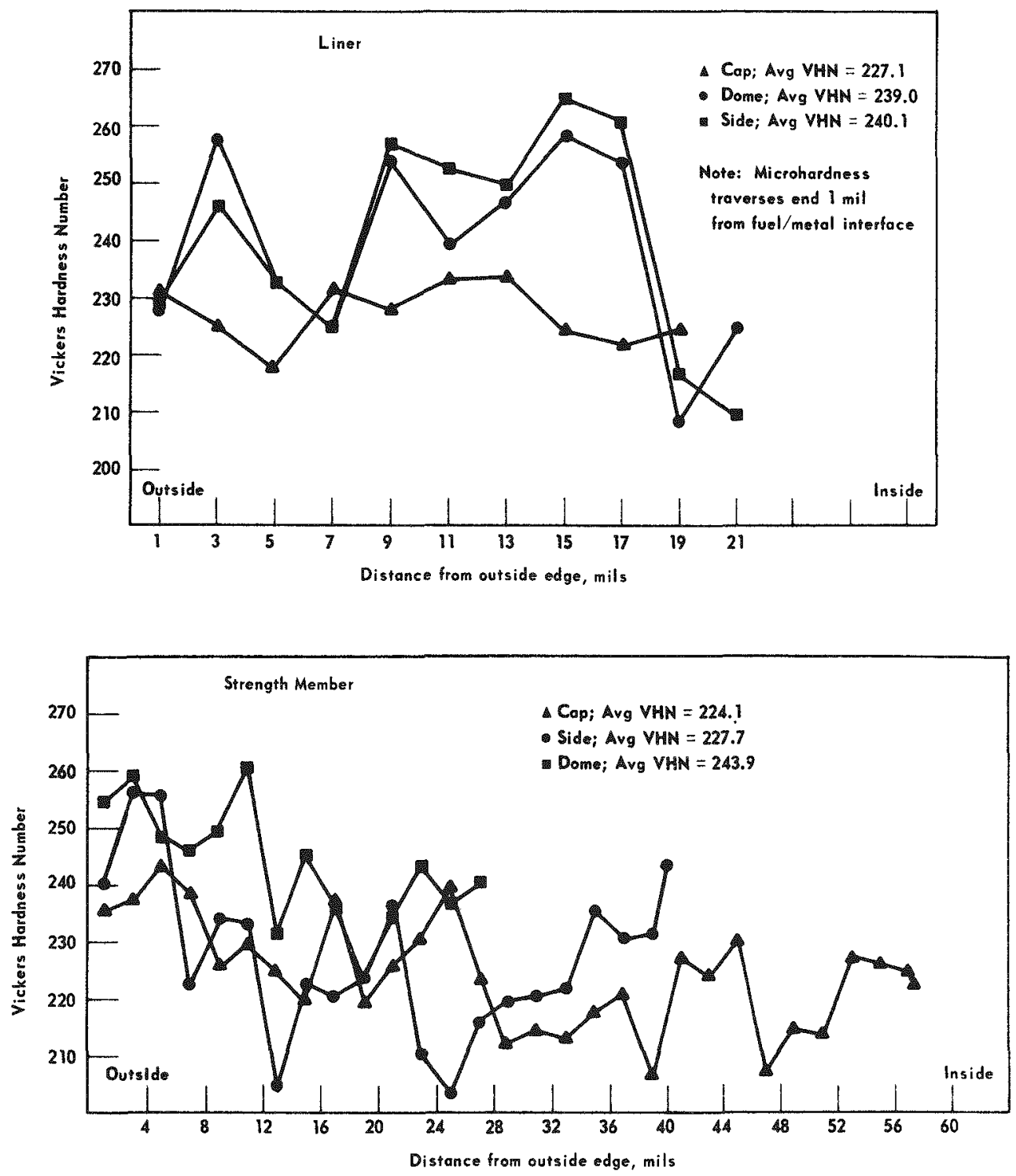

FIGURE 20 - Microhardness traverse for $1173 \mathrm{~K}, 60-d a y$ P-type capsule.

clad, or of nitrogen through the clad, to a depth of approximately $6 \mathrm{mils}$ into the strength member. Metallographic examination of these specimens in the as-polished condition revealed no evidence of detrimental reaction. The aforementioned white-appearing phase was observed along the fuel/metal interface of the specimens penetrating up to $5 \mu \mathrm{m}$ into the T-1ll liner. Also very small gray deposits, such as shown in Figure 21, were seen randomly located along the fuel/metal interface. This same phenomenon was observed in the original pretreated specimens and has been identified as yttrium adhering to the T-11l surface. Microhardness traverses across the liner and strength member of the specimen tested for 60 days at $1373 \mathrm{~K}$ are shown in Figure 22. The liner shows obvious evidence of embrittlement, 


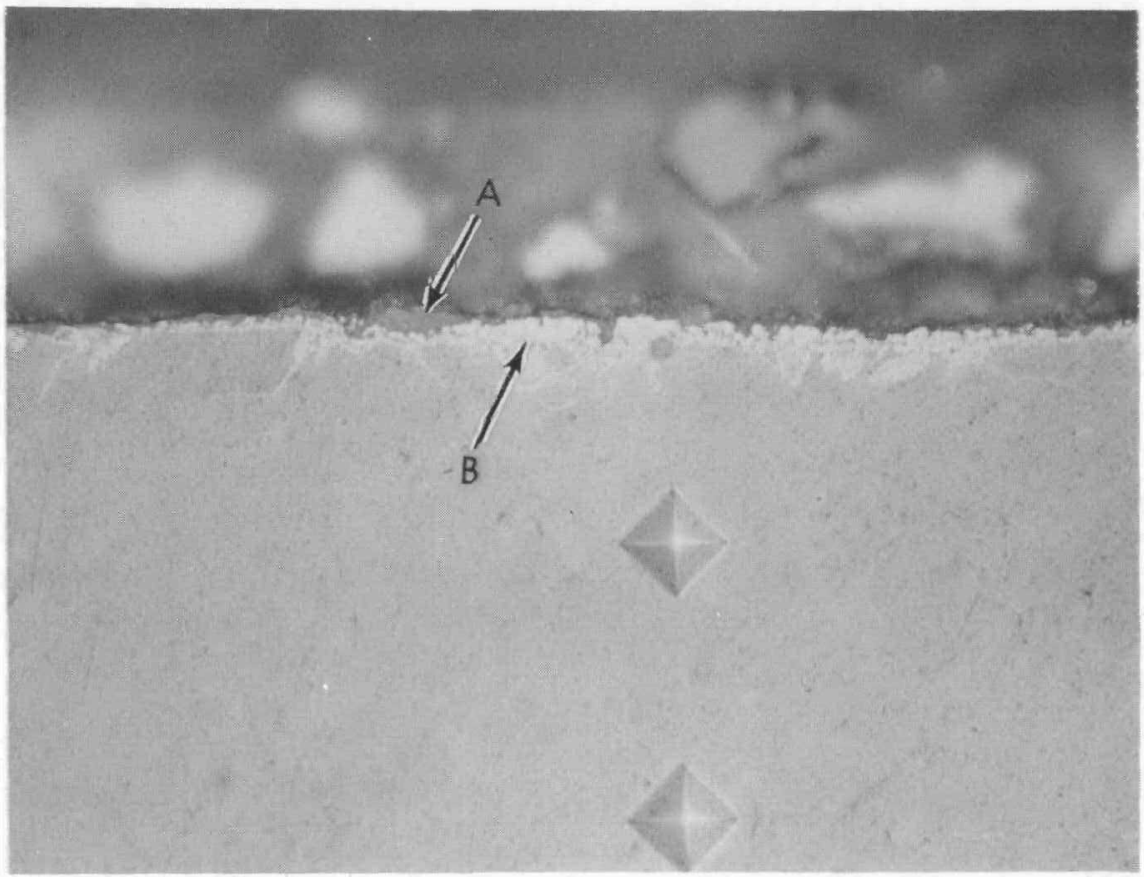

$600 x-$ as-polished condition

FIGURE 21 - Photomicrograph of T-III liner showing gray surface deposit (A), and white-appearing phase (B).

particularly in the dome region, while the gradient from the outside of the strength member indicates the clad was not completely effective at this temperature.

Oxygen, nitrogen, and average hardness numbers for all three capsules are summarized in Table 9. If oxygen numbers are compared with those of the F-type capsules, it is evident that pretreatment greatly restricts oxidation, since the $1173 \mathrm{~K} \mathrm{~F}$-type specimen is actually more embrittled than the corresponding $1373 \mathrm{~K}$ P-type specimen.

The 240-day tests showed little change from the 60-day results as far as oxygen embrittlement of the liners at or below $1173 \mathrm{~K}$ is concerned. Except for the usual localized spots revealed along the fuel/liner interface of the specimens by etching, there is no indication of reaction in, or embrittlement of, the liner or strength member of the specimen tested at $873 \mathrm{~K}$ (Figure 23).

Data for the specimen that was tested for 240 days at $1173 \mathrm{~K}$ are shown in Figure 24. Except for two slightly higher values (approximately 300 VHN) near the middle of the liner sidewall, the liner of the specimen showed no evidence of embrittlement. A microhardness gradient increasing toward the outside edge is indicated for the sidewall and dome of the strength member of the specimen tested at $1173 \mathrm{~K}$, suggesting nitrogen diffusion through the clad into the strength member. 
Table 9

OXYGEN, NITROGEN AND AVERAGE MICROHARDNESS DATA FOR 60-DAY P-TYPE SPECIMENS

Sample

Temperature

873

\begin{tabular}{l} 
Location \\
\hline Liner Wall \\
Liner Dome \\
Strength Member Wall \\
Strength Member Dome
\end{tabular}

$\mathrm{O}_{2} \quad \mathrm{~N}_{2}$

\begin{tabular}{|c|c|c|}
\hline $\begin{array}{l}\mathrm{O}_{2} \\
\text { (ppm) } \\
\end{array}$ & $\begin{array}{l}\mathrm{N}_{2} \\
\text { (ppm) } \\
\end{array}$ & $\begin{array}{c}\text { Average } \\
\text { VHN }\end{array}$ \\
\hline 183 & 14 & 227 \\
\hline 156 & 16 & 237 \\
\hline 83 & 37 & 221 \\
\hline 82 & 34 & 236 \\
\hline 266 & 26 & 240 \\
\hline 164 & 8 & 239 \\
\hline 188 & 78 & 228 \\
\hline 96 & 52 & 244 \\
\hline 1006 & 27 & 346 \\
\hline 1000 & 42 & 340 \\
\hline 113 & 134 & 231 \\
\hline 837 & 213 & 238 \\
\hline
\end{tabular}

1173

Liner Wall

Liner Dome

Strength Member Wall

Strength Member Dome

1373

Liner Wall

Liner Dome

Strength Member Wall

Strength Member Dome

837

238

Photomicrographs and microhardness traverses of the liner and strength member of the specimen tested for 240 days at $1373 \mathrm{~K}$ are shown in Figures 25 and 26. Slight embrittlement of the sidewall of the liner of the specimen is indicated by an average VHN of 323. However, microhardness values across the liner dome are low. A photomicrograph of the outside edge of the strength member of the $1373 \mathrm{~K}$ specimen is shown in Figure 26 along with microhardness traverses across the strength member. The high microhardness values at the outside edge of the strength member are in the white phase reaction area shown in the photomicrograph. This reaction layer exists around the entire outer surface of the strength member of the specimen. Electron microprobe analysis shows it consists predominantly of components from the Hastelloy-C clad. Chromium, iron, nickel, tantalum, and tungsten were found, with a phase structure quite similar to that reported for Hastelloy-X/tantalum interaction. ${ }^{0}$

Oxygen, nitrogen, and average VHN values for liners and strength members of the 240-day pretreated specimens are shown in Table 10. Except for the slightly higher nitrogen values for the strength member of the $1173 \mathrm{~K}$ specimen, data for the specimens tested for 240 days at $873 \mathrm{~K}$ and $1173 \mathrm{~K}$ are very similar. The higher nitrogen value for the strength member of the $1173 \mathrm{~K}$ specimen correlates with the microhardness gradient near its outside edge, described previously. Increased nitrogen diffusion through the clad into the strength member with increased temperature also accounts for the higher nitrogen values for the strength member of the specimen tested at $1373 \mathrm{~K}$. Considerable oxygen contamination of the liner occurred in the $1373 \mathrm{~K}$ specimen. The strength member also shows some slight oxygen pickup. However, the microhardness values are much lower than would be expected for T-11l containing this much oxygen. This could result if the 240-day, $1373 \mathrm{~K}$ heat treatment overaged the T-1Il alloy and incoherent $\mathrm{HfO}_{2}$ precipitates formed. This material would then be in a more ductile condition. 

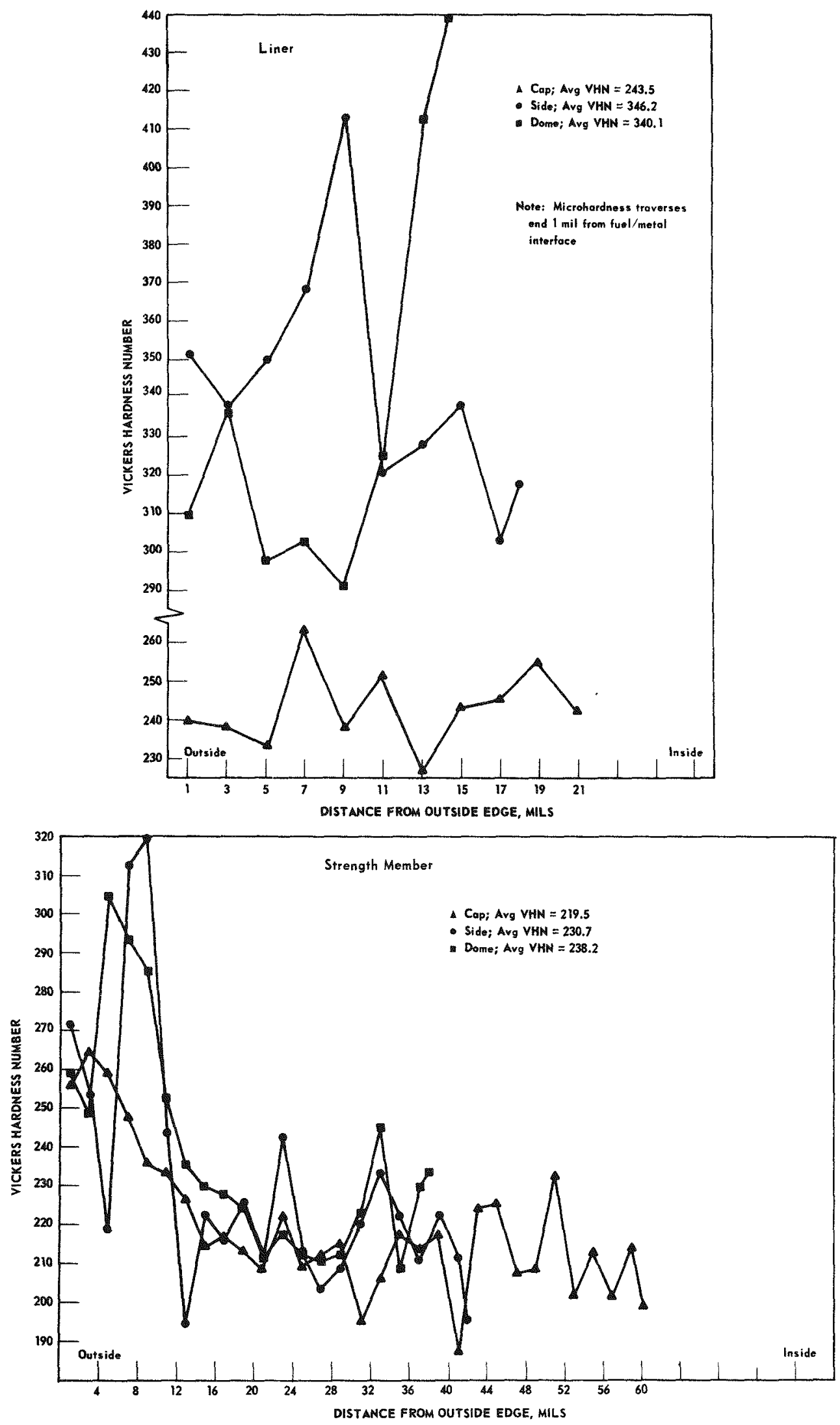

FIGURE 22 - Microhardness traverses for $1373 \mathrm{~K}, 60-d a y$-type capsule. 


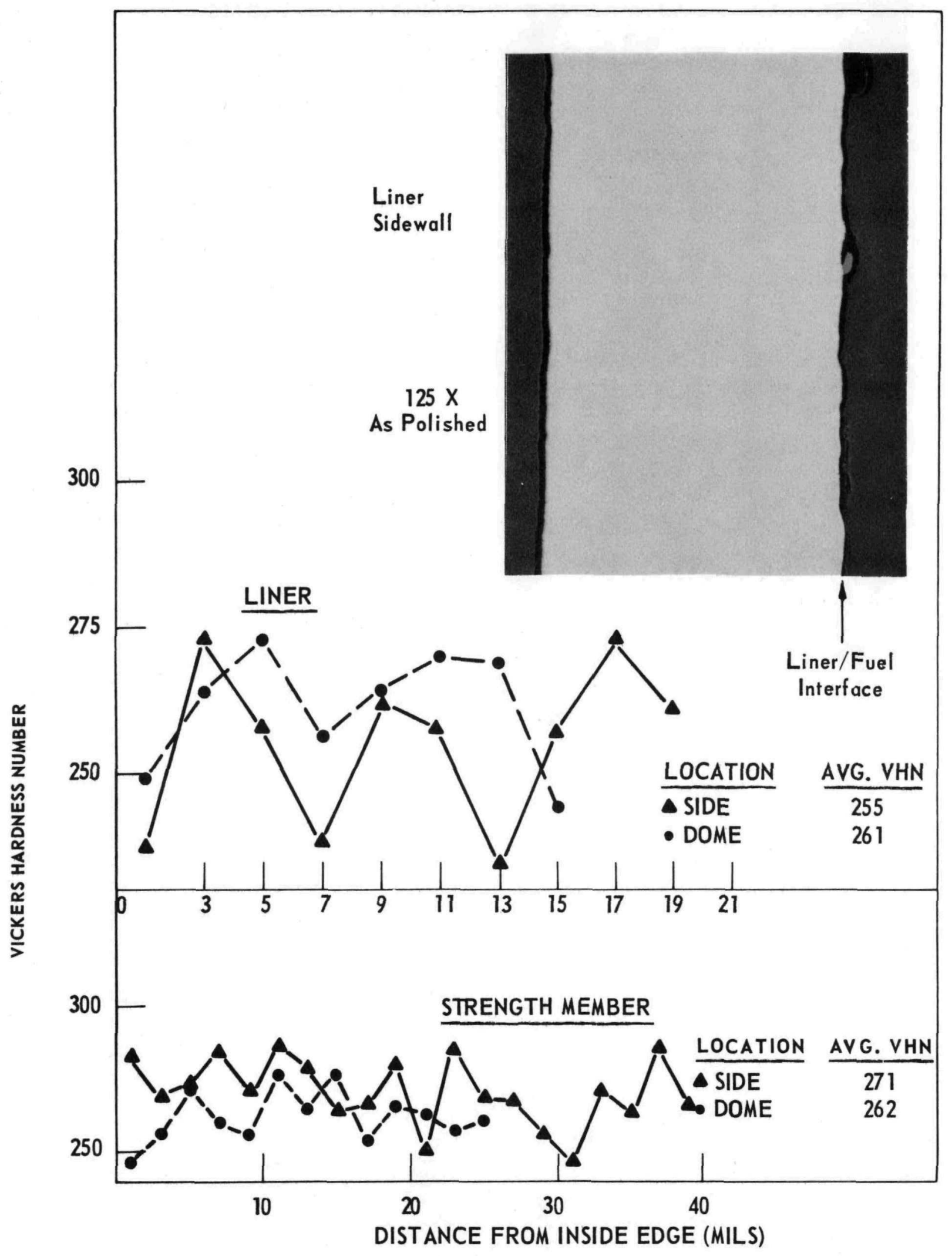

FIGURE 23 - Photomicrograph and microhardness traverses for $873 \mathrm{~K}, 240-$ day P-type capsule. 


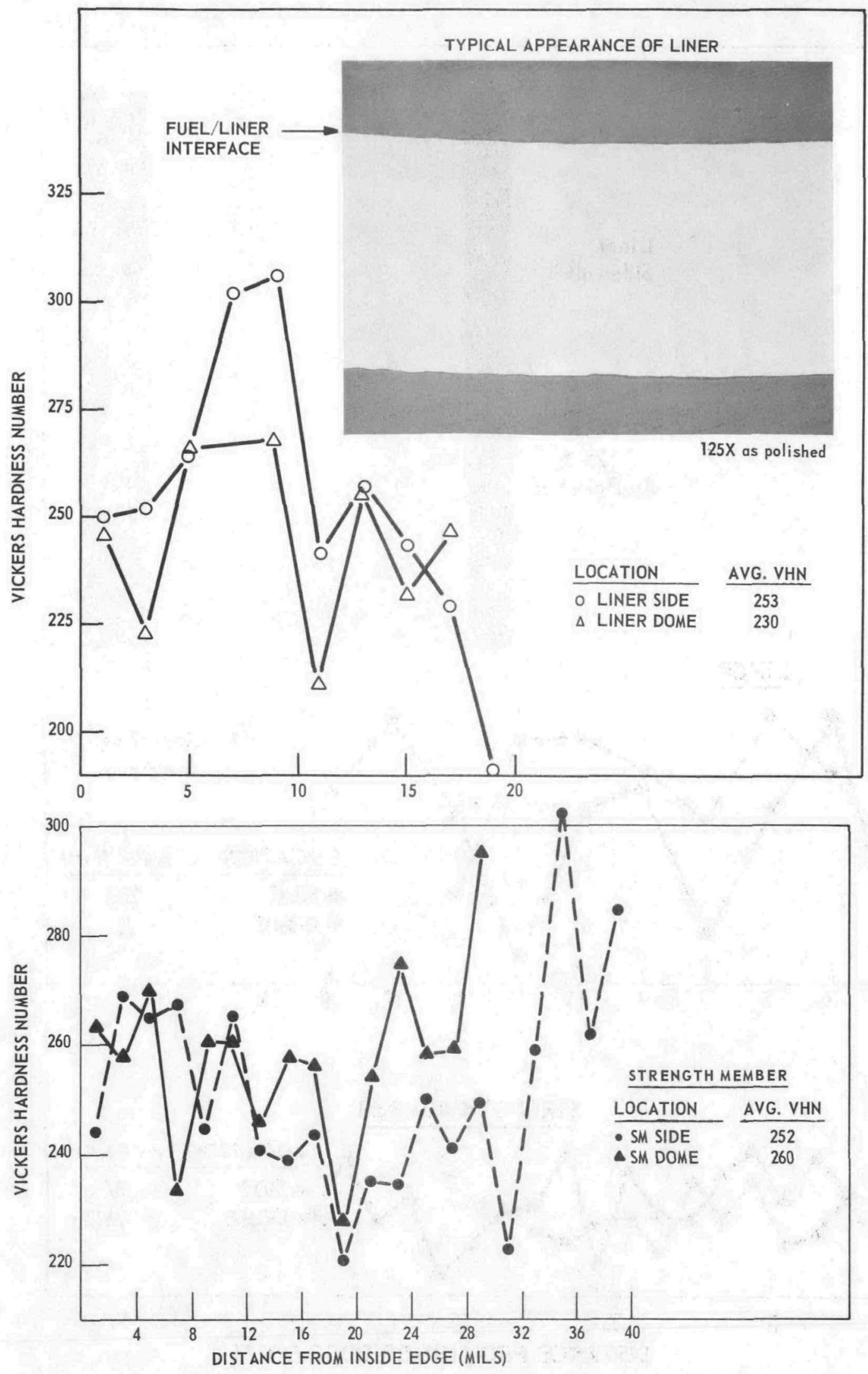

FIGURE 24 - Photomicrograph and microhardness traverses for $1173 \mathrm{~K}, 240-$ day P-type capsule. 


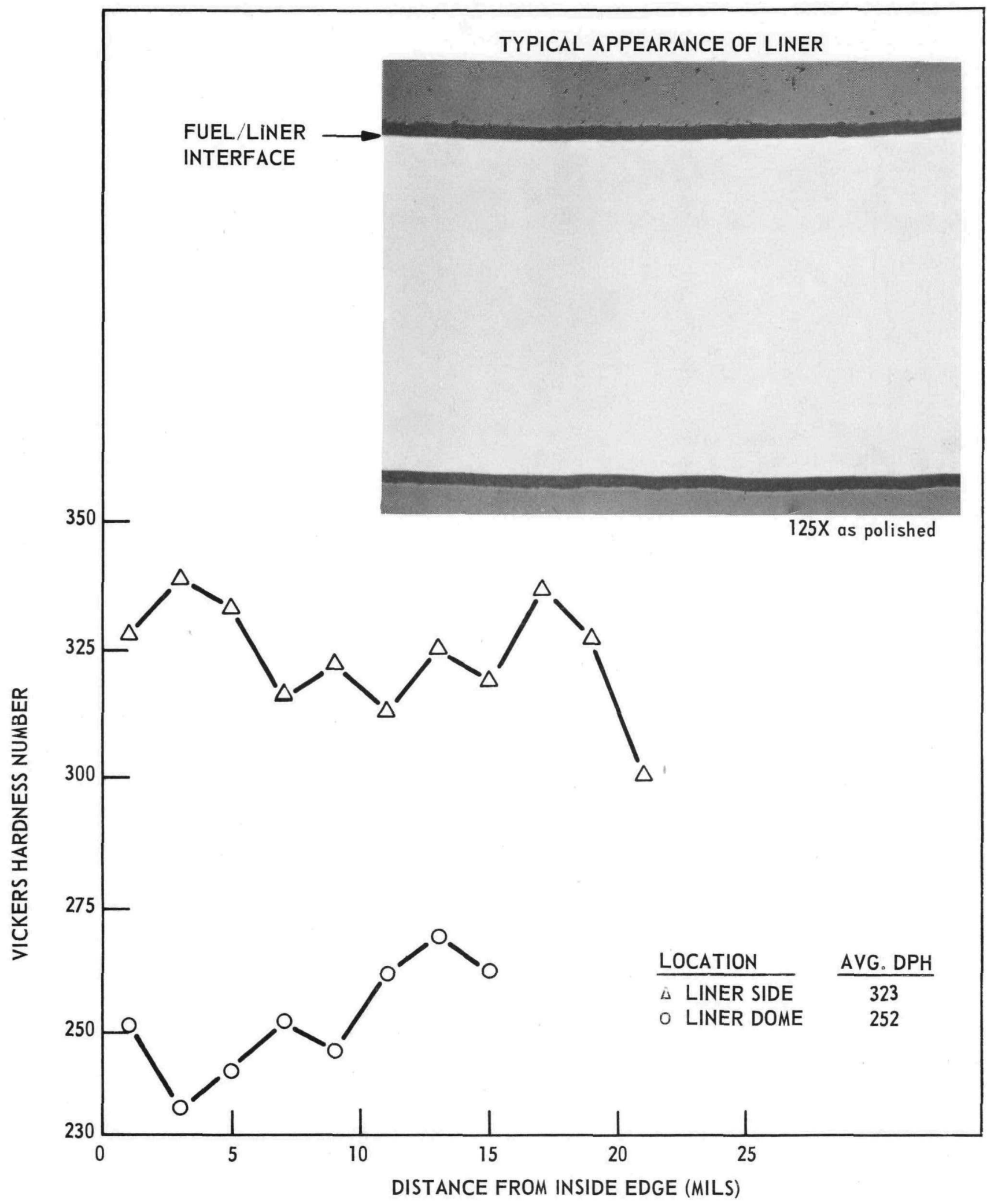

FIGURE 25 - Photomicrograph and microhardness traverses for $1373 \mathrm{~K}, 240-$ day p-type capsule liner. 


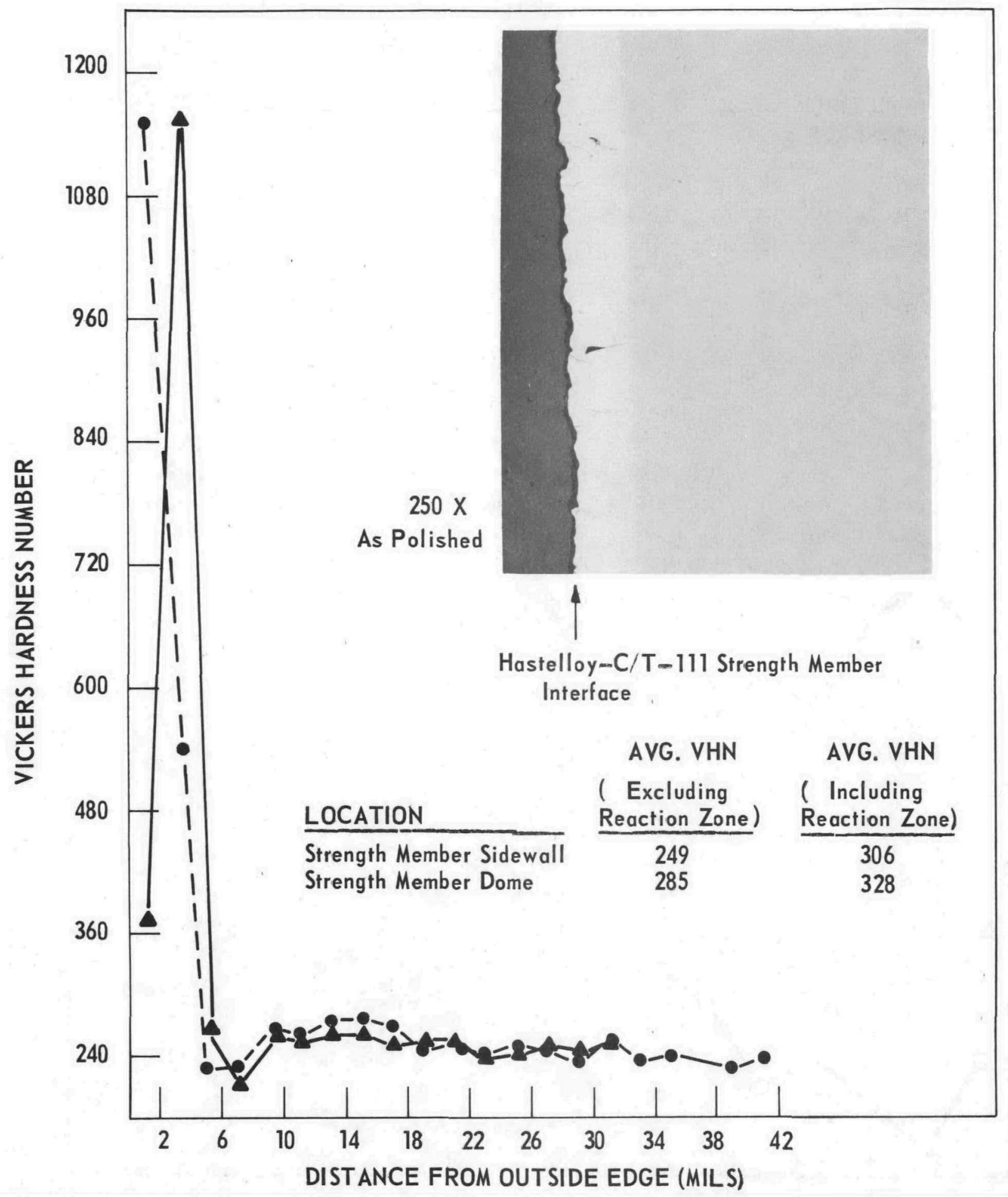

FIGURE 26 - Photomicrograph and microhardness traverses for $1373 \mathrm{~K}, 240-$ day P-type capsule strength member. 
Table 10

OXYGEN, NITROGEN, AND AVERAGE MICROHARDNESS

DATA FOR 240-DAY P-TYPE SPECIMENS

Sample

Temperature

$\left({ }^{\circ} \mathrm{K}\right)$

873

Location

$\mathrm{O}_{2} \quad \mathrm{~N}$

Liner Sidewall

(ppm) (ppm)

Average

Liner Dome

268

Strength Member Sidewall

395

Strength Member Dome

47

90

18

(VHN)

1173

Liner Sidewall

319

Liner Dome

249

Strength Member Sidewall

68

Strength Member Dome

118

35

255

261

271

0
$15 \quad 262$

1373

Iiner Sidewall

2509

Liner Dome

3345

Strength Member Sidewall

125

Strength Member Dome

250

253

230

252

260

323

252

$\begin{array}{ll}150 & 249^{\mathrm{a}} \\ 197 & 285^{\mathrm{a}}\end{array}$

"Average does not include vapor-deposited Hastelloy-C layer on outside surface of sample.

The data obtained from the two P-type capsules aged for 2 yr add further support to the pretreatment concept. Except for the usual localized oxygen-enriched zones along the fuel/liner interface formed during pretreatment, there was no evidence of fuel/liner reaction, or of embrittlement of the liners by the fuel as a result of aging in either specimen.

Microhardness data and typical microstructures for the liner and strength member of the $873 \mathrm{~K}$ specimen are shown in Figures 27 and 28 , respective1y. In the liner, hardness values are quite low except at the typical oxygen-enriched zones at the fuel/liner interface mentioned above. The 304 VHN value shown in Figure 27 coincides with such a spot. The strength member shows a hardness gradient near the outside edge of the sidewall. Electron microprobe analysis revealed no evidence of diffusion of components from Hastelloy-C, so the gradients most likely are due to nitrogen permeation through the Hastelloy-C clad.

The metallographic data obtained from the $1173 \mathrm{~K}$ specimen liner and strength member are shown in Figures 29 and 30 . Again the liner microhardness data are generally quite low, except at isolated spots throughout the thickness. (The cause of this effect will be discussed below.) The strength member showed a much more pronounced hardness gradient than did the $873 \mathrm{~K}$ capsule, as would be expected. Again, no Hastelloy-C constituents could be found, indicating that the observed effect was most probably due to nitrogen permeation through the clad.

oxygen, nitrogen and average Vickers hardness data are summarized in Table 11. The nitrogen values for the strength members tend to confirm the hypothesized cause of the observed hardness gradients. Most striking, however, is the very high oxygen content of the $1173 \mathrm{~K}$ liner in 
LINER SIDEWALL (125X)

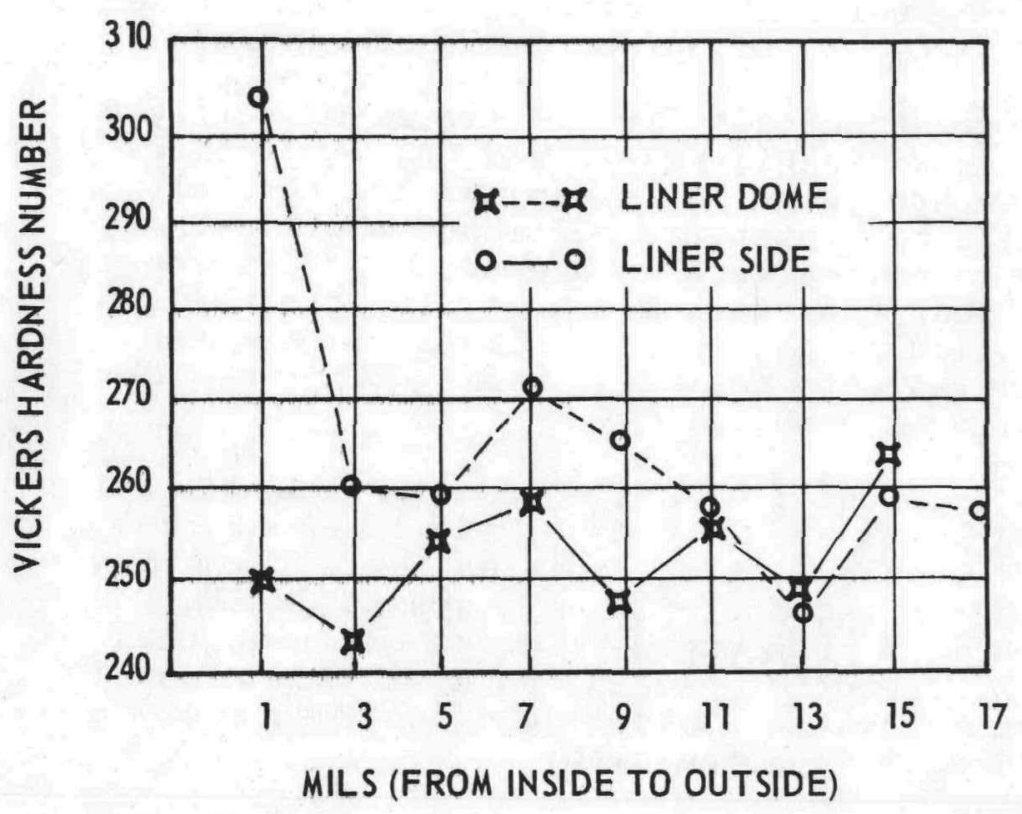

INSIDE EDGE

FIGURE 27 - Microhardness traverses and photomicrograph for p-type liner ( 2 yr at $873 \mathrm{~K}$ ). 
INSIDE EDGE

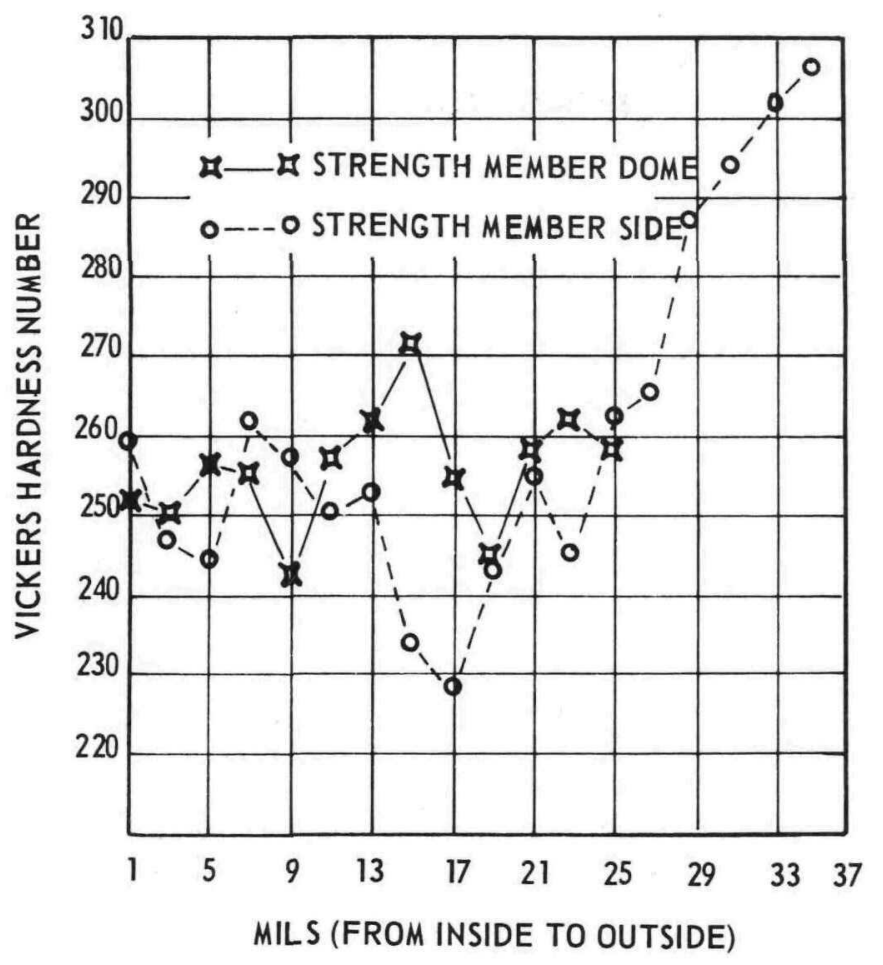

STRENGTH MEMBER SIDEWALL (125X)

FIGURE 28 - Microhardness traverses and photomicrograph for p-type strength member ( 2 yr at $873 \mathrm{~K})$. 
LINER SIDEWALL (125X)

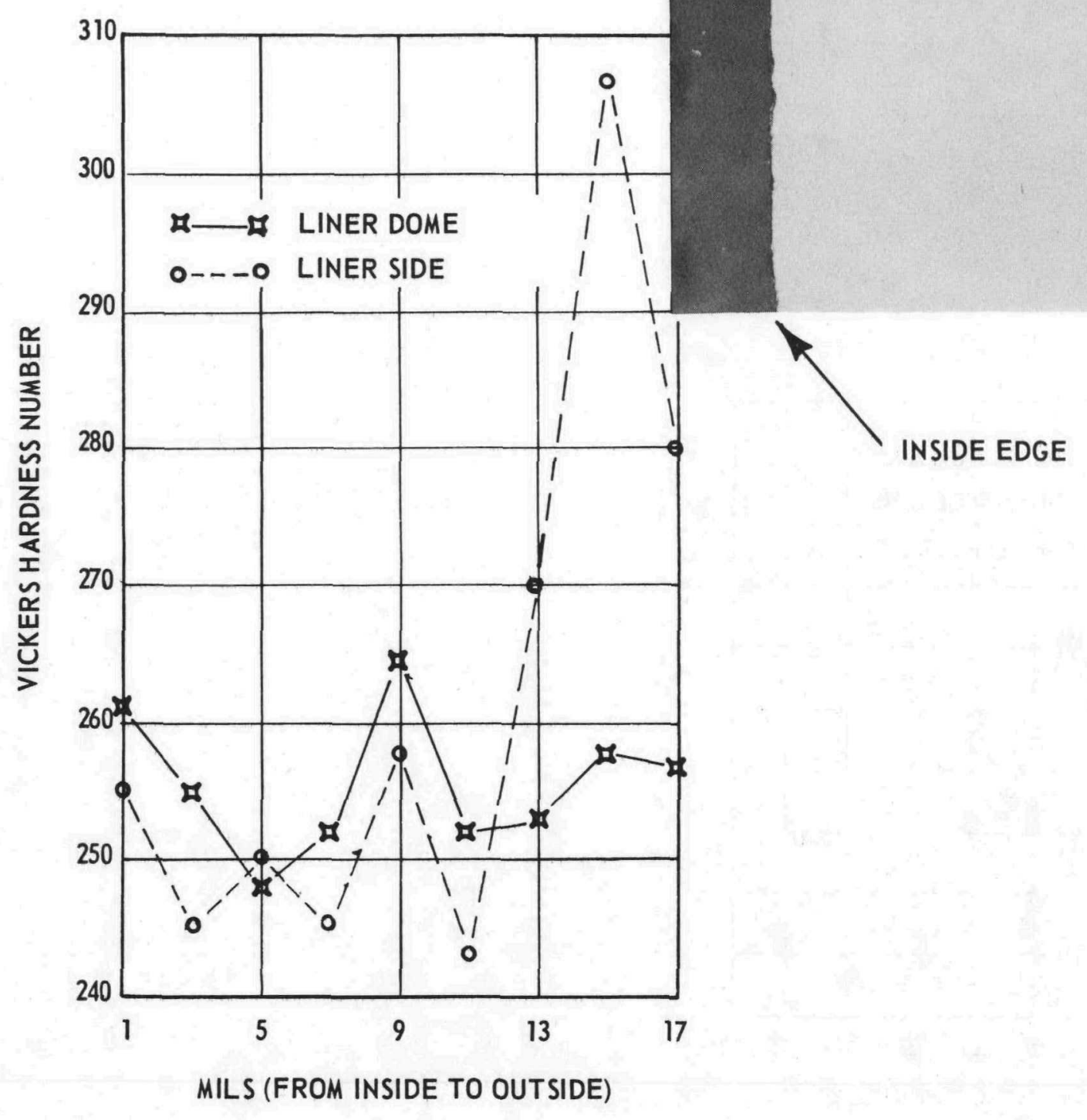

FIGURE 29 - Microhardness traverses and photomicrograph for p-type liner (2 yr at $1173 \mathrm{~K})$. 
INSIDE EDGE

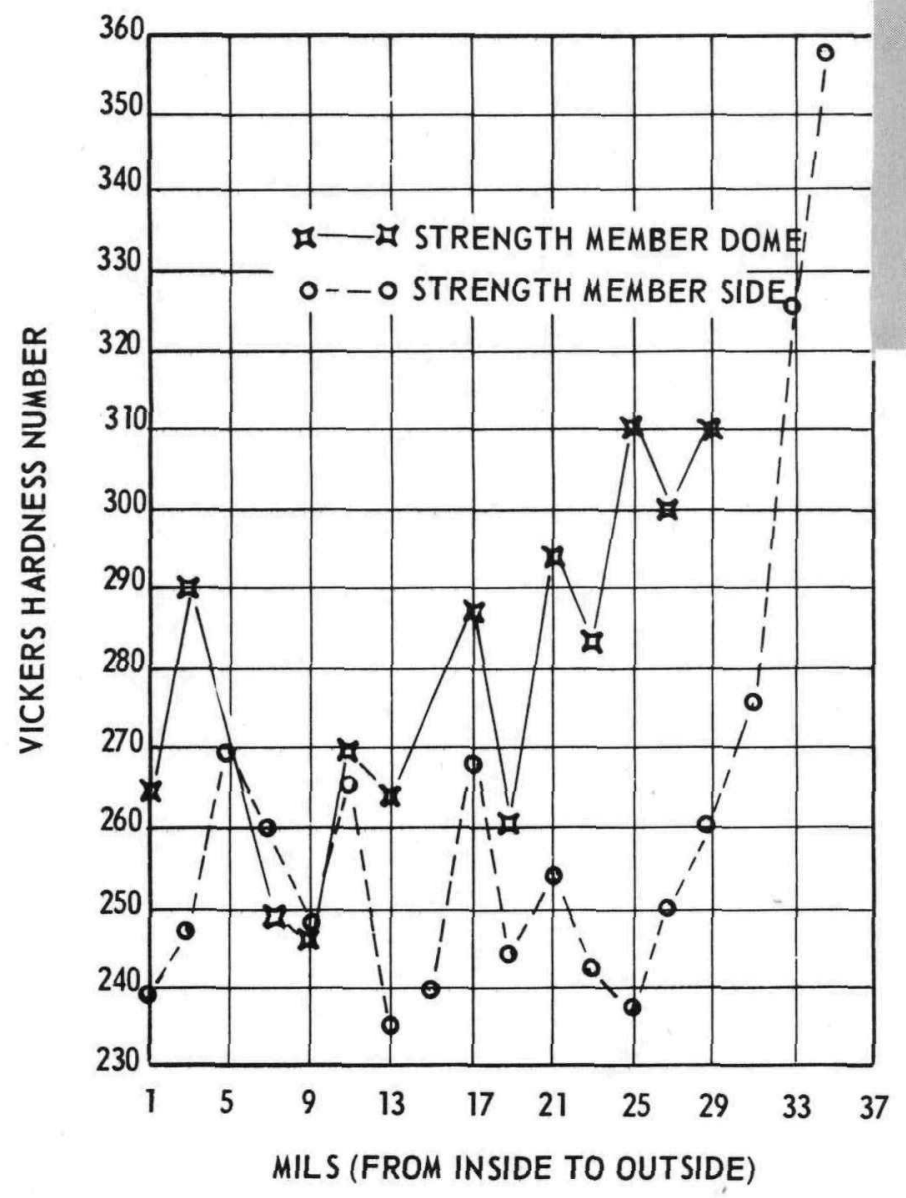

STRENGTH MEMBER

DOME (125X)

FIGURE 30 - Microhardness traverses and photomicrograph for p-type strength member (2 yr at $1173 \mathrm{~K}$ ). 
Table 11

P-TYPE CAPSULE DATA

\begin{tabular}{|c|c|c|c|c|}
\hline Sample & Location & $\begin{array}{c}\mathrm{O}_{2} \\
(\mathrm{ppm})\end{array}$ & $\begin{array}{l}\mathrm{N}_{2} \\
\text { (ppm) }\end{array}$ & $\begin{array}{c}\text { Average } \\
\text { VHN }\end{array}$ \\
\hline \multirow{5}{*}{$2 y r @ 873 \mathrm{~K}$} & Liner Sidewall & 315 & 10 & 264 \\
\hline & Liner Dome & 95 & 0 & 253 \\
\hline & Strength Member Sidewall & 88 & 10 & 261 \\
\hline & Liner Sidewall & 1215 & 27 & 261 \\
\hline & Liner Dome & 932 & 14 & 256 \\
\hline \multirow[t]{2}{*}{2 yr $@ 1173 \mathrm{~K}$} & Strength Member Sidewall & 69 & 41 & 262 \\
\hline & Strength Member Dome & 74 & 44 & 279 \\
\hline
\end{tabular}

light of the low hardness values. Both sets of results were rechecked numerous times with every effort made to assure that no plutonia was adhering to the liner, but no reasons could be found to doubt either hardness or oxygen data. Such results would be expected of material which has undergone extensive oxygen contamination followed by longterm, high-temperature aging. It does not seem possible that such aging could occur at $1173 \mathrm{~K}$, and it was definitely not observed in the equivalent F-type capsule which contained nearly three times as much oxygen. While a short-term high-temperature excursion near the end of the aging period could explain these results, the furnace control system should preclude this and it would have also led to overaging of the nitrogencontaminated strength member. Therefore the only hypothesis that appears consistent with all observations is that the liner material was contaminated prior to testing - probably during rolling. Based on the liner microhardness data, experience with other capsules and a knowledge of the properties of overaged, contaminated $T-111$, it appears that little of the observed oxygen could have been absorbed during aging.

(Unfortunately, during the earlier capsule fabrication when these specimens were made the only T-III available had indeed been contaminated during rolling. It was thought at that time that most material with high oxygen content had been eliminated. This apparently was not the case.)

Comparison of the 60-day and 240-day P-type capsule results indicates that no measurable embrittlement takes place at or below $1173 \mathrm{~K}$. Even at $13.73 \mathrm{~K}$, while oxygen uptake by the liner is severe, microhardness values indicate the liner remains rather ductile.

Retreatment studies

With the effectiveness of the pretreatment process established, efforts were directed to determining the feasibility of treating previously fabricated capsules to force the yttrium $/ \mathrm{PuO}_{2}$ reaction. Two specimens which had been fabricated more than 1 yr earlier were returned to Mound from Sandia. Neither of the capsules had seen temperatures in excess of $673 \mathrm{~K}$ and they spent most of their time below $400 \mathrm{~K}$. The clad was removed from one of the sources and the specimen was heated for $1 \mathrm{hr}$ at $1623 \mathrm{~K}$. This specimen is referred to as the "retreated" capsule. The remaining sample was sectioned and examined without heat treatment for comparison. 
Metallographic examination of both specimens in the as-polished condition revealed no evidence of reaction. Microhardness traverses were made across the liners and the strength members of the specimens. The results are shown in Figure 31 for the comparison capsule and in Figure 32 for the "retreated" capsule. No embrittlement of either specimen is indicated by the data.
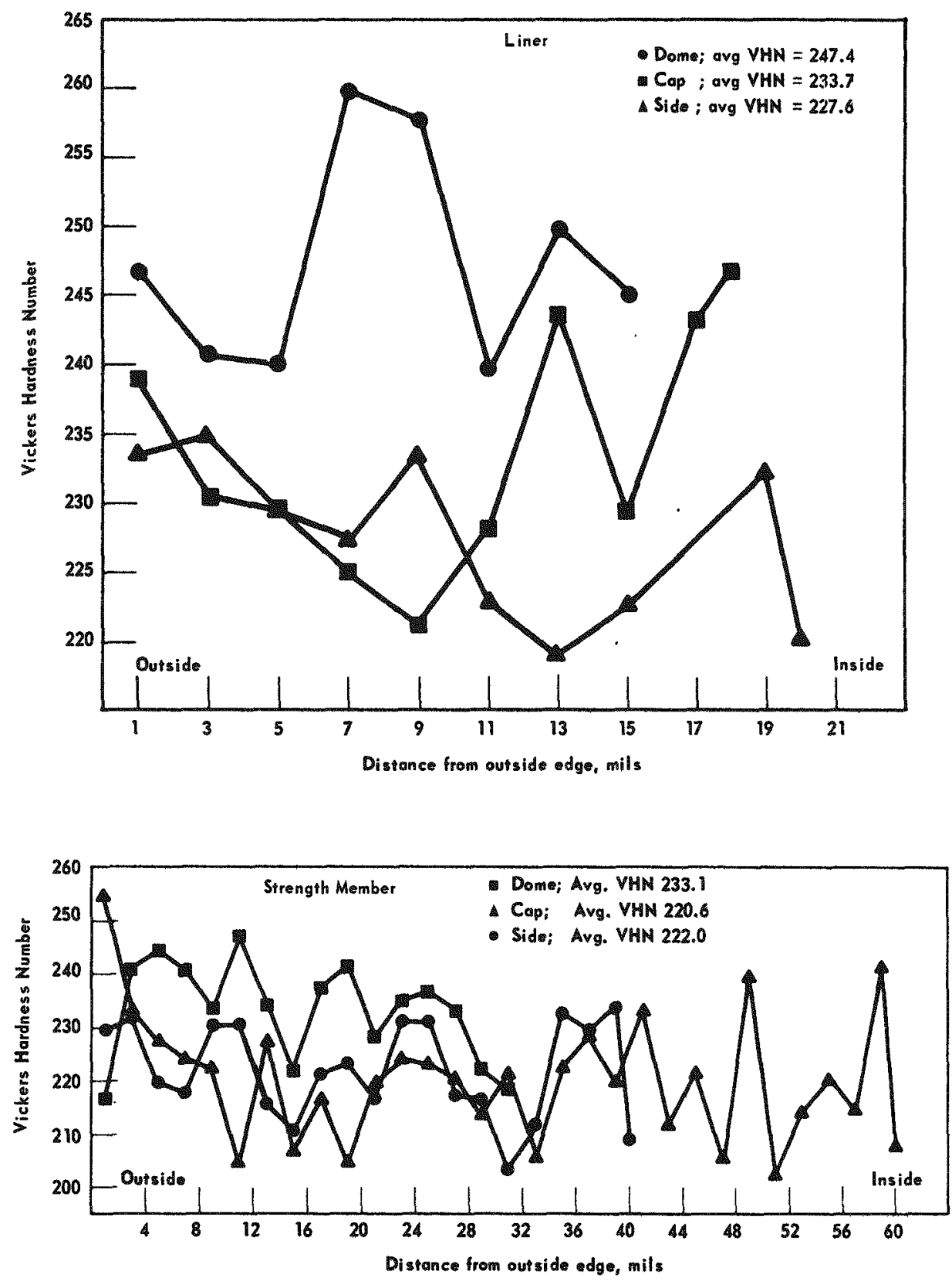

FIGURE 31 - Microhardness traverses for nonretreated capsule. 

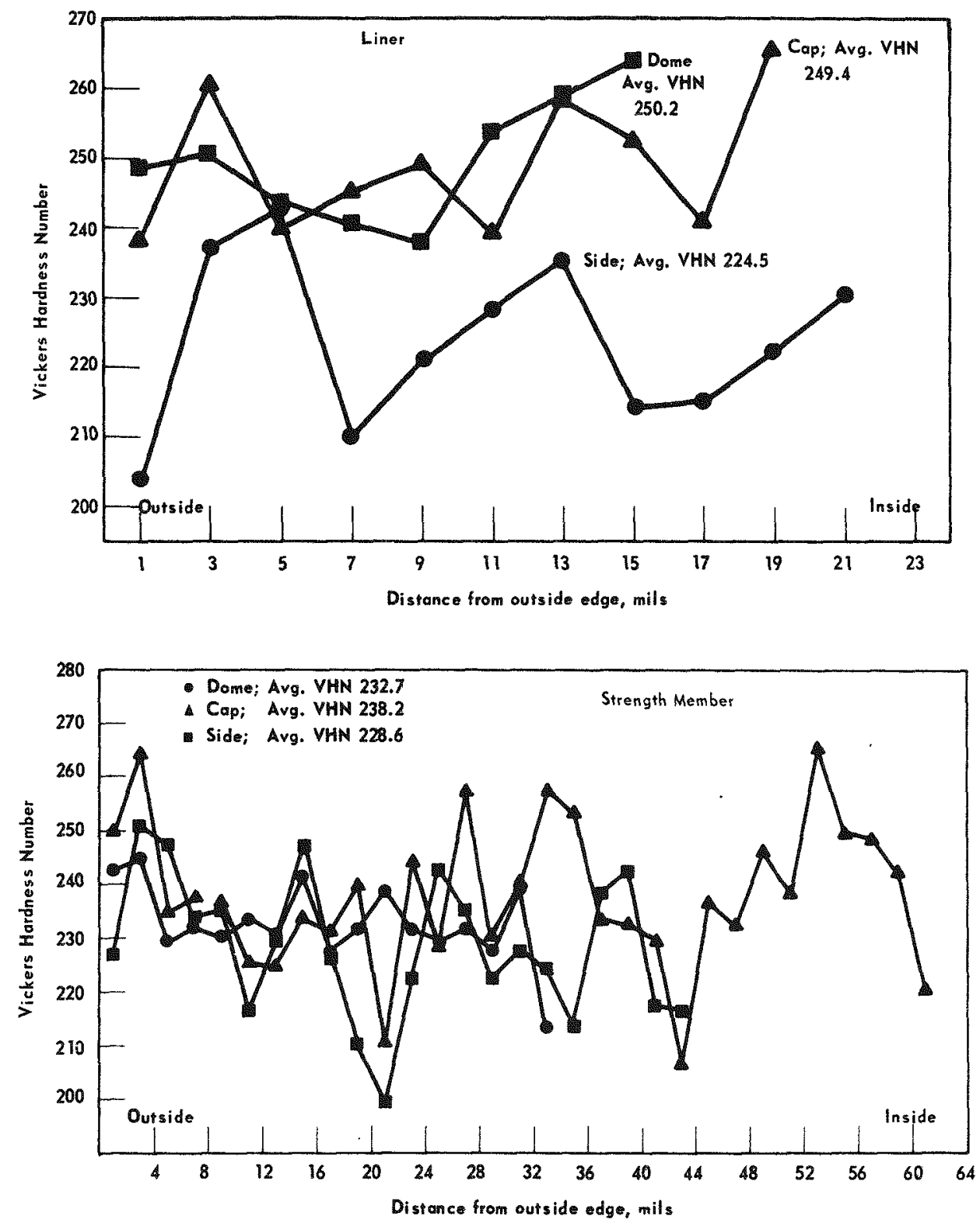

FIGURE 32 - Microhardness traverses for retreated capsules.

Samples from the liners and the strength members of the specimens were analyzed for oxygen and nitrogen. The values obtained are shown in Table 12. There is very little difference between the values obtained from the "retreated" and comparison capsules, except for two unexplainably high nitrogen values for the strength member and liner walls of the comparison capsule.

During analysis of the "retreated" capsules, one of the microhardness traverses yielded a series of anomalously high values (374 VHN maximum), near the inside edge of the liner, much like the pretreated foil specimen. Etching revealed the embrittled spot shown in Figure 33 . In addition to 


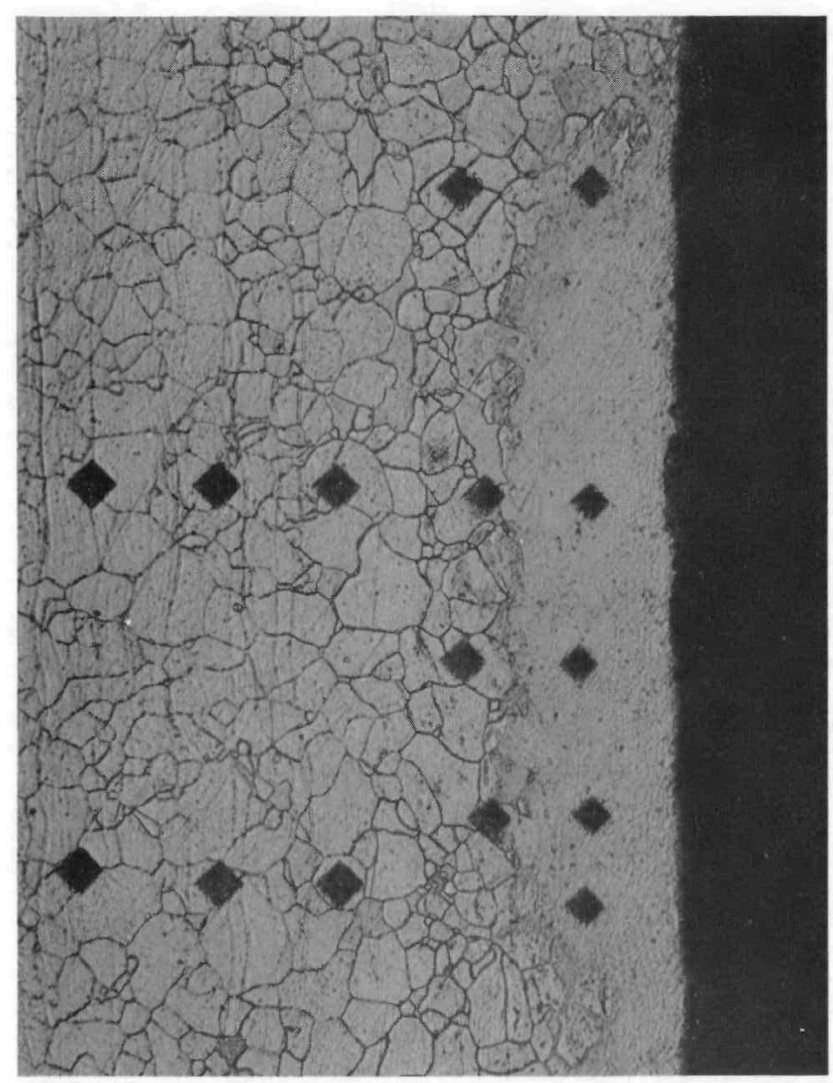

FIGURE 33 - Photomicrograph showing embrittled spot located along fuel/ T-11l interface of retreated specimen (250X etched).

Table 12

OXYGEN AND NITROGEN DATA FOR "RETREATED"

AND "NONRETREATED" CAPSULES

Sample Description

Retreated

( $1 \mathrm{hr}$ @ $1623 \mathrm{~K}$ )

Comparison Capsule (Nonretreated)

\begin{tabular}{|c|c|c|}
\hline Sample Origin & $\begin{array}{c}\mathrm{O}_{2} \\
(\mathrm{ppm}) \\
\end{array}$ & $\begin{array}{l}\mathrm{N}_{2} \\
(\mathrm{ppm})\end{array}$ \\
\hline Liner Wall & 198 & 24 \\
\hline Liner Dome & 96 & 22 \\
\hline Strength Member Wall & 40 & 24 \\
\hline Strength Member Dome & 98 & 54 \\
\hline Liner Wall & 209 & 82 \\
\hline Liner Dome & 168 & 42 \\
\hline Strength Member Wall & 91 & 123 \\
\hline Strength Member Dome & 55 & 24 \\
\hline
\end{tabular}


this spot, several other similar appearing but smaller areas were revealed along the liner edge. Etching of previous capsules also revealed similar microstructures. Repeated attempts to determine the nature of this region by electron microprobe analysis were unsuccessful. No difference could be found between the composition of the spots and the composition of the parent material. It was, therefore, hypothesized that these were most likely regions of localized oxygen enrichment. The sensitivity of the electron microprobe for this element is poor, and up to 8 wt $\frac{0}{6}$ could be present without being detected. Verification of the oxygen was finally obtained by use of an ion microanalyzer. The somewhat higher hardness values are indicative of T-lll containing overaged hafnia particles. 8,9 As long as the hafnia particles are overaged, or large, they do not degrade the mechanical properties of the liner and hence are of little consequence.

Neutron emission rates of the fuel removed from the specimens were compared to neutron emission rates obtained when the specimens were fabricated. Assuming any change in the neutron emission rate was due to reoxidation of the fuel after sectioning with oxygen of natural isotopic abundance, fuel stoichiometries of $\mathrm{PuO}_{2.01 \pm 0.01}$ and $\mathrm{PuO}_{1.80 \pm 0.02}$ were indicated for the comparison capsule and "retreated" capsule, respectively. This indicates that no oxygen was gettered by yttrium and that no oxygen from the fuel reacted with the liner during the approximately 1 yr of self-heating of the capsule. Nearly complete reaction between the $\mathrm{PuO}_{2}$ and the yttrium is indicated in the "retreated" capsule.

\section{Pellet Pretreatment Tests}

The last pretreatment test involved a capsule designed for a pellet fuel form of the geometry shown in Figure 34. The capsule was pretreated at

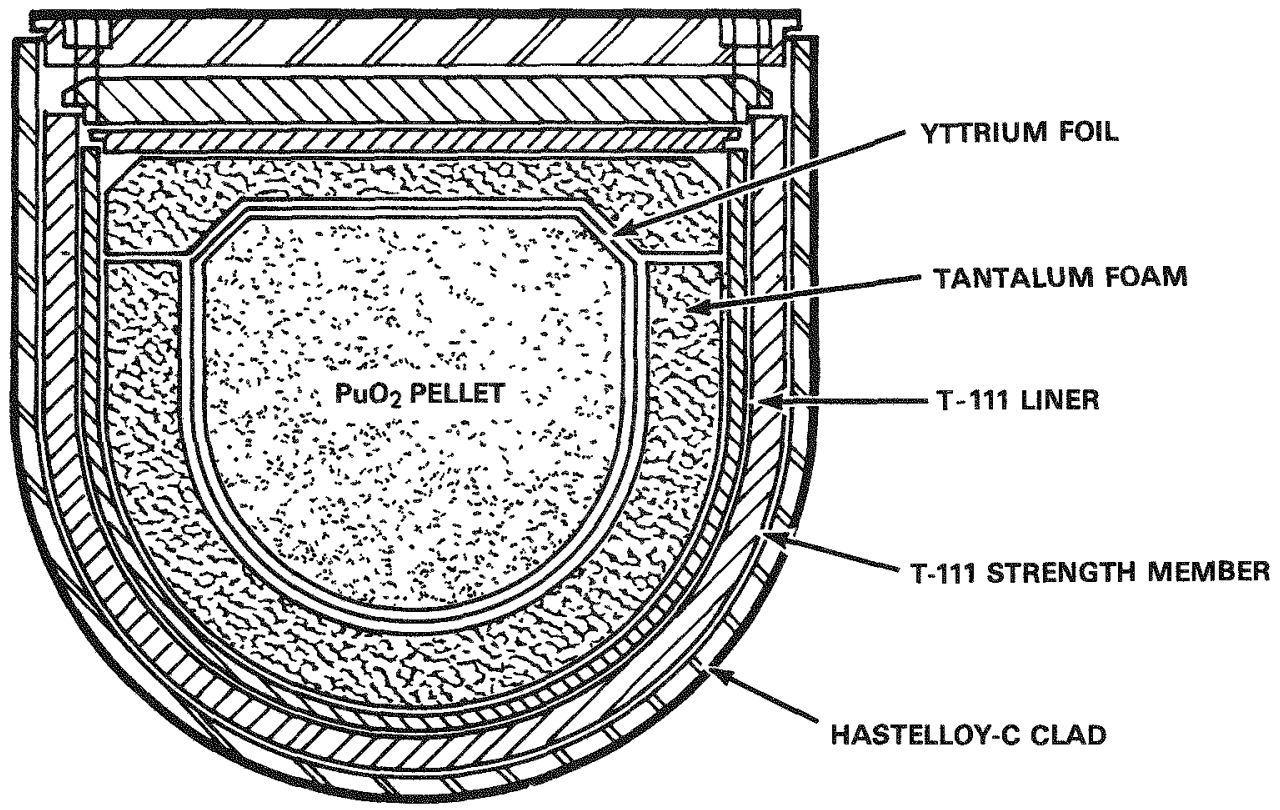

FIGURE 34 - Pellet pretreatment capsule geometry. 
$1623 \mathrm{~K}$ for $\mathrm{I} \mathrm{hr}$, sectioned, and evaluated. Metallographic examination of the liner and the strength member of the specimen in the as-polished condition revealed no evidence of reaction.

Metallographic examination of the tantalum foam revealed no obvious evidence of reaction, except for the random location of small gray deposits (apparently at points of contact) along the tantalum-yttrium interface. Electron microprobe analysis indicated that these were deposits of yttrium oxide. Attempts were made to locate oxygen gradients in the tantalum foam, but none were detected. When the specimen was sectioned, the yttrium foil surrounding the pellet was observed to be fairly ductile, suggesting that very little oxidation of the foil occurred during the pretreatment. This was confirmed by metallographic examination of the foil. Photomicrographs of the foil from the specimen were compared to photomicrographs of yttrium in the "oxidized" and "as-received" condition. Only slight oxidation of the foil from the specimen was indicated. These observations together with the oxygen and nitrogen data in Table 13 suggest that most of the oxygen given up by the fuel was taken by the tantalum foam support.

Table 13

OXYGEN AND NITROGEN DATA FOR THE

PRETREATED PLUTONIA PELIET CAPSULE

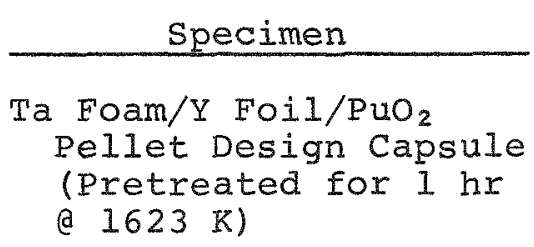

Ta Foam (As Received)

\begin{tabular}{|c|c|c|}
\hline Sample Location & $\begin{array}{c}\mathrm{O}_{2} \\
(\mathrm{ppm}) \\
\end{array}$ & $\begin{array}{c}\mathrm{N}_{2} \\
\text { (ppm) }\end{array}$ \\
\hline Tantalum Foam & 1775 & 54 \\
\hline Yttrium Foil & 1618 & 171 \\
\hline Liner Dome & 126 & 18 \\
\hline Liner Wall & 161 & 17 \\
\hline Strength Member Dome & 106 & 12 \\
\hline Strength Member Wall & 28 & 12 \\
\hline & 682 & 24 \\
\hline
\end{tabular}

Microhardness traverses were conducted across the lid, sidewall, and dome of the liner and the strength member of the specimen. The values obtained are shown in Figure 35. No interstitial contamination of the T-lll alloy is indicated by the data.

The fuel pellet was removed from the specimen and submitted for neutron counting. Comparison of the values obtained before and after pretreatment indicated essentially no change in the stoichiometry of the ${ }^{238} \mathrm{PuO}_{2}$ pellet. The lack of reduction in stoichiometry of the pellet further verifies the limited oxidation of the yttrium foil. Apparently the density and reduced surface area of the pellet as compared with the shards results in greatly reduced oxygen transport at the pretreatment temperature.

\section{Oxygen Transport Studies}

Because of the difference between the P-type and F-type capsules and the observed hardness gradients, much discussion has centered about the actual mechanism by which oxygen is transported to a $T-111$ liner in a heat source capsule. Two mechanisms are possible: (1) transport through 

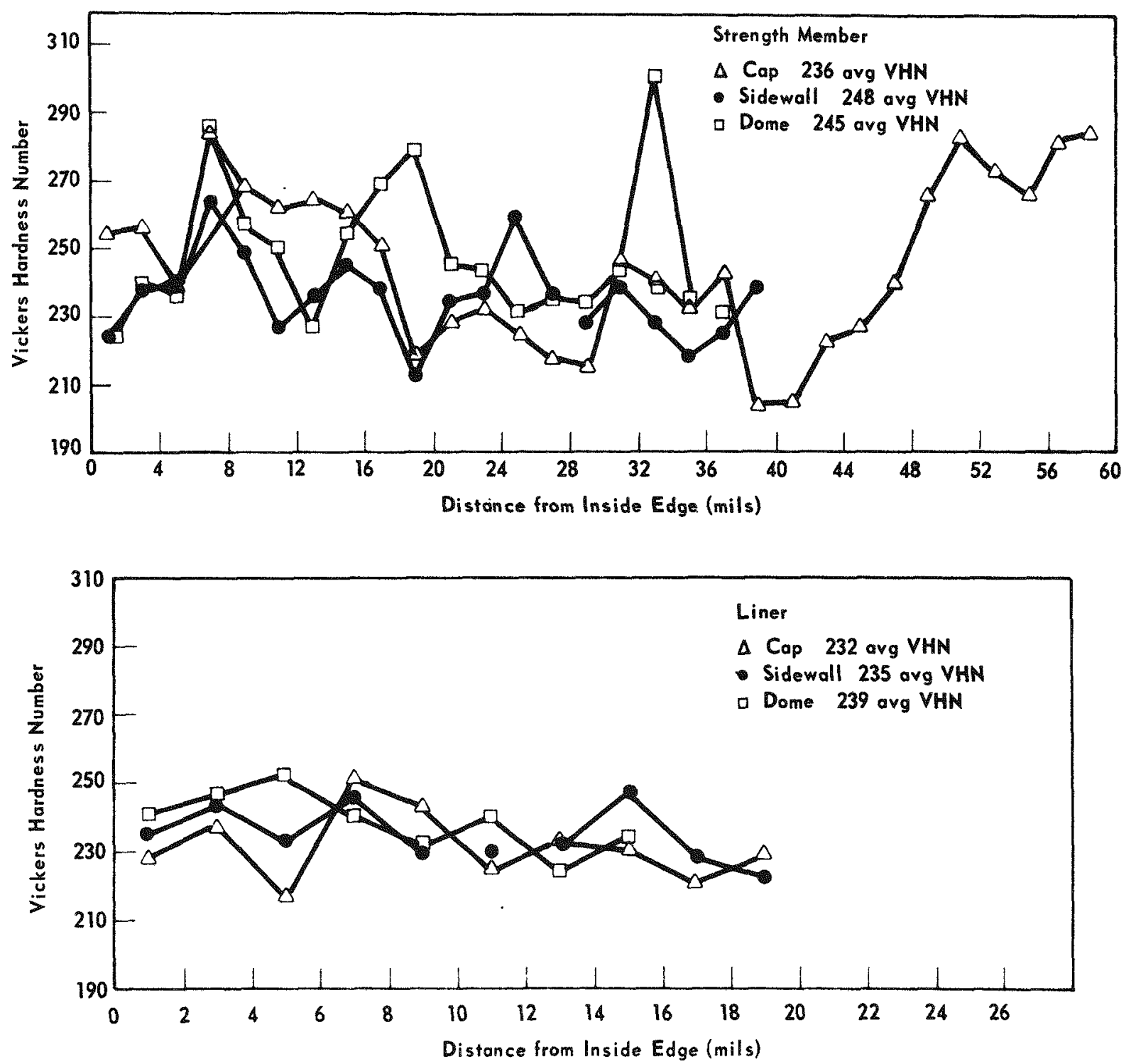

FIGURE 35 - Microhardness traverses for pretreated plutonia pellet capsule.

the vapor phase; or (2) solid-state diffusion across the fuel-1iner interface. Although it was expected that solid-state diffusion across the fuelliner interface was the primary mechanism, the contribution of the vaporphase transport was not known. In order to establish the importance of each mechanism to the total oxygen uptake a simple set of experiments was conducted.

Two capsules were loaded with fuel pellets in the configurations shown in Figure 2. Both capsules utilized standard hardware with 6-W plutonia pellets. The pellet in one capsule was wrapped several times with $0.51-$ $\mathrm{mm}$ iridium wire to provide a standoff so that the fuel could not touch the liner. The pellet in the second capsule was placed in direct contact 
with the liner bottom. After welding, the capsules were radiographed to verify internal geometry and then placed on test for 60 days at $1173 \mathrm{~K}$. After removal from the furnace the capsules were cross-sectioned and examined. Microhardness measurements were made at various locations around the capsules and samples were selected for oxygen and nitrogen analyses.

A summary of the oxygen and nitrogen analyses and microhardness traverses is given in Table 14. From this table, it is apparent that oxygen transfer occurs by solid-state contact much more readily than by the vaporphase mechanism. For the capsule with the standoff pellet, the oxygen analyses indicated identical values at the dome and the sidewall. However, for the direct-contact pellet, there was considerable difference between the dome of the capsule where the pellet was in direct contact and the sidewall where it was not.

Table 14

OXYGEN, NITROGEN, AND AVERAGE HARDNESS DATA FOR OXIDATION MECHANISM TESTS (1173 K, 60 DAYS)

\begin{tabular}{|c|c|c|c|c|}
\hline Specimen & Location & $\begin{array}{l}\mathrm{O}_{2} \\
\text { (ppm) } \\
\end{array}$ & $\begin{array}{l}\mathrm{N}_{2} \\
\text { (ppm) } \\
\end{array}$ & $\begin{array}{c}\text { Average } \\
\text { VHN } \\
\end{array}$ \\
\hline $\begin{array}{l}\text { Direct Contact } \\
\text { Pellet Capsule }\end{array}$ & $\begin{array}{l}\text { Liner Sidewall } \\
\text { Liner Bottom } \\
\text { Strength Member Sidewall } \\
\text { Strength Member Bottom }\end{array}$ & $\begin{array}{r}828 \\
2402 \\
174 \\
227\end{array}$ & $\begin{array}{l}60 \\
54 \\
50 \\
44\end{array}$ & $\begin{array}{l}404 \\
858 \\
225 \\
250\end{array}$ \\
\hline $\begin{array}{l}\text { Standoff Pellet } \\
\text { Capsule }\end{array}$ & $\begin{array}{l}\text { Liner Sidewall } \\
\text { Liner Bottom } \\
\text { Strength Member Sidewall } \\
\text { Strength Member Bottom }\end{array}$ & $\begin{array}{l}694 \\
694 \\
138 \\
227\end{array}$ & $\begin{array}{l}38 \\
54 \\
86 \\
58\end{array}$ & $\begin{array}{l}444 \\
422 \\
228 \\
252\end{array}$ \\
\hline
\end{tabular}

Microhardness traverses for each liner are shown in Figures 36 and 37. Differences in average hardness values for equivalent locations could be related to the relative position of the pellet with respect to the liner, with higher average values due to closer proximity of the pellet at that point. In the case of the standoff pellet capsule, the liner sidewall is slightly harder than the dome while the corners are softer. This is probably due to a higher dislocation density in these regions as a result of the fabrication technique.

If the reaction kinetics in the vapor transport case are described by the Langmuir equation, as stated by Inouye, 11 the actual oxygen pressure must be at least $10^{6}$ times the amount over pure plutonial2 at $1173 \mathrm{~K}$. This would be possible if transport were dominated by oxygen-bearing impurities within the fuel, which could either volatilize stoichiometrically or release oxygen to the atmosphere.

\section{DISCUSSION}

The only microstructural change in the liner which could be related to the pretreatment process was the occurrence of the isolated spots of high hardness mentioned earlier. Although these regions, characterized by their high oxygen concentration in the form of overaged hafnia precipitates, 


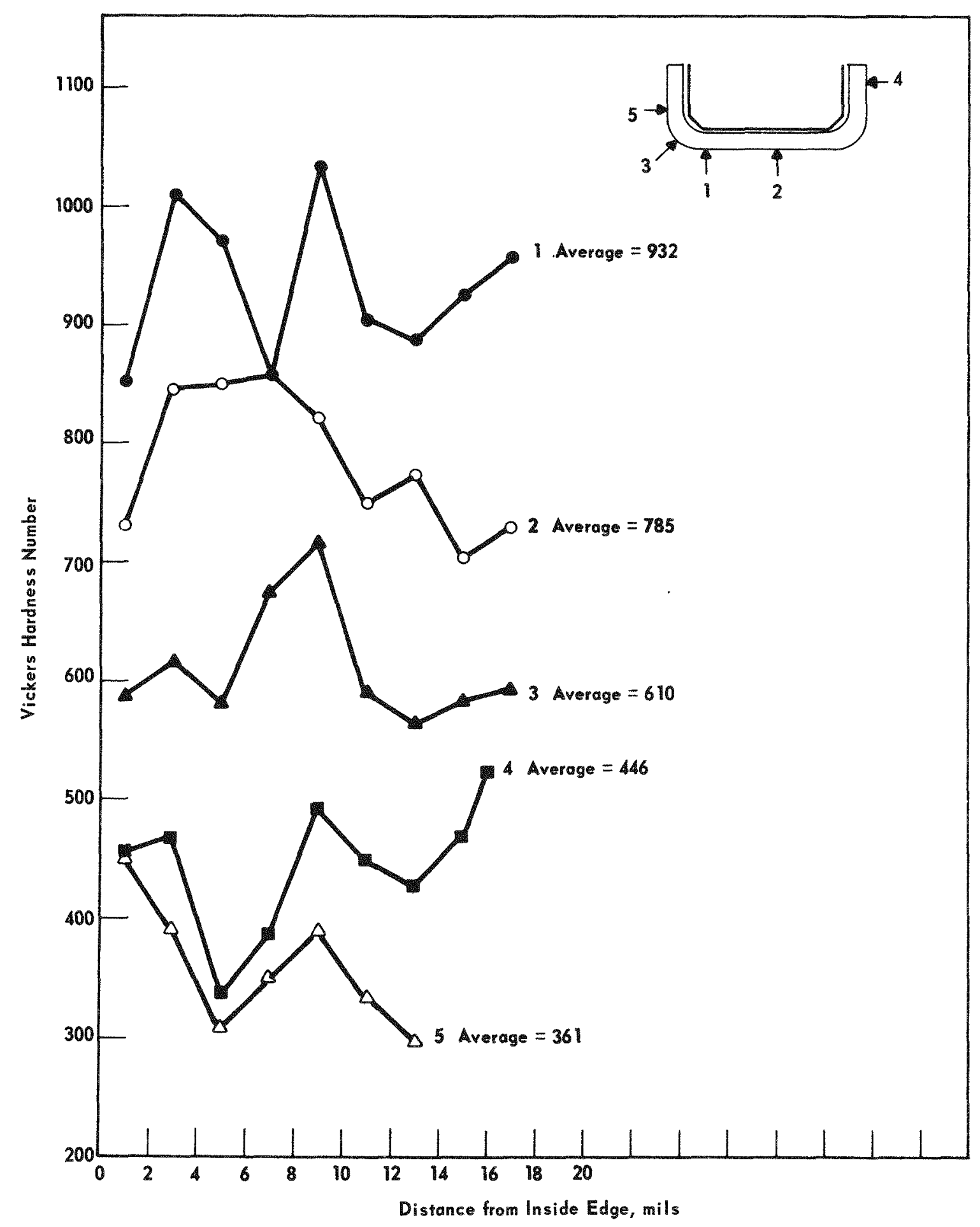

FIGURE 36 - Microhardness traverses on liner of direct-contact pellet capsule (1173 K, 60 days). 


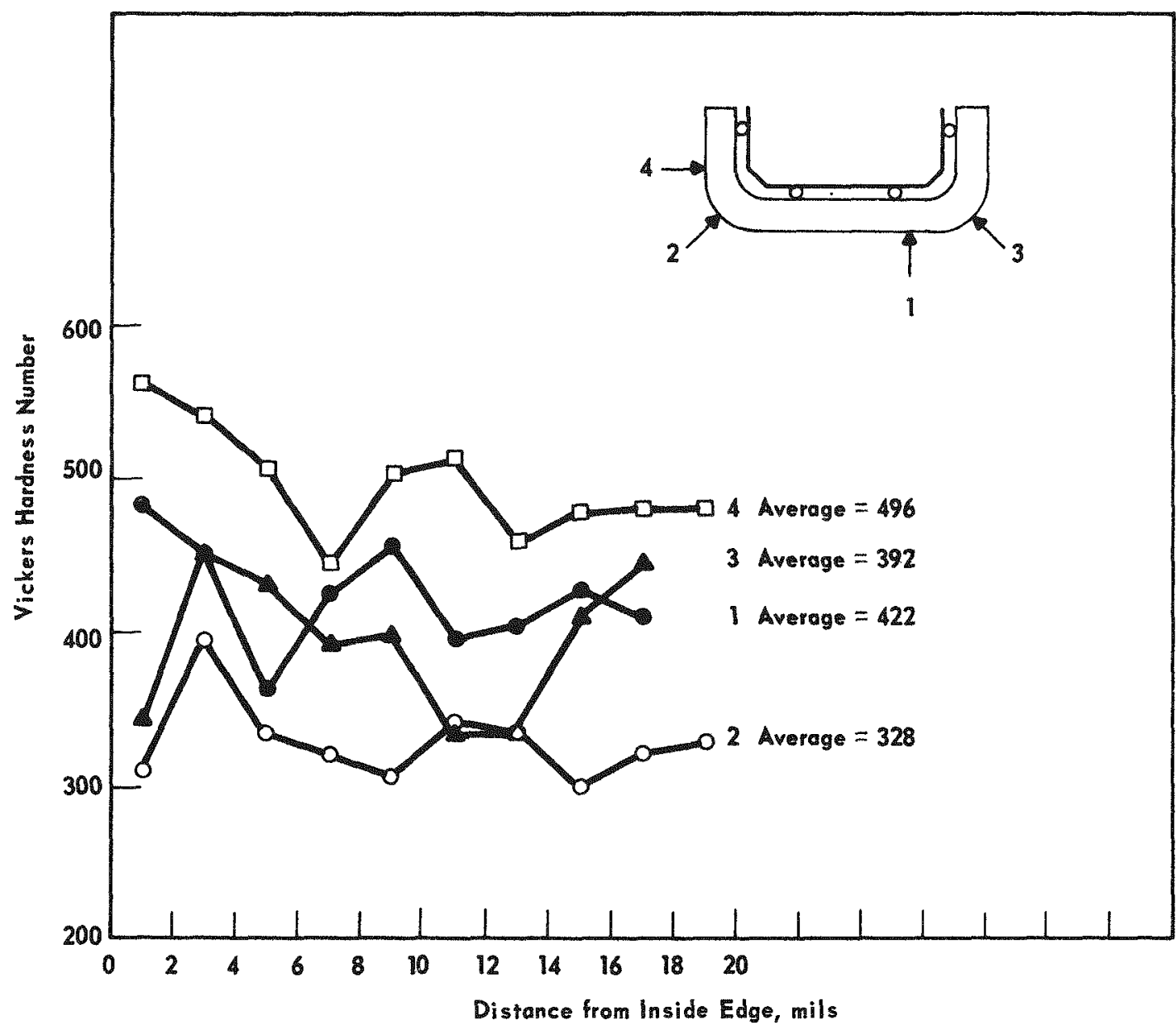

FIGURE 37 - Microhardness traverses on liner of standoff pellet capsule (1173 K, 60 days). 
do not affect the mechanical properties of the liner, they are of some interest. The maximum depths of these spots as a function of capsule treatment are listed in Table 15. From this it is apparent that they do not increase with time, and as such are solely related to the pretreatment process. However, the use of yttrium powder leads to shallower zones than with the chips, indicating a correlation between the form and/ or number of yttrium particles and the depth of the spots. For this reason further tests are planned to evaluate the effect of yttrium particle size, shape, and amount on the occurrence of the hardened regions.

Table 15

SUMMARY OF METALLOGRAPHIC DATA ON SMALL REACTION ZONES IN PRETREATED CAPSULES

\begin{tabular}{|c|c|c|c|}
\hline Sample & Pretreatment & Heat Treatment & $\begin{array}{c}\text { Zone } \\
\text { Depth } \\
\text { (mils) } \\
\end{array}$ \\
\hline Blank & $1 \mathrm{hr} @ 1623 \mathrm{~K}$ & -- & None \\
\hline $\mathrm{PuO}_{2}$ Only & $1 \mathrm{hr}$ \& $1623 \mathrm{~K}$ & -- & $12(\max )$ \\
\hline $\mathrm{PuO}_{2}+\mathrm{Y}$ Chips & I hr @ $1623 \mathrm{~K}$ & -- & 6.9 \\
\hline $\mathrm{PuO}_{2}+\mathrm{Y}$ Chips & $1 \mathrm{hr} @ 1623 \mathrm{~K}$ & -- & 6.0 \\
\hline $\mathrm{PuO}_{2}+\mathrm{Y}$ Chips & $1 \mathrm{hr} @ 1623 \mathrm{~K}$ & -- & 5.4 \\
\hline $\mathrm{PuO}_{2}+\mathrm{Y}$ Chips & I hr a $1623 \mathrm{~K}$ & -- & 5.0 \\
\hline $\mathrm{PuO}_{2}+\mathrm{Y}$ Powder & I hr $1673 \mathrm{~K}$ & 60 days @ $1173 \mathrm{~K}$ & 4.9 \\
\hline $\mathrm{PuO}_{2}+\mathrm{Y}$ Powder & $1 \mathrm{hr} @ 1673 \mathrm{~K}$ & -- & 4.6 \\
\hline $\mathrm{PuO}_{2}+\mathrm{Y}$ Powder & $1 \mathrm{hr}$ @ $1623 \mathrm{~K}$ & 240 days a $873 \mathrm{~K}$ & 3.9 \\
\hline $\mathrm{PuO}_{2}+\mathrm{Y}$ Powder & $1 \mathrm{hr} @ 1623 \mathrm{~K}$ & 60 days @ $1373 \mathrm{~K}$ & 3.4 \\
\hline $\mathrm{PuO}_{2}+\mathrm{Y}$ Powder & $1 \mathrm{hr} @ 1623 \mathrm{~K}$ & 60 days a $873 \mathrm{~K}$ & 3.1 \\
\hline $\mathrm{PuO}_{2}+\mathrm{Y}$ Powder & I hr e $1723 \mathrm{~K}$ & 60 days @ $1173 \mathrm{~K}$ & 2.7 \\
\hline $\mathrm{PuO}_{2}+\mathrm{Y}$ Powder & $1 \mathrm{hr} @ 1573 \mathrm{~K}$ & 60 days @ $1173 \mathrm{~K}$ & 2.4 \\
\hline
\end{tabular}

To underscore the effectiveness of the pretreatment process, oxygen, nitrogen, and average microhardness values for the liners of the $\mathrm{P}-$ and F-type capsules aged at $1173 \mathrm{~K}$ are compared in Table 16. The advantages of the pretreatment operation are evidenced by the lower oxygen and hardness values of the P-type specimen liners. Although some initial oxygen uptake by the liner occurs during pretreatment, very little if any additional oxygen pickup or embrittlement occurs with time in the pretreated specimen. However, the F-type specimens show increasing oxygen uptake and embrittlement of the liner with time.

Assuming the oxygen uptake of the liner in the F-type capsules is thermally activated, the controlling activation energy can be determined from the slope of log $(r)$ versus $1 / T$, where $r$ is the rate of oxygen absorption. The value of $r$ can be obtained from the relation

$$
r=\frac{C_{t}-C_{0}}{t}
$$


Table 16

COMPARISON OF P- AND F-TYPE $1173 \mathrm{~K}$ IINER DATA

\begin{tabular}{|c|c|c|c|c|c|}
\hline Time & $\begin{array}{l}\text { Capsule } \\
\text { Type } \\
\end{array}$ & Location & $\begin{array}{c}\mathrm{O}_{2} \\
\text { (ppm) } \\
\end{array}$ & $\begin{array}{l}\mathrm{N}_{2} \\
\text { (ppm) } \\
\end{array}$ & $\begin{array}{c}\text { Average } \\
\text { VHN } \\
\end{array}$ \\
\hline \multirow{2}{*}{60 Days } & $P$ & $\begin{array}{l}\text { Sidewall } \\
\text { Dome }\end{array}$ & $\begin{array}{l}266 \\
164\end{array}$ & $\begin{array}{r}26 \\
8\end{array}$ & $\begin{array}{l}240 \\
239\end{array}$ \\
\hline & $F$ & $\begin{array}{l}\text { Sidewall } \\
\text { Dome }\end{array}$ & $\begin{array}{l}1883 \\
1070\end{array}$ & $\begin{array}{l}110 \\
100\end{array}$ & $\begin{array}{l}291 \\
252\end{array}$ \\
\hline \multirow{2}{*}{240 Days } & P & $\begin{array}{l}\text { Sidewall } \\
\text { Dome }\end{array}$ & $\begin{array}{l}319 \\
249\end{array}$ & $\begin{array}{l}21 \\
20\end{array}$ & $\begin{array}{l}253 \\
230\end{array}$ \\
\hline & $F$ & $\begin{array}{l}\text { Sidewall } \\
\text { Dome }\end{array}$ & $\begin{array}{r}1330 \\
>2000\end{array}$ & $\begin{array}{r}6 \\
11\end{array}$ & $\begin{array}{l}816 \\
728\end{array}$ \\
\hline \multirow{2}{*}{2 Years } & $\mathrm{P}$ & $\begin{array}{l}\text { Sidewali } \\
\text { Dome }\end{array}$ & $\begin{array}{r}1215 \\
932\end{array}$ & $\begin{array}{l}27 \\
14\end{array}$ & $\begin{array}{l}261 \\
256\end{array}$ \\
\hline & F & $\begin{array}{l}\text { Sidewall } \\
\text { Dome }\end{array}$ & $\begin{array}{l}2543 \\
3667\end{array}$ & $\begin{array}{l}96 \\
40\end{array}$ & $\begin{array}{l}717 \\
834\end{array}$ \\
\hline
\end{tabular}

where $C_{1}$ is the concentration at time $t$, and $C_{0}$ is the initial concentration. For purposes of discussion, the average oxygen content for the strength members of the aged capsules in Table 6 was used to obtain $\mathrm{C}_{0}=71 \mathrm{ppm}$. The values* of $\mathrm{r}$ obtained by this method are plotted versus $1 / T$ in Figure 38, with the indicated least-squares line corresponding to an activation energy of $94.6 \mathrm{~kJ} / \mathrm{mole}(22.6 \mathrm{kcal} / \mathrm{mole})$. Considering the difficulties involved, this value is quite close to the 95.8 to $114.3 \mathrm{~kJ} / \mathrm{mole}(22.9$ to $27.3 \mathrm{kcal} / \mathrm{mole})$ reported for oxygen diffusion in tantalum. ${ }^{13}$ That this is the controlling process is further supported by the microhardness gradients observed in the $1173 \mathrm{~K}, 60$-day specimen, such as shown in Figure 39. These gradients can occur only if the rate of oxygen supply to the fuel/T-11l interface is greater than the diffusion rate in the alloy. The fact that the activation energy obtained from these data is on the lower end of the reported energy range, even though $\mathrm{T}-11 \mathrm{l}$ is an alloy, may be related to the presence of pipe, or dislocation-enhanced, diffusion in the T-111. This would also explain why the oxygen content was highest in areas of high residual strain and welldefined dislocation network structure. This is graphically indicated in Figure 37, where the highest strain area of the sidewall is also the hardest region, although all points were equidistant from the fuel.

\footnotetext{
FDue to the anomalously high oxygen content and near-background microhardness values for the $1173 \mathrm{~K}, 60$-day capsule, these results were not used. The problem with these data could be due to several things, but most likely is that either fuel was adhering to the liner segments analyzed or the fuel was excessively heated during closure due to insufficient clearance.
} 


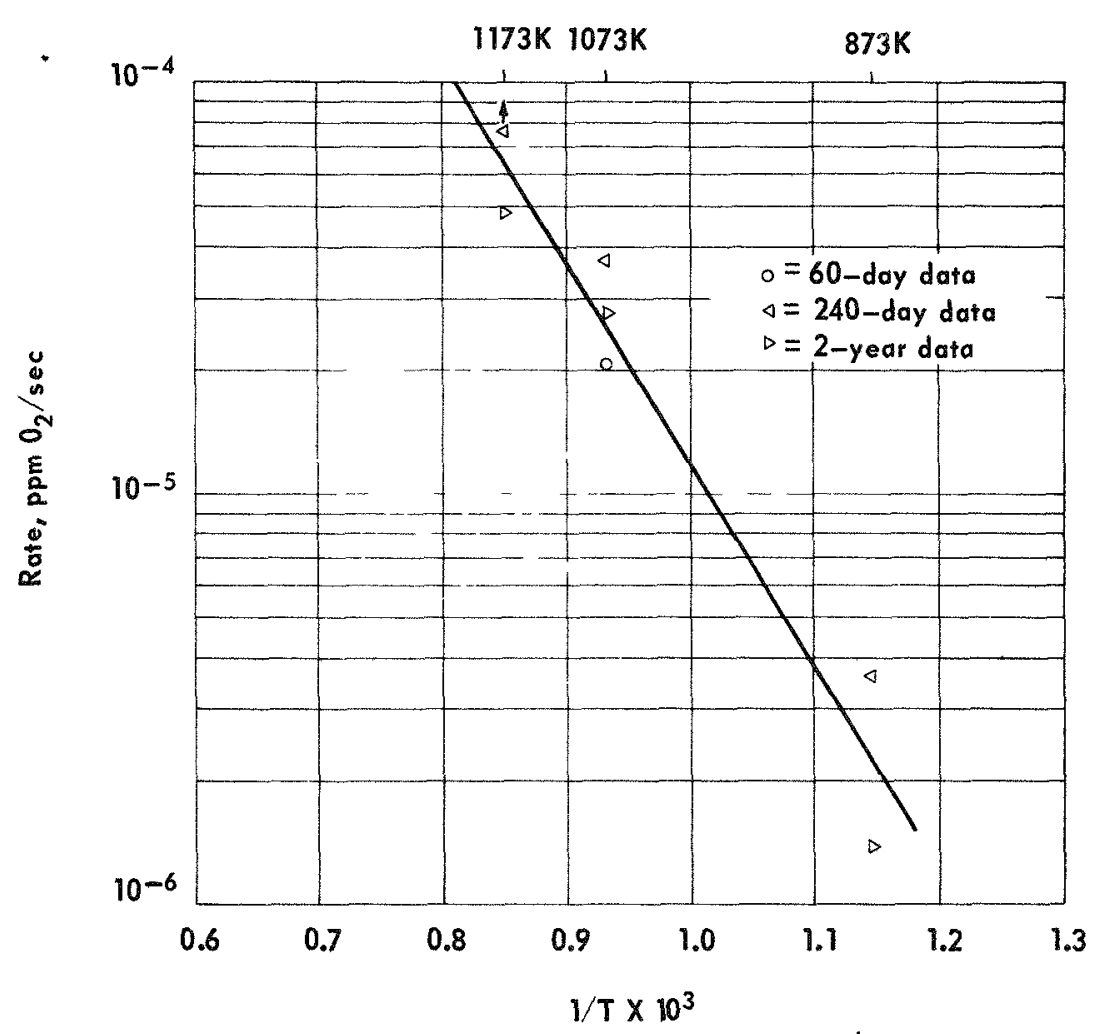

FIGURE 38 - Plot of log (r) versus I/T used for activation energy determination for F-type capsules.

From these results it is readily apparent that pretreatment must simply stop the supply of oxygen to the liner at lower ( $\leq 1173 \mathrm{~K}$ ) temperatures. Since for the p-type capsules oxygen pickup during aging did occur only in the $1373 \mathrm{~K}$ specimen, it is not possible to determine an activation energy which could then be used to identify the controlling transport process. However, it is possible to form some conclusions based on other facts and known plutonia properties.

Analysis of data obtained from the L-type specimens indicated that volatile oxide impurities in the fuel controlled at least the vapor transport in the F-type capsules. However, one of the most obvious results of pretreatment should be the reduction of the low-energy oxides, at least to the point where they are in equilibrium with PuO 1.75-1.80. Therefore, they no longer need to be considered separately and the discussion can be restricted to the properties of pure substoichiometric plutonia.

Chereau and Wadier ${ }^{14}$ calculated the diffusion coefficient for oxygen in substoichiometric plutonia at $1353 \mathrm{~K}$ and found it to be about $8 \times 10^{-5}$ $\mathrm{cm}^{2} / \mathrm{sec}$. Their resistivity measurements on the same material indicated that the ionic mobility was fairly insensitive to temperature and that, for $\mathrm{PuO}_{1.772}$, the activation energy is only $6.5 \mathrm{kcal} / \mathrm{mole}$. This would indicate that oxygen transport in the fuel is not the rate-controlling process. One must therefore conclude that the oxygen is available to the liner and simply does not react. The only possible explanation for 


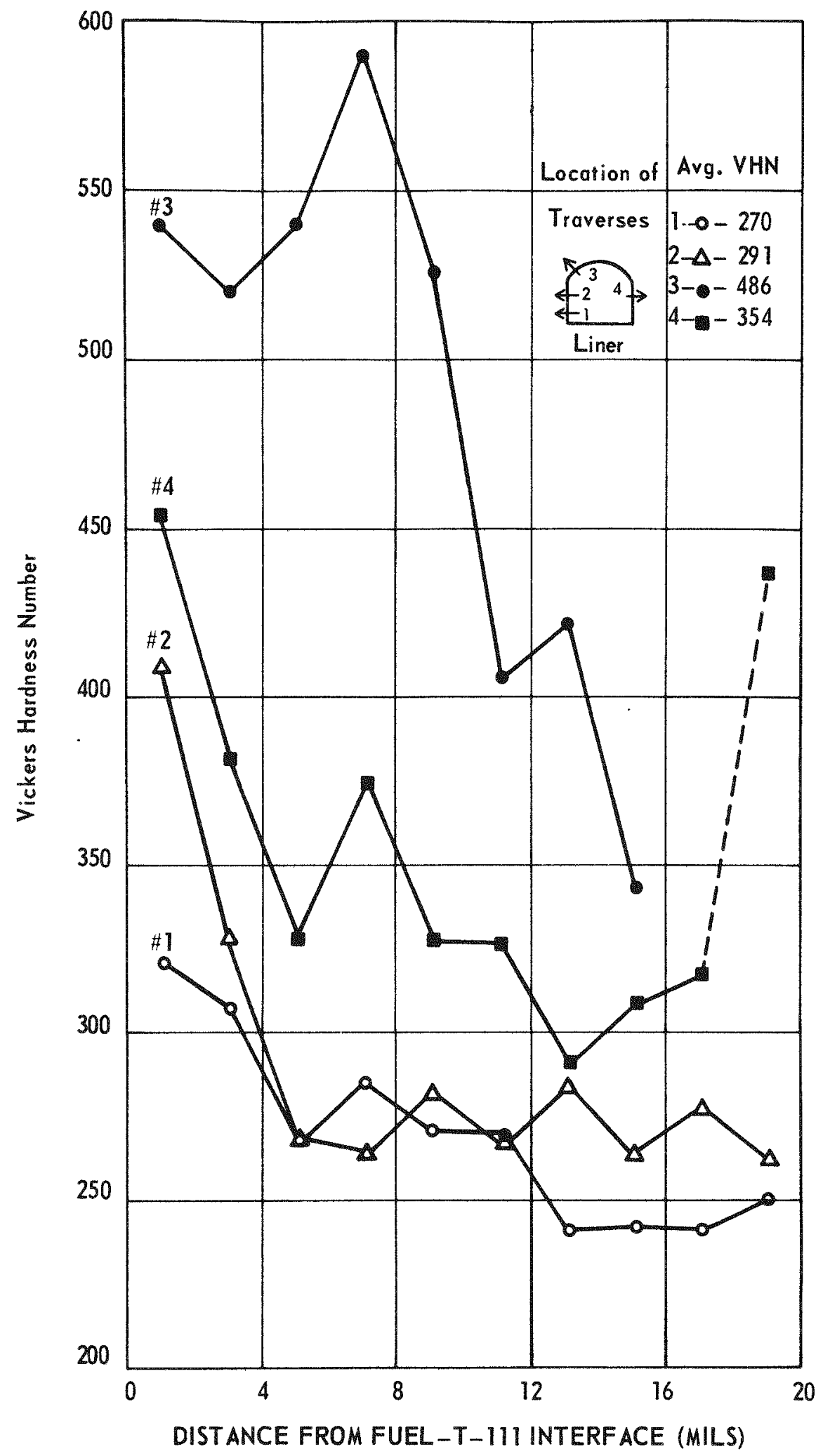

FIGURE 39 - Microhardness traverses showing oxygen gradient in $1173 \mathrm{~K}$, 60-day F-type capsules. 
this phenomenon is that at, and below, $1173 \mathrm{~K}$ it is energetically unfavorable for the fuel to give up oxygen to the liner, while at $1373 \mathrm{~K}$ the situation is reversed.

If one extends the free-energy data of Ackermann, Faircloth and Rand 2 to the temperatures of interest, it is obvious that it is energetically unfavorable for oxygen to go to the liner to form $\mathrm{Ta}_{2} \mathrm{O}_{5} .{ }_{15}$ However, the free energy of formation of hafnia from bulk hafnium ${ }^{15}$ is approximately equal to that for $\mathrm{PuO}_{1.75}$. Considering that the hafnium is in solution in the alloy and hence this free-energy value is probably shifted, it is quite likely that the observed behavior is due to the relative free energies of formation of hafnia in $\mathrm{T}-11 \mathrm{l}$ and $\mathrm{PuO}_{1.75}$. Therefore, it seems reasonable to describe the pretreatment process as a reduction of the stoichiometry of the fuel to a point where, at or below $1173 \mathrm{~K}$, it is unfavorable for hafnium in the liner to further reduce it. In this temperature range the system is essentially nonreactive and the components can be considered to be chemically inert. Above this temperature, as at $1373 \mathrm{~K}$, this equilibrium is disturbed and the hafnium in the T-Ill is able to further reduce the fuel. This process should proceed until the hafnium is exhausted or the fuel is reduced to the point where equilibrium is once more established. It is hoped that this hypothesis can be verified in future tests in which lower oxygen-to-plutonium ratios will be sought.

\section{CONCLUSIONS}

This study was undertaken in an effort to develop techniques for improving the long-term high-temperature compatibility between plutonium-238 dioxide and the tantalum-base alloy, T-111. This alloy possesses almost ideal mechanical properties for use as a primary encapsulant for this radioisotope, especially with regard to accident survival requirements. However, as most other tantalum-base materials, it suffers severe oxygen embrittlement during prolonged high-temperature exposure to the plutonium238 dioxide. The present tests were designed specifically to evaluate the hypothesis ${ }^{3}$ that reduction of fuel stoichiometry to the range $\mathrm{PuO}_{1.75}$ to PuO $_{1.80}$ would suspend this embrittlement process, producing a state of thermodynamic equilibrium within the capsule. Reduction was to be achieved in situ by mixing yttrium metal with the $\mathrm{PuO}_{2}$ just prior to capsule closure. Test temperatures ranged from $773 \mathrm{~K}$ to $1373 \mathrm{~K}$, while aging times of 60 days, 240 days, and 2 yr were used.

Initial results indicated the fuel was not reduced by the yttrium except at the highest test temperature, even though the T-11l was embrittled in capsules held as low as $1073 \mathrm{~K}$. The lack of $\mathrm{Y}_{2} \mathrm{O}_{3}$ formation was attributed to the presence of a protective oxide on the yttrium. Based on this assumption, T-111 oxidation kinetics, 8,9 and the lack of embrittlement of some welds which had accidently been contaminated with the $\mathrm{PuO}_{2} / \mathrm{Y}$ mixture, it was decided to try to force the reaction. Capsules were heated to above $1573 \mathrm{~K}$ for $\mathrm{I} \mathrm{hr}$ and then examined. It was found that the fuel had been reduced to the desired stoichiometry with only negligible effects to the T-111. Subsequent aging of such "pretreated" capsules indicated that no embrittlement of the T-IIl was observed, even after $2 \mathrm{yr}$, for temperatures as high as $1173 \mathrm{~K}$. Nonpretreated specimens showed severe embrittlement for the same test conditions.

In order to help in the understanding of these results, the dominant oxygen transport process within the capsules was determined, using two 
specimens containing hot-pressed plutonia pellets. In one, the pellet was allowed to touch the capsule walls, while in the other it was held off by iridium wire. Solid-state transport was found to be the dominant mechanism, but some vapor transport was observed. Analyses of these results indicated that the vapor-phase contribution must be governed by the presence of volatile oxide impurities within the fuel.

Analysis of the oxygen absorption rate of the T-1ll for nonpretreated capsules indicated that the rate-controlling mechanism was the diffusion of oxygen in the T-lll. This result, coupled with the known oxygen mobility data for substoichiometric plutonia, ${ }^{4}$ was used to show that pretreatment did indeed seem to produce the hypothesized thermodynamic equilibrium between the plutonia and the T-1Il, at temperatures up to at least $1173 \mathrm{~K}$.

\section{ACKNOWLEDGEMENTS}

The authors would like to gratefully acknowledge the contributions of several people at Mound Laboratory. M. D. Kelly, K. L. Breakall, R. I. Wise, and E. Stacy performed most of the metallography and D. I. Roesch performed the electron microprobe analyses. R. L. Goss and Virginia I. George performed the oxygen and nitrogen analyses. M. E. Anderson made the fuel stoichiometry determinations. 


\section{REFERENCES}

1. J. E. Selle et al. The Compatibility of ${ }^{238} \mathrm{PuO}_{2}$ with Various Refractory Metals and Alloys: Interim Report, MLM-1706 (Oct. 23, 1970), $214 \mathrm{pp}$.

2. R. L. Andelin and J. D. Watrous, Plutonia-Curia Compatibility Testing; April-June 1970, Quarterly Report No. 7, MDC-G-1700, Donald W. Douglas Laboratories, Richland, Washington (July 1970).

3. Mound Laboratory Isotopic Power Fuels Programs: January-March 1971, MLM-1817 (June 15, 1971), pp. 36-41. See also U. S. Patent No. 3659107.

4. R. M. Al'touskii et al., Corrosion of Yttrium, (Moscow, 1969), AECTR-7176.

5. K. A. Gschneidner, Jr. and N. Kippenhan, Thermochemistry of Rare Earth Carbides, Nitrides, and Sulfides for Steelmaking, IS-RIC-5, Rare Earth Information Center, Institute for Atomic Research, Iowa State University, Ames, Iowa, 1971.

6. P. E. Teaney and J. E. Selle, "An Evaluation of the Use of a Quantitative Image Analyzer to Determine Microhardness Values," Proceedings of the Fourth Annual Technical Meeting of the International Microstructural Analysis Society, 1972, pp. 291-301.

7. J. A. Haefling, F. A. Schmidt and O. N. Carlson, J. Less-Common Metals, ㄱ. 433 (1964).

8. H. Inouye and C. T. Liu, Low Pressure Oxidation of T-111 and Effect on Tensile Properties, ORNL-TM-462I (August 1974).

9. D. E. Etter and W. H. Smith, J. Less-Common Metals, 27, 109 (1972).

10. I. J. Kirby and H. T. Fullon, Promethium Heat Source Compatibility Studies, Part II, Metal-Metal Compatibility at $1100^{\circ} \mathrm{C}$, BNWL-398 (May 1967).

i1. H. Inouye in Refractory Metal Alloys - Metallurgy and Technology, I. Machling, R. T. Begley and E. D. Weisert (ed.), Plenum Press, New York, N. Y., 1968, pp. 165-195.

12. R. J. Ackermann, R. I. Faircloth and M. H. Rand, J. Phys. Chem., 70, 3698 (1966).

13. Y. I. Gerassimov et al., "Tantalum: Physico-Chemical Properties of Its Compounds and Alloys," in Atomic Energy Review, Special Issue No. 3, 0. Kubaschewski (ed.), International Atomic Energy Agency, Vienna, 1972.

14. P. Chereau and J. F. Wadier, J. Nucl. Mater, 46,1 (1973).

15. J. P. Coughlin, Heats and Free Energies of Formation of Inorganic Oxides, Bureau of Mines Bulletin 542, 1954 . 